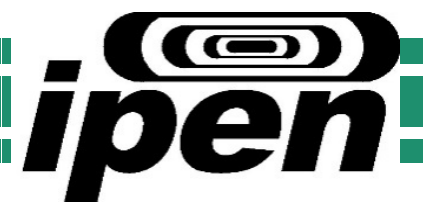

AUTARQUIA ASSOCIADA À UNIVERSIDADE DE SÃO PAULO

\title{
CARACTERIZAÇÃO MICROESTRUTURAL E COMPORTAMENTO À OXIDAÇÃO EM TEMPERATURAS ELEVADAS DE LIGAS TiAI
}

\author{
RAFAELA CERQUEIRA BATISTA DE OLIVEIRA
}

Dissertação apresentada como parte dos requisitos para obtenção do Grau de Mestre em Ciências na Área de Tecnologia Nuclear - Materiais

Orientador:

Prof. Dr. Antônio Augusto Couto 
INSTITUTO DE PESQUISAS ENERGÉTICAS E NUCLEARES

Autarquia associada à Universidade de São Paulo

\title{
CARACTERIZAÇÃO MICROESTRUTURAL E COMPORTAMENTO À OXIDAÇÃO EM TEMPERATURAS ELEVADAS DE LIGAS TiAI
}

\author{
RAFAELA CERQUEIRA BATISTA DE OLIVEIRA
}

Dissertação apresentada como parte dos requisitos para obtenção do Grau de Mestre em Ciências na Área de Tecnologia Nuclear - Materiais

Orientador:

Prof. Dr. Antônio Augusto Couto

Versão Corrigida

Versão Original disponível no IPEN

São Paulo

2018 
Autorizo a reprodução e divulgação total ou parcial deste trabalho, para fins de estudo e pesquisa, desde que citada a fonte. 


\section{AGRADECIMENTOS}

A Deus e ao Senhor Jesus pela vida e oportunidades que me têm sido concedidas ao decorrer dos anos.

À minha família pelo apoio, compreensão e incentivo aos meus estudos.

Aos professores que acreditaram em mim e me encorajaram a sempre ir além, contribuindo não apenas para a minha formação profissional, mas também, pessoal.

Ao professor Couto, orientador do trabalho, por ter me apresentado o tema acreditando no meu potencial e me instruído desde então para atingir a meta proposta.

À professora Marina por compartilhar um pouco do seu conhecimento comigo durante as nossas conversas acerca dos ensaios de resistência a oxidação.

À profissionais como Mariano, René, Olandir e Rodrigo que estiveram sempre dispostos a me ajudar em etapas específicas do projeto.

À Fundação CAPES pela bolsa oferecida (Edital CAPES/Eletronuclear de 2012).

Às seguintes instituições e departamentos pela colaboração prestada na elaboração deste trabalho:

- Universidade de São Paulo (USP);

- Laboratório de Microscopia e Microanálise do Centro de Ciência e Tecnologia de Materiais do IPEN/CNEN;

- $\quad$ Escola de Engenharia de Lorena (EEL/USP);

- Universidade Presbiteriana Mackenzie.

E ainda, àquelas pessoas que contribuíram indiretamente para 0 desenvolvimento deste trabalho. 


\section{RESUMO}

OLIVEIRA, Rafaela C. B. Caracterização microestrutural e comportamento à oxidação em temperaturas elevadas de ligas TiAl. 2018. P. 65. Dissertação de mestrado em Tecnologia Nuclear. Instituto de Pesquisas Energéticas e Nucleares - IPEN/CNEN-SP. São Paulo.

As ligas $\gamma$-TiAl são atraentes para diversos segmentos industriais, tais como aeronáutico, aeroespacial e automobilístico, visto a sua combinação única de propriedades mecânicas aliadas a sua baixa densidade, alto ponto de fusão $\left(1400-1500{ }^{\circ} \mathrm{C}\right)$, boa resistência à oxidação e à fluência, dentre outros. Contudo, apresentam como limitadores de aplicação uma baixa ductilidade à temperatura ambiente e insuficiente resistência à oxidação quando submetida às temperaturas superiores a $800{ }^{\circ} \mathrm{C}$. Portanto, diversos elementos de liga têm sido adicionados à liga $\gamma$-TiAl com o intuito de melhorar estas propriedades. Diante disto, o objetivo deste trabalho é caracterizar a microestrutura e o comportamento em oxidação em temperaturas elevadas das ligas $\gamma$-TiAl: Ti-48Al-2Nb-2Cr-0,5B ( $\%$ at.) e Ti-44Al-4Nb$1 \mathrm{Mo}-0,5 \mathrm{~B}$ (\% at.). Os lingotes foram fundidos em um forno a arco elétrico sob atmosfera de argônio e a partir deles foi realizada a caracterização microestrutural por meio de difração de raios $\mathrm{X}$, microscopia óptica e microscopia eletrônica de varredura. As análises permitiram identificar em ambas as ligas as fases $\gamma$-TiAl (matriz), $\alpha_{2}-\mathrm{Ti}_{3} \mathrm{Al}$ e $\beta$ (B2). A microestrutura ao longo da seção transversal das ligas apresentou-se heterogênea, com grãos equiaxiais e uma estrutura lamelar na região central do lingote. Outro fato a ser evidenciado é a presença de regiões dendríticas em ambas as ligas, sendo que na liga Ti$48 \mathrm{Al}-2 \mathrm{Nb}-2 \mathrm{Cr}-0,5 \mathrm{~B}(\%$ at. $)$ também foram observadas colônias de fragmentos dendríticos. $\mathrm{O}$ ensaio termogravimétrico foi realizado sob $1000{ }^{\circ} \mathrm{C}$, ao ar por $7 \mathrm{~h}$, e a partir dele observou-se que a resistência à oxidação de ambas as ligas apresentaram baixo ganho de massa quando submetidas a temperaturas inferiores a $850{ }^{\circ} \mathrm{C}$, entretanto, a $1000{ }^{\circ} \mathrm{C}$ o comportamento das curvas evidencia que a liga $\mathrm{Ti}-48 \mathrm{Al}-2 \mathrm{Nb}-2 \mathrm{Cr}-0,5 \mathrm{~B}(\%$ at.) possui uma melhor resistência a oxidação do que Ti-44Al-4Nb-1Mo-0,5B (\% at.) nesta temperatura.

Palavras - chave: $\gamma$-TiAl; microestrutura; dendritas; oxidação; temperaturas elevadas. 


\begin{abstract}
OLIVEIRA, Rafaela C. B. Microstructural characterization and oxidation behavior of high temperatures of TiAl alloys. 2018. P. 65. Master's dissertation in Nuclear Technology. Institute of Energy and Nuclear Research - IPEN/CNEN-SP. São Paulo.

$\gamma$-TiAl alloys are attractive to a number of industrial segments such as aeronautics, aerospace and automotive, since their unique combination of mechanical properties combined with their low density, high melting point $\left(1400-1500^{\circ} \mathrm{C}\right)$, good oxidation and creep resistance, and others. However, they have as application limiters a low ductility at room temperature and insufficient oxidation resistance when exposed to temperatures exceeding $800^{\circ} \mathrm{C}$. Several alloying elements have been added to the $\gamma$-TiAl alloy in order to improve these properties. Therefore, the objective of this study is to characterize the microstructure and oxidation behavior at high temperatures of two $\gamma$-TiAl alloys: Ti-48Al$2 \mathrm{Nb}-2 \mathrm{Cr}-0.5 \mathrm{~B}$ (wt.\%) and Ti-44Al-4Nb-1Mo-0.5B (wt.\%). The ingots were melt in an electric arc furnace under an argon atmosphere and then, the microstructural characterization was carried out by diffraction X-ray, optical microscopy (OM) and scanning (SEM). By the analyzes was possible to identify the phases $\gamma$-TiAl (matrix), $\alpha_{2}-$ $\mathrm{Ti}_{3} \mathrm{Al}$ and $\beta$ (B2) in both alloys. The microstructure along the cross section of the alloys was heterogeneous showing equiaxial grains, and dendritic regions in both alloys. In the Ti $-48 \mathrm{Al}-2 \mathrm{Nb}-2 \mathrm{Cr}-0.5 \mathrm{~B}$ (wt.\%) alloy colonies of dendritic fragments were also observed. The thermogravimetric test was performed under $1000{ }^{\circ} \mathrm{C}$ in air for $7 \mathrm{~h}$. As result it it was observed that the oxidation resistance of both alloys showed low mass gain when the temperature was up to $850{ }^{\circ} \mathrm{C}$, however, at $1000{ }^{\circ} \mathrm{C}$ the curves' behavior evidence that the Ti-48Al-2Nb-2Cr-0.5B (wt.\%) alloy has a better oxidation resistance than Ti-44Al-4Nb$1 \mathrm{Mo}-0.5 \mathrm{~B} \quad(\mathrm{wt} . \%)$ at this temperature.
\end{abstract}

Key-words: $\gamma$-TiAl; microstructure; dendritic; oxidation; high temperatures. 


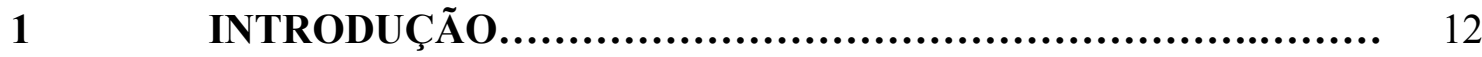

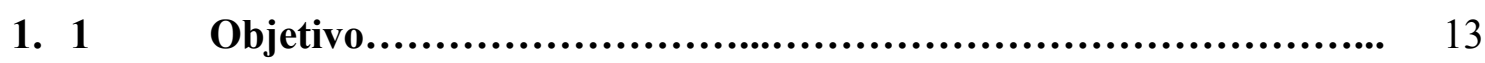

$2 \quad$ REVISÃO DA LITERATURA....................................... 14

2. 1 Ligas de titânio......................................................... 14

2. 2 Aluminetos de titânio (TiAl)............................................ 15

2. 3 Fases do Sistema Ti-Al................................................ 16

2. $4 \quad$ Intermetálicos $\boldsymbol{\gamma}$-TiAl................................................. 18

2. 4. 1 Influência dos elementos liga.......................................... 19

2. 4. 2 Gerações de ligas....................................................... 21

2. 4. 3 Características microestruturais...................................... 22

2. 5 Resistência a oxidação................................................... 23

3 MATERIAIS E MÉTODOS......................................... 26

3. 1 Composições abordadas................................................ 26

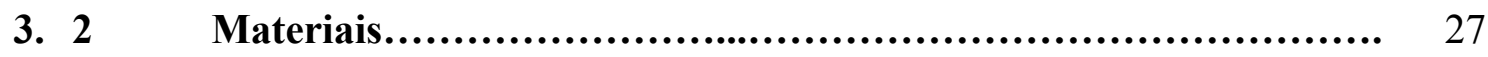

3. 3 Caracterização microestrutural (antes do ensaio de oxidação)....... 29

3. 3. 1 Técnica de difração de raios X............................................ 29

3. 3. 2 Análise via microscopias óptica e eletrônica de varredura................ 33

3. 4 Ensaio de resistência a oxidação........................................... 34

$4 \quad$ RESULTADOS E DISCUSSÃO........................................ 37

4. 1 Identificação das fases..................................................... 37

4. 2 Grau de tetragonalidade............................................. 38

4. 3 Análise microestrutural por microscopias óptica e eletrônica de varredura.......................................................... 38

4. 4 Análise do comportamento da resistência a oxidação sob temperaturas elevadas................................................ 52

4. 4. 1 Curvas de ganho em massa versus tempo.............................. 53

4. 4. 2 Análise das amostras oxidadas por difração de raios X.................. 55

4. 4. 3 Caracterização da camada de óxidos via microscopia eletrônica de varredura........................................................... 56

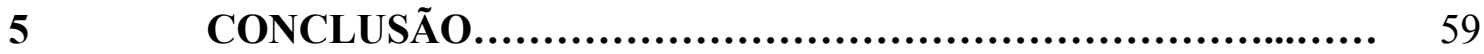

REFERÊNCIAS BIBLIOGRÁFICAS................................ 60 


\section{LISTA DE FIGURAS}

Página

Figura 1 - Comparação entre resistência mecânica e a densidade de vários materiais à temperatura ambiente.

Figura 2 - Gráficos comparativos entre as ligas TiAl e outros materiais estruturais, no que diz respeito a (a) relação entre módulo de Young, resistência e temperatura e (b) resistência específica em função de temperatura.

Figura 3 - Diagrama de fases de um sistema Ti-Al.

Figura 4 - Representação esquemática das estruturas cristalinas das fases $\alpha$-Ti (hexagonal compacta), $\beta$-Ti (estrutura cúbica de corpo centrado), $\alpha_{2}-$ $\mathrm{Ti}_{3} \mathrm{Al}$ (hexagonal) e $\gamma$-TiAl (tetragonal de faces centradas), respetivamente.

Figura 5- Relação entre o Módulo de Young de TiAl e outros materiais estruturais em função de temperatura.

Figura 6 - Principais microestruturas encontradas em uma liga $\gamma$-TiAl bifásica: (a) parcialmente lamelar, (b) near- $\gamma$, (c) duplex e (d) totalmente lamelar, obtidas pelo recozimento de ligas de composição genérica Ti(45-49)Al sob uma condição de temperatura específica.

Figura 7 - Localização aproximada das composições estudadas no diagrama de fases de um sistema Ti-Al

Figura 8 - Matéria-prima utilizada para fabricação das ligas de Ti, Al, Mo e Cr comercialmente puras, e compostos de $\mathrm{Al}-6,22 \% \mathrm{~B}$ e $\mathrm{Nb}-20 \% \mathrm{Al}$.

Figura 9 - Lingote da liga Ti-48Al-2Nb-2Cr-0,5B (\% at.).................... 28

Figura 10 - Estrutura cristalina tetragonal ordenada $\left(\mathrm{L1}_{0}\right)$ da fase $\gamma$-TiAl.......... 30

Figura 11 - Difratograma da composição estequiométrica de TiAl (ficha de número 65-5414).

Figura 12 - Espectro de difração referente a cinco ligas contendo Al, Ti e Zr em composições diferentes

Figura 13 - Representação dos planos adotados para análise da estrutura cristalina do $\gamma$-TiAl. (a) Planos no eixo $z$ da célula unitária e (b) planos no eixo $\mathrm{x}$.

Figura 14 - Área do lingote selecionada para o corte...

Figura 15 - Mapeamento das amostras em regiões. (a) Ti-48Al-2Nb-2Cr-0,5B (\% at.) e (b) liga Ti-44Al-4Nb-1Mo-0,5B (\% at.).

Figura 16 - Sequência de cortes realizados a partir do lingote para a obtenção das amostras para o ensaio de resistência a oxidação (Sequência 1-2-3-4)..

Figura 17 - Amostras das ligas Ti-48Al-2Nb-2Cr-0,5B (\% at.) e Ti-44Al-4Nb$1 \mathrm{Mo}-0,5 \mathrm{~B}$ (\% at.) dentro de tubos de quartzo com as extremidades protegidas por lã de vidro antes de serem oxidadas em forno tipo mufla por $7 \mathrm{~h}$ sob variação de temperatura de 25 a $1000{ }^{\circ} \mathrm{C}$ e resfriadas lentamente. 
Figura 18 - Difratogramas das ligas Ti-48Al-2Nb-2Cr-0,5B (\% at.) e Ti-44Al$4 \mathrm{Nb}-1 \mathrm{Mo}-0,5 \mathrm{~B}$ (\% at.), onde constam as fases $\gamma$-TiAl, $\alpha_{2}-\mathrm{Ti}_{3} \mathrm{Al}, \beta(\mathrm{B} 2)$, e seus respectivos planos de difração................................

Figura 19 - Zona coquilhada da liga Ti-48Al-2Nb-2Cr-0,5B (\% at.) observada na parte superior da amostra. Micrografia óptica em campo claro.

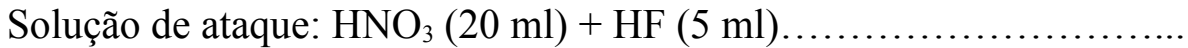

Figura 20 - Área inicial de solidificação da liga Ti-44Al-4Nb-1Mo-0,5B (\% at.). Microestrutura óptica representativa da região 1. Solução de ataque: $\mathrm{HNO}_{3}(20 \mathrm{ml})+\mathrm{HF}(5 \mathrm{ml})$

Figura 21 - Micrografia óptica referente à região da amostra da liga Ti-48Al-2Nb$2 \mathrm{Cr}-0,5 \mathrm{~B}$ (\% at.) ressaltada ao lado esquerdo inferior da imagem, onde observa-se em (a) a zona coquilhada e em (b) a zona colunar. Solução de ataque: $\mathrm{HNO}_{3}(20 \mathrm{ml})+\mathrm{HF}(5 \mathrm{ml})$.

Figura 22 - Zona colunar da liga Ti-48Al-2Nb-2Cr-0,5B (\% at.). Micrografia óptica em campo claro referente à região (b) ressaltada na figura 21 . Solução de ataque: $\mathrm{HNO}_{3}(20 \mathrm{ml})+\mathrm{HF}(5 \mathrm{ml})$

Figura 23 - Zona colunar da liga Ti-44Al-4Nb-1Mo-0,5B (\% at.). Micrografia óptica em campo claro. Solução de ataque: $\mathrm{HNO}_{3}(20 \mathrm{ml})+\mathrm{HF}(5 \mathrm{ml})$

Figura 24 - Ramificação dendrítica principal com projeções promissoras para originar a ramificação secundária na parte superior. Micrografia eletrônica de varredura formada por elétrons secundários referente a liga de Ti-48Al-2Nb-2Cr-0,5B (\% at.). Solução de ataque: $\mathrm{HNO}_{3}(20$ $\mathrm{ml})+\mathrm{HF}(5 \mathrm{ml})$

Figura 25 - Região 2 da amostra de Ti-44Al-4Nb-1Mo-0,5B (\% at.) onde podem ser visualizadas duas regiões dendríticas: (a) com ramificações mais espaçadas formando estruturas similares a grãos e outra com ramificações que tendem a estar mais alinhadas (b). Micrografia óptica em campo claro. Solução de ataque: $\mathrm{HNO}_{3}(20 \mathrm{ml})+\mathrm{HF}(5 \mathrm{ml})$

Figura 26 - Área de transição entre região dendrítica (b) e a zona equiaxial (c) da liga Ti-44Al-4Nb-1Mo-0,5B (\% at.). Micrografia óptica em campo

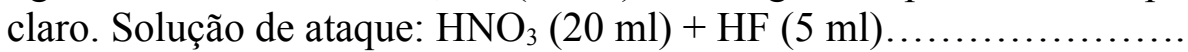

Figura 27 - Grãos formados a partir da interligação de longas ramificações dendríticas na liga Ti-48Al-2Nb-2Cr-0,5B (\% at.). Microscopia óptica em campo escuro. Sem solução de ataque.

Figura 28 - Micrografia óptica referente à região 4 da amostra de Ti-48Al-2Nb$2 \mathrm{Cr}-0,5 \mathrm{~B}$ (\% at.) em que são visualizadas longas ramificações dendríticas curtas e com poucas interligações. Solução de ataque: $\mathrm{HNO}_{3}(20 \mathrm{ml})+\mathrm{HF}(5 \mathrm{ml})$

Figura 29 - Micrografia óptica referente à região 4 da amostra de Ti-48Al-2Nb$2 \mathrm{Cr}-0,5 \mathrm{~B}$ (\% at.) em que são visualizadas fragmentos dendríticos.

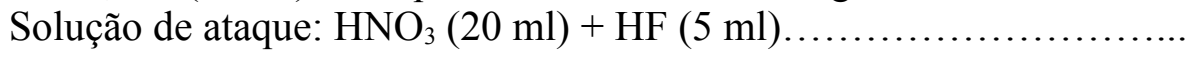

Figura 30 - (a) Ramificações e (b) fragmentos dendríticos da liga Ti-48Al-2Nb$2 \mathrm{Cr}-0,5 \mathrm{~B}$ (\% at.) visualizados na região $4 \mathrm{da}$ amostra. Micrografia óptica em campo escuro. Sem solução de ataque......................

Figura 31 - Zona equiaxial visualizada na liga Ti-44Al-4Nb-1Mo-0,5B (\% at.). 
Micrografia óptica em campo claro. Solução de ataque: $\mathrm{HNO}_{3}(20 \mathrm{ml})$ $+\mathrm{HF}(5 \mathrm{ml})$

Figura 32 - Interface entre (c) ramificações dendríticas e (d) colônia de grãos equiaxiais, localizada na região 5 da amostra de Ti-48Al-2Nb-2Cr0,5B (\% at.). Microscopia óptica em campo claro. Solução de ataque: HNO3 (20 ml) + HF (5 ml)

Figura 33 - Diferença dimensional e estrutural dos grãos encontrados na região 5 da amostra de Ti-48Al-2Nb-2Cr-0,5B (\% at.). Em (c) grãos formados por ramificações dendríticas e em (d) grãos com dimensões menores e mais uniformes (equiaxiais). Microscopia óptica em campo claro.

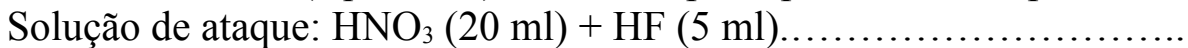

Figura 34 - Micrografia óptica refente a região 4 da amostra de Ti-44Al-4Nb$1 \mathrm{Mo}-0,5 \mathrm{~B}$ (\% at.). Interface entre diferentes micrestruturas. (d) e (f) zonas colunares com espaçamento visualmente diferenciado; (e) região de intersecção de ramificações dendríticas provenientes de diferentes direções; (g) zona de grãos equiaxiais que se iniciam em uma faixa estreita ao lado da zona lamelar mais fina (f) e percorre o limite superior da amostra; (h) provável microestrutura de transição entre os grãos equiaxiais (g) e a zona colunar (d); e (i), interface de transição entre a zona colunar e outra, similar a uma região dendrítica.

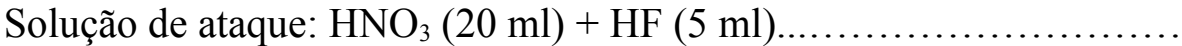

Figura 35 - Zonas colunares referentes a liga Ti-44Al-4Nb-1Mo-0,5B (\% at.). Em (d) notam-se lamelas mais espaçadas do que em (f). Micrografias ópticas em campo claro. Solução de ataque: $\mathrm{HNO}_{3}(20 \mathrm{ml})+\mathrm{HF}(5$ $\mathrm{ml})$

Figura 36 - Microestruturas presentes na região. (e) intersecção de ramificações dendríticas provenientes de diferentes direções; (g) zona de grãos equiaxiais, a região dendrítica; (h) provável microestrutura de transição entre os grãos equiaxiais (g) e a zona colunar; e (i) interface de transição entre a zona colunar e outra, similar a uma região dendrítica.

Figura 37 - Presença de fase no contorno dos grãos. Ainda que a fase tenha reagido com a solução utilizada para o ataque químico, é possível observar resquícios de sua existência nos contornos de grãos. Ligas (a) Ti-48Al-2Nb-2Cr-0,5B (\%at.) e (b) Ti-44Al-4Nb-1Mo-0,5B (\%at.). Microscopia eletrônica de varredura formada por elétrons secundários. Solução de ataque: $\mathrm{HNO}_{3}(20 \mathrm{ml})+\mathrm{HF}(5 \mathrm{ml})$

Figura 38 - Identificação da fase $\alpha_{2}-\mathrm{Ti}_{3} \mathrm{Al}$ nas ligas. (a) Ti-48Al-2Nb-2Cr-0,5B (\%at.) e (b) Ti-44Al-4Nb-1Mo-0,5B (\%at.). Microscopia eletrônica de varredura formada por elétrons secundários. Solução de ataque: $\mathrm{HNO}_{3}$ $(20 \mathrm{ml})+\mathrm{HF}(5 \mathrm{ml})$.

Figura 39 - Contraste entre a evidência da fase $\alpha_{2}-\mathrm{Ti}_{3} \mathrm{Al}$. Em (a) Ti-48Al-2Nb-2Cr0,5B (\%at.) é encontrada de forma intensa do que em (b) Ti-44Al$4 \mathrm{Nb}-1 \mathrm{Mo}-0,5 \mathrm{~B}$ (\%at.), provavelmente devido a maior concentração de alumínio. Microscopia óptica em campo claro. Solução de ataque: $\mathrm{HNO}_{3}(20 \mathrm{ml})+\mathrm{HF}(5 \mathrm{ml})$ 
Figura 40 - Observação da fase $\alpha_{2}-\mathrm{Ti}_{3} \mathrm{Al}$ na região mais interna dos grãos e provável localização da fase $\beta$ nos contornos de grão. Ligas (a) Ti48Al-2Nb-2Cr-0,5B (\%at.) e (b) Ti-44Al-4Nb-1Mo-0,5B (\%at.). Microscopia eletrônica de varredura formada por elétrons secundários.

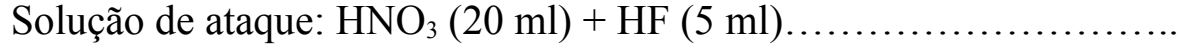

Figura 41 - (a) Variação da temperatura ao decorrer do tempo de ensaio e (b) curvas de ganho em massa versus tempo das ligas Ti-48Al-2Nb-2Cr0,5B (\%at.) e Ti-44Al-4Nb-1Mo-0,5B (\%at.) registradas em ensaio termogravimétrico em uma DTG com fluxo de ar de $100 \mathrm{~mL} / \mathrm{min}$ e variação de temperatura de 25 a $1000{ }^{\circ} \mathrm{C}$...............................

Figura 42 - Curvas de ganho em massa versus tempo das ligas Ti-48Al-2Nb-2Cr0,5B (\%at.) e Ti-44Al-4Nb-1Mo-0,5B (\%at.) registradas em ensaio termogravimétrico em uma DTG com fluxo de ar de $100 \mathrm{~mL} / \mathrm{min}$ e variação de temperatura de 25 a $1000{ }^{\circ} \mathrm{C}$, com destaque para $\mathrm{o}$ comportamento parabólico adotado pelas duas ligas....................

Figura 43 - Difratogramas de raios x das ligas Ti-48Al-2Nb-2Cr-0,5B (\%at.) e Ti44Al-4Nb-1Mo-0,5B(\%at.) após o ensaio de oxidação em mufla sob temperatura de $1000{ }^{\circ} \mathrm{C}$ durante 7 horas..........................

Figura 44 - Camada de óxido formada nas amostras de (a) Ti-48Al-2Nb-2Cr-0,5B (\% at.) e (b) Ti-44Al-4Nb-1Mo-0,5B (\%at.) após ensaio de oxidação em mufla sob temperatura de $1000{ }^{\circ} \mathrm{C}$ durante 7 horas. Micrografia eletrônica de varredura obtida por elétrons secundários................ 


\section{INTRODUÇÃO}

Ao longo dos anos, o mercado industrial tem se tornado cada vez mais competitivo. Assim, para que uma indústria garanta a sua consolidação no mercado, bem como o seu desenvolvimento, faz-se necessário que elas invistam sempre na pesquisa por novos materiais cujas propriedades ofereçam vantagens quando comparados com aqueles comumente empregados no processo produtivo, como melhor qualidade e/ou custobenefício $^{[1]}$.

Visto os satisfatórios resultados obtidos em âmbito laboratorial, nos últimos trinta anos ou mais, os estudos dos intermetálicos TiAl, NiAl e FeAl foram intensificados consideravelmente, atingindo um nível de maturidade tão elevado que lhes possibilita competir com aqueles materiais ditos tradicionais em aplicações onde se faz necessária a manutenção das propriedades mecânicas, elétricas, térmicas ou magnéticas sob condições ambientais peculiares como altas temperaturas, por exemplo ${ }^{[1-3]}$.

Quando comparadas com as outras ligas, os aluminetos de titânio (TiAl) se revelam promissores para aplicações estruturais em substituição às superligas de $\mathrm{Ni}{ }^{[4-7]}$, visto que apresentam principalmente, alto ponto de fusão $\left(1400-1500{ }^{\circ} \mathrm{C}\right)$, manutenção de elevados níveis de resistência mecânica em condições de temperaturas entre 600 e 950 ${ }^{\circ} \mathrm{C}$, e além disso, seu maior diferencial consiste na baixa densidade $\left(3,8-4,0 \mathrm{mg} / \mathrm{cm}^{2}\right)$, que resulta em uma redução de até $50 \%$ em massa dos componentes fabricados a partir desta liga ${ }^{[1,2,8-11]}$

Estas características torna o TiAl particularmente atrativo para inúmeras vertentes industriais onde a redução do peso e a resistência dos componentes são consideradas extremamente relevantes sob temperaturas de trabalho da ordem dos $800{ }^{\circ} \mathrm{C}$, tais como, lâminas de turbina, rotores do turbo-alimentador, válvulas de automóveis, turbocompressor, dentre outros ${ }^{[1-3,12-14] \text {. }}$

Estes aluminetos possuem três principais compostos: $\gamma$-TiAl, $\alpha_{2}-\mathrm{Ti}_{3} \mathrm{Al}$ e $\mathrm{TiAl}_{3}{ }^{[8,}$ ${ }^{15,16]}$. A princípio, diversos pesquisadores descartaram a possibilidade de que a liga $\gamma$-TiAl teria aplicação industrial devido a algumas das suas limitações, como baixa ductilidade e insuficiente resistência à oxidação quando submetida à temperaturas superiores a $800{ }^{\circ} \mathrm{C}{ }^{[8,}$ 
10, 16-21]. Entretanto, por apresentarem boa resistência à oxidação sob temperatura ambiente e manutenção da resistência sob condições de temperaturas acima de $800{ }^{\circ} \mathrm{C}$, as pesquisas voltadas a esta liga foram intensificadas ${ }^{[17]}$.

Com o aprimoramento do conhecimento acerca das ligas $\gamma$-TiAl e desenvolvimento de novas tecnologias têm sido possível obter avanços no seu processamento, bem como, no controle da sua microestrutura mediante a associação da fase $\alpha_{2}-\mathrm{Ti}_{3} \mathrm{Al}$, ainda que em pequena quantidade, às ligas $\gamma$-TiAl, ${ }^{[16]}$, permitindo assim, a sua aplicação em lâminas de turbinas de baixa pressão e partes de aeronaves, por exemplo [5].

A adição de elementos terciários às ligas $\gamma$-TiAl foi um dos recursos utilizados no intuito de aprimorar as suas propriedades e a medida que foram sendo conhecidos os seus efeitos três gerações de ligas foram desenvolvidas e a quarta encontra-se em âmbito de projeto ${ }^{[10,22]}$. As composições que tiveram maior interesse e aplicação industrial correspondem às ligas Ti-48Al-2Cr-2Nb (4822) e Ti-43,5Al-4Nb-1Mo-0,1B (TNM), pertencentes a segunda e terceira geração, respectivamente. A primeira encontra-se em operação desde 2011 na General Eletric TM na fabricação de lâminas fundidas em baixa pressão e temperatura ${ }^{[5,7,19]}$, e a segunda, entrou serviço em 2016 através do Pratt \& Whitney PurePower TM na fabricação de lâminas de turbinas em baixa pressão e temperatura por processo de forjamento ${ }^{[5,23]}$.

Existem vários estudos relacionados a estas ligas, porém, são poucos os documentos que relatam o comportamento delas à oxidação antes de terem sido submetidas a tratamentos térmicos. Assim, as tendo como base, as ligas Ti-48Al-2Nb-2Cr-0,5B (\% at.) e Ti-44Al-4Nb-1Mo-0,5B (\% at.) fundidas em forno a arco elétrico e brutas de fusão tiveram a sua microestrutura analisada via difração de raios $\mathrm{X}$, microscopia óptica e microscopia eletrônica de varredura, além de terem sido submetidas a dois ensaios de resistência a oxidação sob $1000{ }^{\circ} \mathrm{C}$ de temperatura, consistindo em um estudo preliminar para realização de ensaios mecânicos visando aplicação em componentes automotivos.

\subsection{Objetivo}

Realizar a caracterização microestrutural e análise do comportamento da resistência à oxidação sob $1000{ }^{\circ} \mathrm{C}$ de temperatura das ligas Ti-48Al-2Nb-2Cr-0,5B (\% at.) e Ti-44Al-4Nb-1Mo-0,5B (\% at.) fundidas em um forno a arco elétrico sob atmosfera de argônio e sem tratamento térmico. 


\section{REVISÃO DA LITERATURA}

\subsection{Ligas de titânio}

Em meados dos anos 50 a liga de titânio foi descoberta como um material estrutural promissor uma vez que foram identificadas propriedades atrativas para diversos setores industriais ${ }^{[24,25]}$. O sucesso dessas ligas têm como base a excelente resistência mecânica, boa resistência a oxidação, baixa condutividade e expansão térmica, e ainda, baixa densidade $\left(4,54 \mathrm{~g} / \mathrm{cm}^{3}\right)$ que possibilita uma redução significativa na massa do componente. Estas propriedades favorecem a sua aplicação na fabricação de componentes como bielas, válvulas, parafusos de aro de roda e molas de suspensão para carros de corrida, recobrimento de cauda e pás de turbinas em motores de aeronaves, além de serem usados como implantes ortopédicos e dentais permanentes ${ }^{[24-26]}$.

O titânio pode existir sob dois tipos de estruturas cristalinas: hexagonal compacta $\left(\alpha\right.$-Ti) em temperaturas inferiores a $882^{\circ} \mathrm{C}$, e a partir deste ponto até o seu ponto de fusão, cúbica de corpo centrado $(\beta$-Ti). Adições de outros elementos à liga alteram a temperatura em que ocorre a transição entre $\alpha$ e $\beta$, sendo que, aqueles responsáveis pelo seu aumento são denominados estabilizadores $\alpha$, uma vez que ampliam o domínio desta estrutura cristalina; já os que diminuem esta temperatura, são chamados de estabilizadores $\beta^{[24]}$.

Os estabilizadores $\beta$ podem ser de dois tipos: elementos isomorfos e eutetoides. Elementos isomorfos são completamente solúveis na fase $\beta$-Ti, sendo molibdênio, vanádio e nióbio, exemplos desta categoria. Já os eutetoides, apresentam uma solubilidade restrita nesta fase, formando componentes intermetálicos por decomposição eutética da fase $\beta^{[24]}$.

O processamento do titânio por métodos convencionais é muito difícil devido à baixa condutividade térmica e alta reatividade química com materiais de ferramentas de corte, o que encarece a sua aplicação. Contudo, desde a descoberta deste elemento como um material promissor, a indústria voltada para o seu processamento têm desenvolvido novas técnicas e composições visando ampliar a gama de aplicações ${ }^{[24]}$. 


\subsection{Aluminetos de titânio (TiAl)}

O alumínio é um dos principais constituintes da maioria das ligas comerciais devido a diversos fatores especialmente pelo seu custo reduzido e baixa densidade. Assim, com as ligas de titânio não é diferente, ao ser associado a esta liga, amplia a sua gama de aplicação em temperaturas ambiente e acima de $550{ }^{\circ} \mathrm{C}$ ao promover um efetivo fortalecimento da fase $\alpha$ na composição ${ }^{[24,27]}$.

Devido à combinação de suas atrativas propriedades mecânicas, baixa densidade e boa resistência a oxidação os aluminetos de titânio são amplamente empregados na fabricação de rotores de turbocompressores em motores automotivos, pás de turbinas aeroenergéticas ${ }^{[28]}$, aeronaves, naves espaciais, vagões ferroviários, navios leves, dentre outros ${ }^{[9,16,23,29,30,31]}$.

No que diz respeito a resistência e densidade, por meio da figura 1 é possível observar que as ligas TiAl apresentam valores intermediários quando comparadas com outros materiais estruturais, tais como os aços e ligas de titânio. Isso evidencia a utilização das ligas TiAl em aplicações em que seja necessário aliar a baixa densidade à resistência mecânica ${ }^{[32]}$.

Figura 1: Comparação entre resistência mecânica e a densidade de vários materiais à temperatura ambiente.

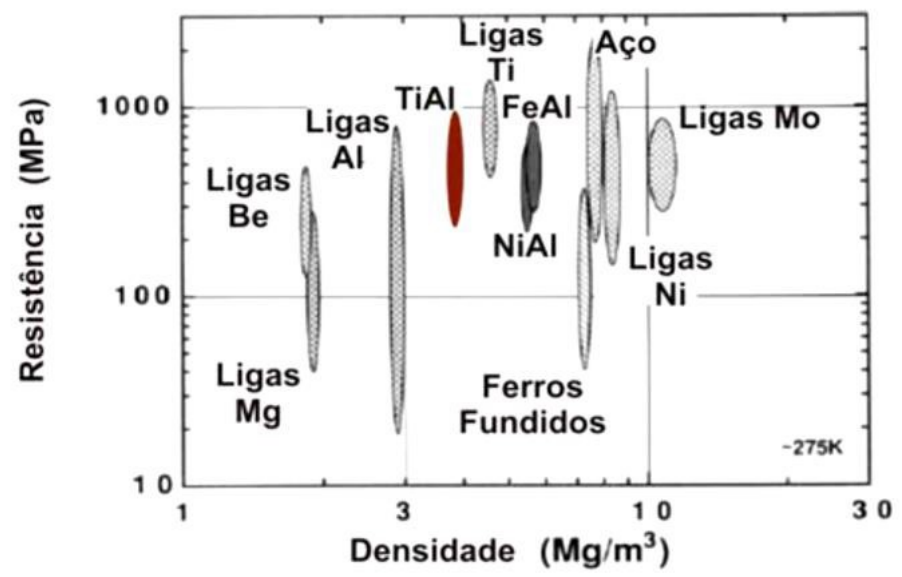

Fonte: SOARES ${ }^{[32]}$

A temperatura exerce influência nas propriedades de vários materiais inclusive nos intermetálicos TiAl, como mostra a figura 2, onde estão sendo relacionados a rigidez do material (módulo de Young), a resistência específica e a temperatura. Quando comparado com outros materiais estruturais, os aluminetos de titânio possuem um alto 
módulo de Young, além de manter elevados níveis de resistência para uma ampla gama de temperaturas ${ }^{[1,32]}$.

Figura 2: Gráficos comparativos entre as ligas TiAl e outros materiais estruturais, no que diz respeito a (a) relação entre módulo de Young, resistência e temperatura e (b) resistência específica em função de temperatura

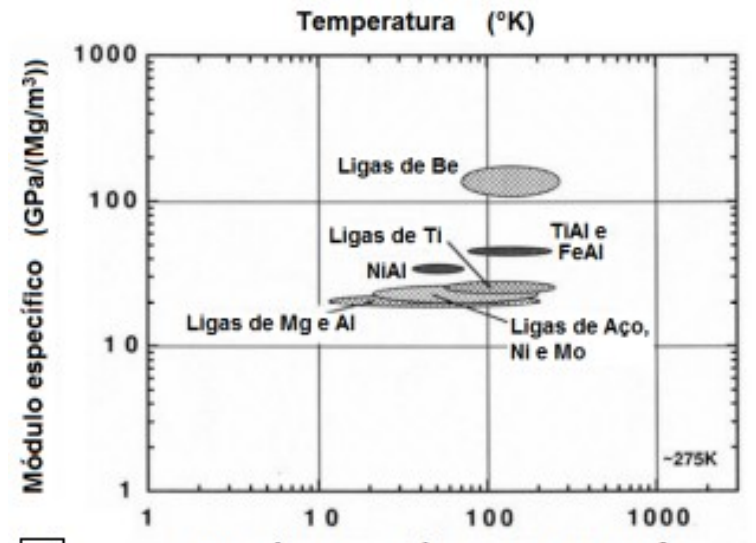

a Resistência especifica $\left(\mathrm{MPa} /\left(\mathrm{Mg} / \mathrm{m}^{3}\right)\right)$

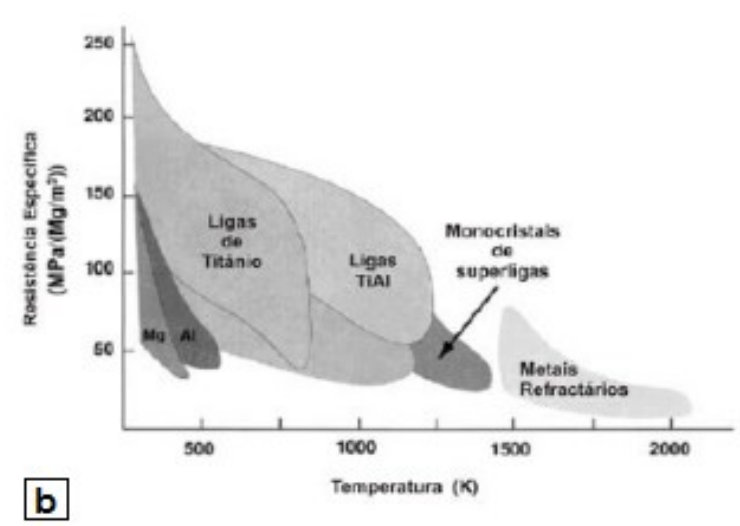

Fonte: (a) SOARES ${ }^{[32]}$ e (b) DUARTE ${ }^{[1]}$

Contudo, as ligas TiAl não são aplicadas de modo mais amplo em áreas de engenharia devido à sua baixa ductilidade, da ordem de 1 a $4 \%$, e reduzida tenacidade à fratura, que varia entre 12 e $35 \mathrm{MPa}^{-1 / 2}$. Visto isso, têm sido propostas inúmeras composições com o intuito de melhorar estas e outras propriedades da liga tendo como base a adição de elementos terciários e quaternários ${ }^{[1,32]}$.

\subsection{Fases do Sistema Ti-Al}

Para realizar a caracterização dos aluminetos de titânio se faz necessária uma análise do diagrama de fases do sistema Ti-Al, o qual está sendo disposto na figura 3. Neste diagrama é possível observar que dependendo da composição e da temperatura uma variedade de soluções sólidas e fases intermetálicas podem ser alcançadas quando associados estes dois elementos, tais como: $\alpha$-Ti (A3), $\beta$-Ti (A2), $\beta_{\mathrm{o}}$ (B2), $\gamma$-TiAl (L1 $\left.1_{0}\right), \alpha_{2}-$ $\mathrm{Ti}_{3} \mathrm{Al}\left(\mathrm{D0}_{19}\right)$ e $\mathrm{Al}_{3} \mathrm{Ti}$. Existe a possibilidade de ocorrer uma transformação entre $\alpha$-Ti (A3) e $\alpha_{2}-\mathrm{Ti}_{3} \mathrm{Al}\left(\mathrm{D}_{19}\right)$, do mesmo modo que entre $\beta_{\mathrm{o}}$ (ordenado) e $\beta$-Ti (desordenado), dependendo da composição da liga ${ }^{[1,2,33]}$. A figura 4 contém uma representação de algumas destas estruturas cristalinas. 
Figura 3: Diagrama de fases de um sistema Ti-Al.

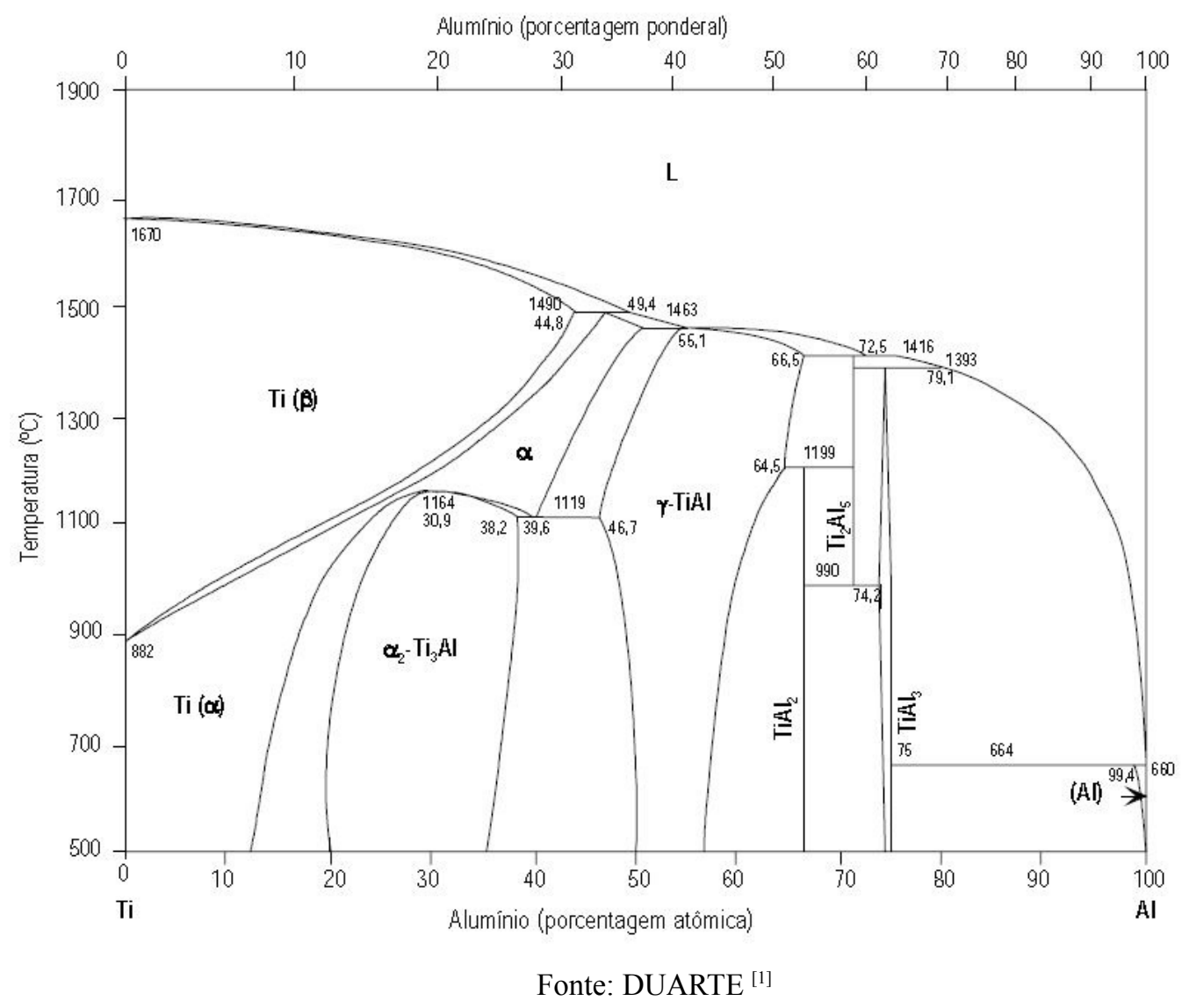

Figura 4: Representação esquemática das estruturas cristalinas das fases $\alpha$-Ti (hexagonal compacta), $\beta$-Ti (estrutura cúbica de corpo centrado), $\alpha_{2}-\mathrm{Ti}_{3} \mathrm{Al}$ (hexagonal) e $\gamma$-TiAl (tetragonal de faces centradas), respetivamente.

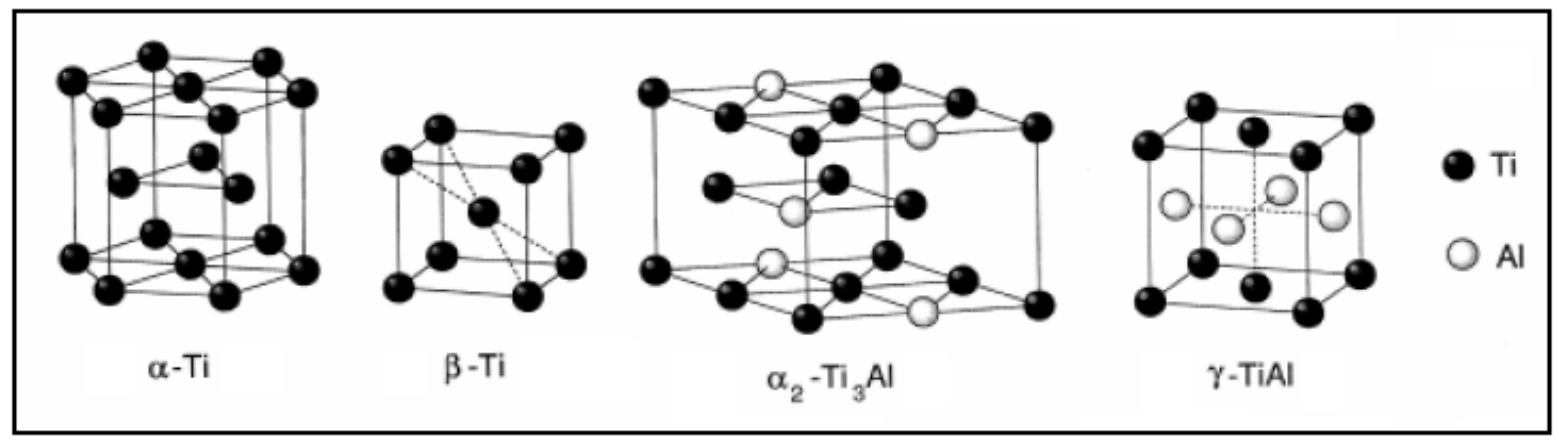

Fonte: DUARTE ${ }^{[1]}$. Adaptado

Os principais intermetálicos são $\gamma$-TiAl, $\alpha_{2}-\mathrm{Ti}_{3} \mathrm{Al}$ e $\mathrm{Al} l_{3} \mathrm{Ti}$, sendo que dentre eles, apenas as ligas baseadas nas duas primeiras fases são consideradas promissoras para o uso sob temperaturas elevadas ${ }^{[8,15,16]}$.

A fase $\alpha_{2}-\mathrm{Ti}_{3} \mathrm{Al}$ resulta de um ordenamento na rede hexagonal compacta da fase $\alpha$-Ti, a qual é estável numa gama de composições até atingir uma temperatura de $1180{ }^{\circ} \mathrm{C}$. 
A malha elementar desta fase é composta por contém 2 átomos de alumínio e 6 de titânio, sendo que dentro da célula hexagonal completa existem três malhas elementares. Quanto aos parâmetros de rede, existe uma relação entre os parâmetros da fase $\alpha_{2} \operatorname{com}$ os da fase $\alpha$ Ti: a (base) $\alpha_{2}=2 a \alpha$ e c (altura) $\alpha_{2}=c \alpha$; com isso, o valor do parâmetro $a$ está compreendido entre 0,564 e $0,578 \mathrm{~nm}$ e o do parâmetro $c$ entre 0,462 e $0,476^{[1]}$.

Já a fase $\gamma$ surge para diversas composições e mantém seu carácter ordenado até o ponto de fusão $\left(1450^{\circ} \mathrm{C}\right)$. Planos de átomos de titânio alternados com planos de alumínio constituem a sequência de empilhamento na direção [001] e nas direções [100] e [010] planos mistos de composição estequiométrica TiAl se alternam. O parâmetro de rede $a$ (base) está compreendido entre 0,397 e $0,401 \mathrm{~nm}$ e $c$ (altura) entre 0,406 e $0,410 \mathrm{~nm}^{[1]}$.

\subsection{Intermetálicos $\gamma$-TiAl}

Este tipo de intermetálico apresenta uma combinação única de alta resistência específica, alto módulo de elasticidade, baixa densidade, boa resistência à oxidação e à fluência sob temperatura ambiente, sendo atraentes para diversos setores industriais tais como aeronáutico, aeroespacial e automobilístico, uma vez que suas propriedades permitem considerá-las superiores às superligas de $\mathrm{Ni}{ }^{[9,16,17,23,28-31,34]}$.

A figura 5 mostra o módulo de Young das ligas $\gamma$-TiAl sendo comparado à outros materiais estruturais em uma determinada faixa de temperatura, evidenciando o seu melhor desempenho em relação à eles ${ }^{[1,29]}$.

Figura 5: Relação entre o Módulo de Young de TiAl e outros materiais estruturais em função de temperatura.

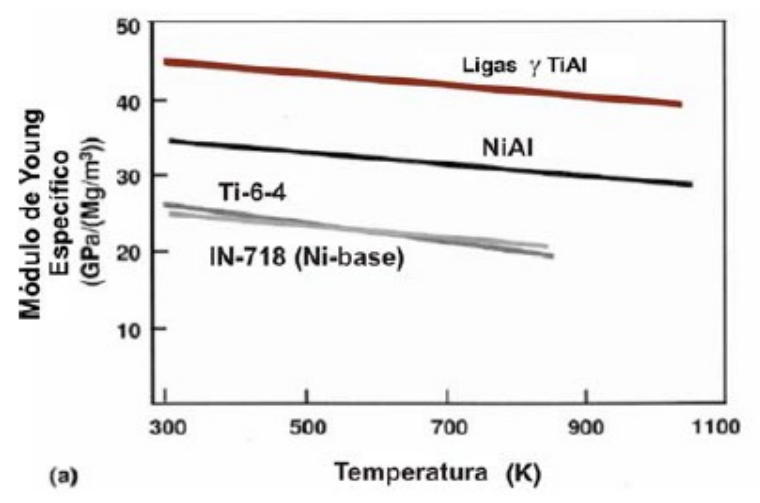

Fonte: DUARTE ${ }^{[1]}$

A princípio, a possibilidade de aplicação industrial da liga $\gamma$-TiAl foi descartada por diversos pesquisadores [8, 10, 17, 35], visto que possui limitações como: 
dificuldades de usinagem decorrentes à baixa ductilidade à temperatura ambiente causada pela presença de muitas fases intermetálicas, insuficiente resistência à oxidação quando submetida à temperaturas superiores a $800^{\circ} \mathrm{C}$, e ainda, baixa tenacidade à fratura influenciada pelo número limitado de sistemas de deslizamento nesta fase ${ }^{[8,10,16,17,19-21]}$.

Todavia, conforme o desenvolvimento de novas tecnologias e aprimoramento do conhecimento acerca das ligas $\gamma$-TiAl têm sido possível obter avanços no seu processamento, bem como, no controle da sua microestrutura mediante a associação da fase $\alpha_{2}-\mathrm{Ti}_{3} \mathrm{Al}$ às ligas $\gamma$-TiAl (liga bifásica) que resulta numa melhora da dureza e da tenacidade à fratura do material. A propriedade de resistência a oxidação em alta temperatura também têm tido uma melhora considerável, por meio da utilização de modificações na superfície (tratamento termoquímico e deposição de revestimentos) e principalmente, adição de outros elementos à liga, ampliando assim a sua gama de aplicação ${ }^{[1,8,35]}$.

\subsubsection{Influência dos elementos liga}

Os elementos de liga são responsáveis pelo aumento da ductilidade, da resistência à oxidação ou a melhoria de um conjunto de propriedades dos intermetálicos através da modificação das suas características microestruturais ${ }^{[1,2]}$.

As ligas bifásicas $\gamma$-TiAl são basicamente compostas por titânio, alumínio e outros elementos, conforme a composição Ti-(45-49)Al-(1-3) $\mathrm{X}_{1}-(1-4) \mathrm{X}_{2}-(0,1-1) \mathrm{X}_{3}{ }^{[1,2]}$.

Os elementos do tipo $\mathrm{X}_{1}$ aumentam a ductilidade da liga e geralmente, refinam o tamanho de grão, como é o caso do vanádio, cromo ${ }^{[7]}$, molibdênio, cromo+manganês ou cromo+vanádio ${ }^{[1,2]}$. Uma adição de 1 a 3 (\% at.) destes elementos é suficiente para duplicar a ductilidade à temperatura ambiente da liga Ti-48 $\mathrm{Al}^{[1,2]}$ desde que a concentração de alumínio esteja compreendida entre 45 e $50 \%{ }^{[2]}$.

De acordo com alguns autores ${ }^{[1,21]}$ a adição de manganês ativa mecanismos de deformação por maclagem na fase $\gamma$, o que aumenta a ductilidade. Já o cromo ${ }^{[36]}$, além de poder influenciar na propriedade de tração das ligas tanto em temperatura ambiente quanto em elevadas por meio do refinamento dos grãos, também reduz a tetragonalidade e o volume das células unitárias da fase $\alpha_{2}-\mathrm{Ti}_{3} \mathrm{Al}$ com mudanças microestruturais intrínsecas ${ }^{[1}$, 4, 9, 16, 21, 37]. Estudos mostram que adições da ordem de 1,5 (\% at.) de molibdênio resulta numa melhora da ductilidade à temperatura ambiente de um modo mais eficaz que as adições de cromo ou manganês ${ }^{[1,2,9,16]}$. 
Elementos como molibdênio, nióbio [5, 23, 36], cromo ${ }^{[36]}$, vanádio [36, 38], manganês, prata, ferro e níquel ${ }^{[38]}$ adicionados às ligas baseadas na fase $\gamma$-TiAl resultam na estabilização da fase $\beta$ que pode efetivamente melhorar a ductilidade à temperatura

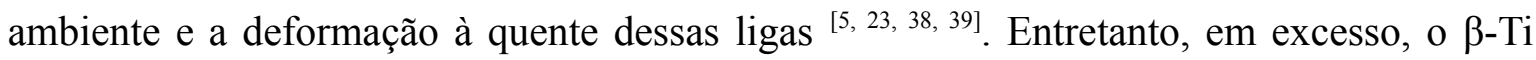
torna-se prejudicial à resistência à fluência.

Em geral, os componentes da categoria $\mathrm{X}_{1}$ influenciam negativamente na resistência à oxidação, por este motivo são acrescentados os elementos encontrados no grupo $\mathrm{X}_{2}$. Nesta categoria, os elementos são eficazes na melhoria da ductilidade, resistência mecânica e principalmente na oxidação das ligas, já que todos os componentes pertencentes a este grupo promovem a formação de uma película contínua de alumina $\left(\mathrm{Al}_{2} \mathrm{O}_{3}\right)$ responsável pela diminuição do fluxo de oxigênio para o interior da liga e por conseguinte a redução da taxa de oxidação ${ }^{[1,2]}$.

O nióbio é encontrado em quase todas as composições de TiAl visto o seu evidente efeito na melhoria da resistência à oxidação, propriedade determinante para possibilitar a utilização da liga sob temperaturas de aproximadamente $800{ }^{\circ} \mathrm{C}[1,9,18,22]$. Entretanto, caso seja empregado em excesso, acima de 10 (\% at.), pode ocasionar alguns problemas na liga como, por exemplo, microssegregação ${ }^{[37]}$ e formação de óxidos mistos de Ti-Nb e Al-Nb ${ }^{[7]}$.

Os elementos que tem um efeito similar ao do nióbio são: tungstênio, molibdênio, silício, ferro, tântalo ${ }^{[9]}$. Existem casos em que, ao contrário da maioria dos estudos, o tântalo é mais eficaz em termos de oxidação em alta temperatura $\left(1000{ }^{\circ} \mathrm{C}\right)$ do que o nióbio ${ }^{[40]}$, porém, ambos os elementos refletem também no aumento da resistência à fluência, uma vez que dificultam o processo de difusão ${ }^{[1,41]}$. Com relação ao cromo, em ligas ternárias ele resulta num efeito prejudicial na resistência a oxidação caso a sua concentração seja inferior a 4 (\% at), entretanto, exibe um efeito benéfico quando encontrado em concentração superior a 8 (\%at) ${ }^{[7]}$.

$\mathrm{O}$ grupo $\mathrm{X}_{3}$, por sua vez, tem por objetivo aprimorar propriedades específicas, por meio de adições em pequenas quantidades. O boro é responsável por promover um refinamento dos grãos, podendo influenciar positivamente na ductilidade, enquanto que o carbono, o azoto e o silício aumentam a resistência à fluência, sendo que este último também melhora a resistência à oxidação. Já o tungstênio, quando presente em solução sólida na liga TiAl $+\mathrm{W}$, melhora a resistência à fluência para uma gama de temperaturas de 550 a $850^{\circ} \mathrm{C}$, resistência mecânica e à oxidação, entretanto, diminui a ductilidade à temperatura ambiente ${ }^{[1]}$. 
Desta forma, verifica-se que cada elemento exerce um tipo de influência nas propriedades das ligas e à medida que tornaram-se conhecidos estes efeitos, foram desenvolvidas diferentes composições químicas, que culminaram nas diferentes gerações de ligas.

\subsubsection{Gerações de ligas}

A primeira delas, Ti-47Al-1V-0,3C, almejava ductilidade e resistência à fluência, porém, mostrou-se inadequada para componentes de motores ${ }^{[1,20]}$. Em seguida, buscando melhorar a ductilidade e a resistência à oxidação, uma segunda geração de ligas foi desenvolvida: Ti- (45-48) Al - (1-3) X1 - (2-5) Y1 - (<1) Z1, onde X1 = Cr, Mn, V; Y1 $=\mathrm{Nb}, \mathrm{Ta}, \mathrm{W}, \mathrm{Mo} ; \mathrm{Z1}=\mathrm{Si}, \mathrm{B}, \mathrm{C}(\% \text { at. })^{[1,5,7]}$.

A liga Ti-48Al-2Cr-2Nb (\% at.) (4822), pertencente a segunda geração, é conhecida por exibir boa resistência à oxidação e um equilíbrio relativamente bom das propriedades mecânicas quando submetida a temperatura de até $750{ }^{\circ} \mathrm{C}{ }^{[19]}$ e está em operação desde 2011 na General Electric (GE) na fabricação de pás de turbina de motores de aeronaves que operam sob baixa pressão. Atualmente, existem cerca de 190.000 pás desse tipo voando no Boeing 787 e no Boeing $747-8^{[5,7,19]}$. Além disso, esta liga também está sendo aplicada na fabricação de rotores de turbocompressores automobilísticos ${ }^{[41]}$.

$\mathrm{Na}$ década seguinte ao surgimento da segunda geração de ligas $\gamma$-TiAl foi criada a terceira a partir de estudos realizados na General Electric. Estas ligas, também conhecidas por TNM, apresentam composições que podem ser representadas como: Ti(42-45) Al - (0-10) X2 - (0-3) Y2 - (0-1) Z2 - (0-0,5) RE, onde X2 = Cr, Mn, Nb, Ta; Y2 $=\mathrm{Mo}, \mathrm{W}, \mathrm{Hf}, \mathrm{Zr} ; \mathrm{Z2}=\mathrm{C}, \mathrm{B}, \mathrm{Si}$; e RE = elementos de terras raras. Estas ligas são obtidas por processos de fusão e deformação plástica e contêm pequenas adições de vários elementos, visando a obtenção de estruturas mais finas e com uma melhora na ductilidade à temperatura ambiente e a deformação à quente mediante a presença da fase $\beta^{[1,5,7,23,38,39]}$.

A liga Ti-43,5Al-4Nb-1Mo-0,1B (\% at.) entrou em serviço em 2016 através do Pratt \& Whitney PurePower na fabricação de lâminas forjadas para turbo ventilador motor (baixa pressão e temperatura), que apresenta melhor desempenho em comparação com a liga $4822^{[5,23]}$. Nesta liga, ao contrário das convencionais onde apenas $\gamma$ e $\alpha_{2}$ são estáveis, as fases $\beta$-Ti (B2), $\gamma$-TiAl e $\alpha_{2}-\mathrm{Ti}_{3} \mathrm{Al}$ são termodinamicamente estáveis à temperatura ambiente. O tamanho refinado de grãos mediante a adição de $\mathrm{B}$ e um volume maior da fração de $\beta$-Ti de alta temperatura (estrutura cúbica desordenada) devido a quantidades 
equilibradas de $\mathrm{Nb}$ e Mo melhora a trabalhabilidade a quente em alta temperatura ${ }^{[5,42]} \mathrm{e}$ características de serviço após processos de fundição, prensagem isostática a "quente" e tratamentos térmicos apropriados ${ }^{[42]}$.

A quarta e última geração ainda está em âmbito de projeto e baseia-se em elementos que reduzem significativamente o processo de difusão para atingir grandes transformações em baixas velocidades de resfriamento ${ }^{[3]}$, condições estas potenciais para investir em hélices de turbina que atuam sob baixa pressão ${ }^{[42]}$.

\subsubsection{Características microestruturais}

As ligas comerciais $\gamma$-TiAl cujo teor de Al variam entre 35 e 65 (\%at.) são comumente divididas em dois grupos: ligas monofásicas e bifásicas. As ligas monofásicas se baseiam exclusivamente na fase $\gamma$-TiAl e não possuem um conjunto equilibrado de propriedades que favorecem a sua aplicação. As ligas bifásicas por sua vez, consistem numa associação das fases $\gamma-\mathrm{TiAl}$ e $\alpha_{2}-\mathrm{Ti}_{3} \mathrm{Al}$ (em pouca quantidade), que resulta não apenas em um melhor controle microestrutural, mas sim, em um melhor conjunto de propriedades quando comparadas às ligas monofásicas ${ }^{[1,2,41]}$.

De acordo com o processamento e tratamento térmico utilizado nas ligas bifásicas $\gamma$-TiAl $+\alpha_{2}-\mathrm{Ti}_{3} \mathrm{Al}$, as microestruturas podem se apresentar de diferentes modos ${ }^{[4}$, ${ }^{7,12]}$ e dentre elas, destacam-se: (a) parcialmente lamelar: que consiste predominantemente de grãos grosseiros lamelares $\gamma$ e $\alpha_{2}$; (b) near- $\gamma$ : composta por grãos grosseiros de $\gamma$ e cordões de grãos finos de $\gamma$ ancorados por finos precipitados de partículas de $\alpha_{2}$; (c) duplex: surge quando ocorre o crescimento competitivo entre os grãos $\gamma$ e $\alpha_{2}$; e (d) totalmente lamelar: composta por lamelas alternadas de $\gamma$ e $\alpha_{2}{ }^{[1,2,41]}$. Na figura 6 são mostradas as principais microestruturas obtidas nas ligas bifásicas $\gamma$-TiAl mediante $o$ recozimento de ligas de composição genérica Ti-(45-49)Al sob uma condição de temperatura específica ${ }^{[1,41]}$.

As microestruturas totalmente lamelar e parcialmente lamelar do TiAl exibem melhor resistência à deformação, elevada tenacidade a fratura e resistência a propagação de trinca do que a duplex. Sendo que, a primeira apresenta melhor resistência a fluência ${ }^{[7]} \mathrm{e}$ balanço entre as propriedades de deformação, ductilidade e resistência mecânica ${ }^{[43,44]}$. Por outro lado, alta resistência a tração, ductilidade e longa vida em fadiga são obtidas pela duplex ${ }^{[3]}$. 
A fase $\gamma$-TiAl possui uma estrutura lamelar constituída por colônias contendo plaquetas lamelares alternadas $\gamma$ e $\alpha_{2}$, e pela fase $\alpha_{2}-\mathrm{Ti}_{3} \mathrm{Al}$ com estrutura duplex contendo grãos equiaxiais de $\gamma$ com pequenas quantidades de grãos $\alpha_{2}{ }^{[12,41]}$. Além destas fases, em alguns casos, nas ligas bifásicas $\gamma$-TiAl também é encontrada a fase $\beta_{0}$-Ti (B2), que desordena para a fase $\beta$-Ti (A2) em temperaturas elevadas ${ }^{[4,7]}$, podendo se formar durante o resfriamento do material dependendo da composição química e do processamento utilizado $^{[41]}$.

Figura 6: Principais microestruturas encontradas em uma liga $\gamma$-TiAl bifásica: (a) parcialmente lamelar, (b) near- $\gamma$, (c) duplex e (d) totalmente lamelar, obtidas pelo recozimento de ligas de composição genérica Ti(45-49)Al sob uma condição de temperatura específica.
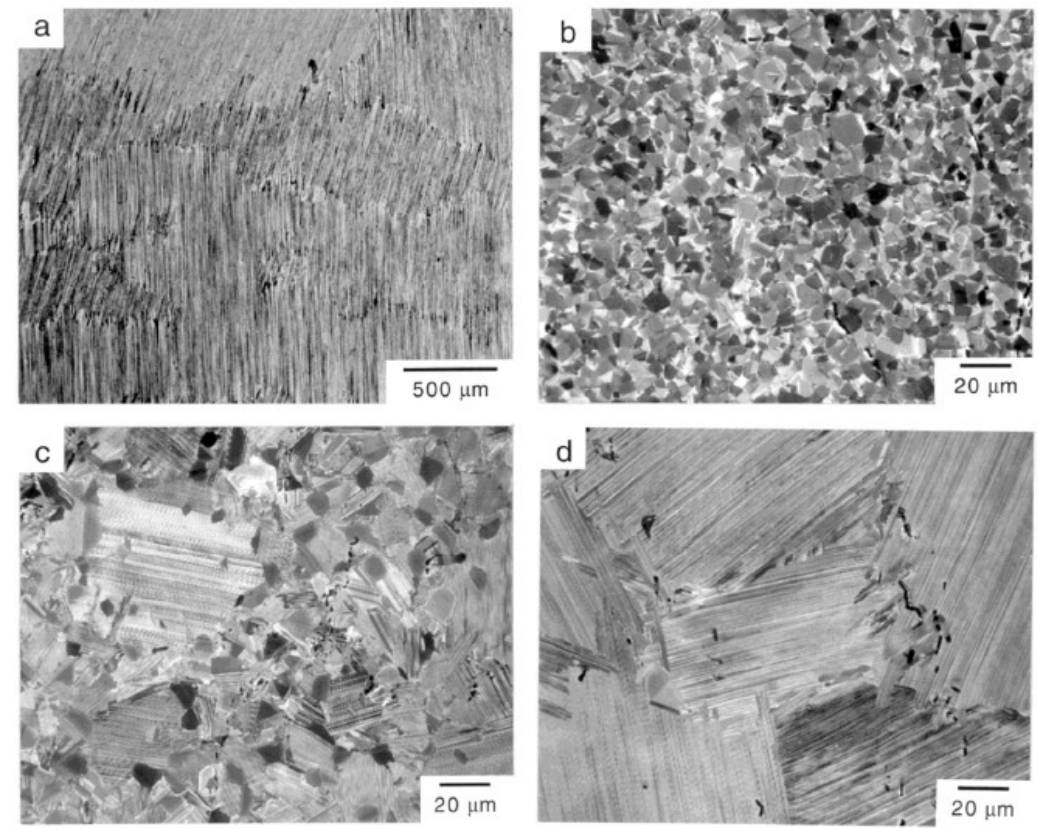

Fonte: SILVA ${ }^{[41]}$

\subsection{Resistência a oxidação}

A resistência à oxidação de ligas à base de alumineto de titânio (TiAl) é um dos aspectos fundamentais para aplicações estruturais que envolvem altas temperaturas. Porém, a baixa resistência à oxidação apresentada por estas ligas quando submetidas a temperaturas superiores a $800{ }^{\circ} \mathrm{C}$ limita a sua utilização ${ }^{[16,19]}$.

O teor de alumínio nas ligas TiAl exerce uma influência significativa na propriedade de resistência à oxidação visto que o aumento da atividade deste elemento na composição bem como sua taxa de difusão resulta na formação de um sistema compacto e 
protetor na superfície do material: a alumina $\left(\mathrm{Al}_{2} \mathrm{O}_{3}\right)$. No entanto, o aumento da sua concentração influencia negativamente na ductilidade destas ligas por meio da formação de $\mathrm{TiAl}_{3}[7,16,44]$.

A propriedade de resistência à oxidação de ligas TiAl é aprimorada mediante a formação de uma camada pura de $\mathrm{Al}_{2} \mathrm{O}_{3}$ em sua superfície, resultante do aumento da atividade de alumínio e da taxa de difusão, camada esta que têm inicialmente um comportamento passivo e, em seguida, cresce muito mais lentamente do que aquelas feitas de óxidos de titânio ${ }^{[16,18]}$. Entretanto, uma vez que submetidas à oxidação ao ar estas ligas tendem a apresentar uma mistura de $\mathrm{Al}_{2} \mathrm{O}_{3}$ e $\mathrm{TiO}_{2}$, e não uma única camada protetora de $\mathrm{Al}_{2} \mathrm{O}_{3}{ }^{[16,34]}$.

Diversos métodos diferentes têm sido utilizados no intuito de melhorar a resistência à oxidação de TiAl, como tratamentos superficiais e principalmente, adição de elementos ternários ou quaternários ${ }^{[1,8,21,34]}$. De fato, melhorias nesta propriedade foram conseguidas através da modificação das composições das ligas, particularmente pela adição de $\mathrm{Mo}, \mathrm{W}$ e $\mathrm{Nb}^{[16]}$.

O mecanismo de crescimento da camada de óxido formado nas ligas intermetálicas em alta temperatura é geralmente controlado pela taxa de difusão de oxigênio e dos elementos adicionados à liga. No caso das ligas TiAl é determinado pela difusão interna do oxigênio e a difusão externa do alumínio ${ }^{[7]}$. O Nb é capaz de impedir a difusão destes dois elementos e o Mo tem a capacidade de aumentar o teor de alumina na parte externa da camada de óxido. Estes dois elementos causam um efeito de dopagem, aumentando a atividade e difusividade do alumínio, ou seja, reduzindo a concentração de vácuos de oxigênio na rede atômica, responsáveis pela difusão de oxigênio que favorece o crescimento de $\mathrm{TiO}_{2}{ }^{[7,16,21]}$.

PILONE e FELLI ${ }^{[21]}$ estudaram o comportamento da resistência a oxidação das ligas Ti-48Al-2Cr-1,5Nb-0,04B, Ti-48Al-2Cr-3Nb-0,04B, Ti-48Al-2Cr-6Nb-0,04B, produzidas por fundição a indução sob uma atmosfera de ar e homogeinizadas a $1100{ }^{\circ} \mathrm{C}$, pelo método termogravimétrico sob temperatura de 900 e $1000{ }^{\circ} \mathrm{C}$. Os resultados evidenciaram que conforme o aumento da porcentagem de $\mathrm{Nb}$ nas ligas o ganho de massa diminuiu e a aderência ao substrato aumentou, com uma consequente melhora da resistência à oxidação. Além disso, ressaltam que concentrações de $\mathrm{Nb}$ superiores a 1,5(\% at) são suficientes para resultar na deteção deste elemento na camada de óxido e reduzir a quantidade de $\mathrm{TiO}_{2}$ na camada de óxido. Isto significa que mesmo em concentrações 
relativamente baixas, o $\mathrm{Nb}$ é capaz de reduzir a taxa de difusão de oxigênio, suprimindo o crescimento do rutilo e favorecendo a formação de alumina.

$\mathrm{O}$ efeito de outros elementos como o $\mathrm{Cr}$ parece depender de vários fatores: teor na liga, composição geral da liga e condições adotadas para o teste de oxidação; visto que, em ligas ternárias, o $\mathrm{Cr}$ tem um efeito prejudicial se o seu conteúdo for inferior a $4 \%$, entretanto, exibe um efeito benéfico quando o seu conteúdo aumenta a teores superiores a $8 \%{ }^{[7]}$. No que diz respeito aos outros elementos de liga, seu mecanismo de ação e seu efeito sinérgico ainda não são completamente compreendidos ${ }^{[18]}$.

OSTROVSKAYA et $a l^{[7]}$ estudou o comportamento da resistência à oxidação ao ar das ligas Ti-48Al-2Cr-2Nb, Ti-48Al-2Nb-0,7Cr-0,3Si, Ti-43,5Al-4Nb-1Mo e Ti$47 \mathrm{Al}-2 \mathrm{Cr}-8 \mathrm{Nb}$ produzidas por derretimento por feixe de elétrons e submetidas ao mesmo tratamento térmico. Foi realizado um ensaio termogravimétrico com duração de $10 \mathrm{~h}$ e uma faixa temperatura de 800 a $1000{ }^{\circ} \mathrm{C}$. Os resultados mostram que as ligas com maior teor de $\mathrm{Nb}$ e Mo apresentaram melhor comportamento de resistência à oxidação do que Ti-48Al$2 \mathrm{Cr}-2 \mathrm{Nb}$ e Ti-48Al-2Nb-0,7Cr-0,3Si. Além disso, a baixa concentração de $\mathrm{Cr}$ nas ligas $48 \mathrm{Al}-2 \mathrm{Cr}-2 \mathrm{Nb}$ e $\mathrm{Ti}-48 \mathrm{Al}-2 \mathrm{Nb}-0,7 \mathrm{Cr}-0,3 \mathrm{Si}$ parece ter exibido um efeito prejudicial na oxidação. 


\section{MATERIAIS E MÉTODOS}

O desenvolvimento deste projeto compreendeu diversas etapas, as quais variaram desde a definição da composição da liga até a aplicação de diferentes técnicas de caracterização microestrutural - antes e após a realização do ensaio de resistência a oxidação -, técnicas estas, empregadas com o intuito de se obter um estudo mais completo.

\subsection{Composições abordadas}

De acordo com a literatura, elementos como o nióbio, molibdênio, e cromo, quando adicionados às ligas baseadas na fase $\gamma$-TiAl resultam numa efetiva melhora da ductilidade à temperatura ambiente e deformação a quente das ligas.

O nióbio têm um efeito significativo na melhoria da propriedade de resistência a oxidação permitindo a aplicação das ligas $\gamma$-TiAl sob temperaturas de aproximadamente $800{ }^{\circ} \mathrm{C}$. O molibdênio, por sua vez, é responsável por estabilizar a microestrutura e melhorar a resistência a oxidação das ligas TiAl. O cromo também é capaz de melhorar a propriedade de tração tanto em temperatura ambiente quanto em temperaturas elevadas, entretanto, pode influenciar de modo positivo ou negativo na propriedade de resistência a oxidação dependendo da sua concentração.

Considerando o efeito destes elementos e visando uma aplicação em componentes submetidos a temperaturas elevadas, foram propostas para estudo duas composições distintas de ligas TiAl baseadas nas ligas comerciais Ti-48Al-2Cr-2Nb (\% at.) (4822) e Ti-43,5Al-4Nb-1Mo-0,1B (\% at.), as quais estão sendo apresentadas na Tabela 1.

Tabela 1: Composição química das ligas abordadas

\begin{tabular}{|c|c|c|c|c|c|c|c|c|c|c|c|}
\hline $\begin{array}{c}\mathbf{T i} \\
\text { (\% at.) }\end{array}$ & $\begin{array}{c}\mathbf{T i} \\
(\% w t .)\end{array}$ & $\begin{array}{c}\text { Al } \\
\text { (\% at.) }\end{array}$ & $\underset{(\% w t .)}{A l}$ & $\begin{array}{c}\mathrm{Nb} \\
\text { (\% at.) }\end{array}$ & $\begin{array}{c}\mathrm{Nb} \\
(\% \mathrm{wt.})\end{array}$ & $\begin{array}{c}\mathbf{C r} \\
\text { (\% at.) }\end{array}$ & $\begin{array}{c}\mathrm{Cr} \\
(\% \mathrm{wt} .)\end{array}$ & $\begin{array}{c}\text { Mo } \\
\text { (\% at.) }\end{array}$ & $\begin{array}{c}\text { Mo } \\
\text { (\%wt.) }\end{array}$ & $\begin{array}{c}\text { B } \\
(\% \text { at. })\end{array}$ & $\begin{array}{c}\text { B } \\
(\% w t .)\end{array}$ \\
\hline 47,7 & 59,0 & 47,8 & 33,3 & 2,0 & 4,8 & 2,0 & 2,7 & - & - & 0,5 & 0,14 \\
\hline 50,7 & 59,5 & 43,8 & 29,0 & 4,0 & 9,1 & - & - & 1,0 & 2,4 & 0,5 & 0,13 \\
\hline
\end{tabular}


A figura 7 mostra a localização aproximada destas composições no diagrama de fases Ti-Al. Contudo, vale ressaltar que a adição de elementos de liga pode influenciar significativamente no domínio das fases, visto que este é o diagrama da composição estequiométrica de TiAl.

Figura 7: Localização aproximada das composições estudadas no diagrama de fases de um sistema Ti-Al.

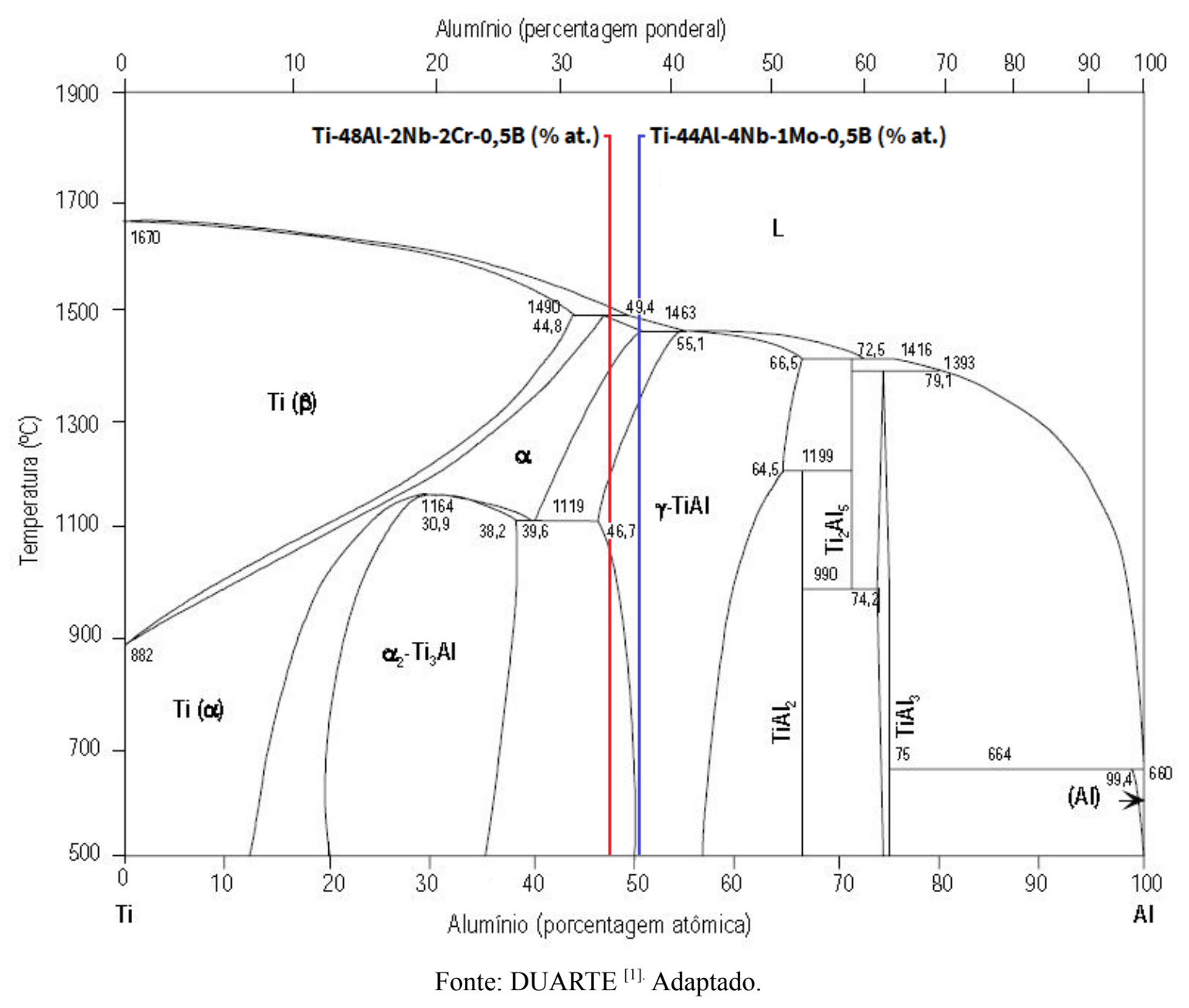

\subsection{Materiais}

A partir da composição química foram realizadas as conversões e cálculos necessários para determinação da representação de cada um dos elementos em peso, para então, ser adquirida a matéria-prima.

Nesta etapa do projeto, a empresa metalúrgica Açotécnica, atuou como parceira, responsabilizando-se pelo fornecimento dos elementos necessários, bem como, disposição de espaço físico e equipamentos como cortadora e balança digital com precisão de quatro casas, para corte e pesagem dos materiais. Na figura 8 é possível visualizar o 
material fornecido: ligas de $\mathrm{Ti}, \mathrm{Al}$, Mo e Cr comercialmente puras, e ainda, compostos de Al- $6,22 \% \mathrm{~B}$ e $\mathrm{Nb}-20 \% \mathrm{Al}$.

Figura 8: Matéria-prima utilizada para fabricação das ligas de Ti, Al, Mo e Cr comercialmente puras, e compostos de $\mathrm{Al}-6,22 \% \mathrm{~B}$ e $\mathrm{Nb}-20 \% \mathrm{Al}$.

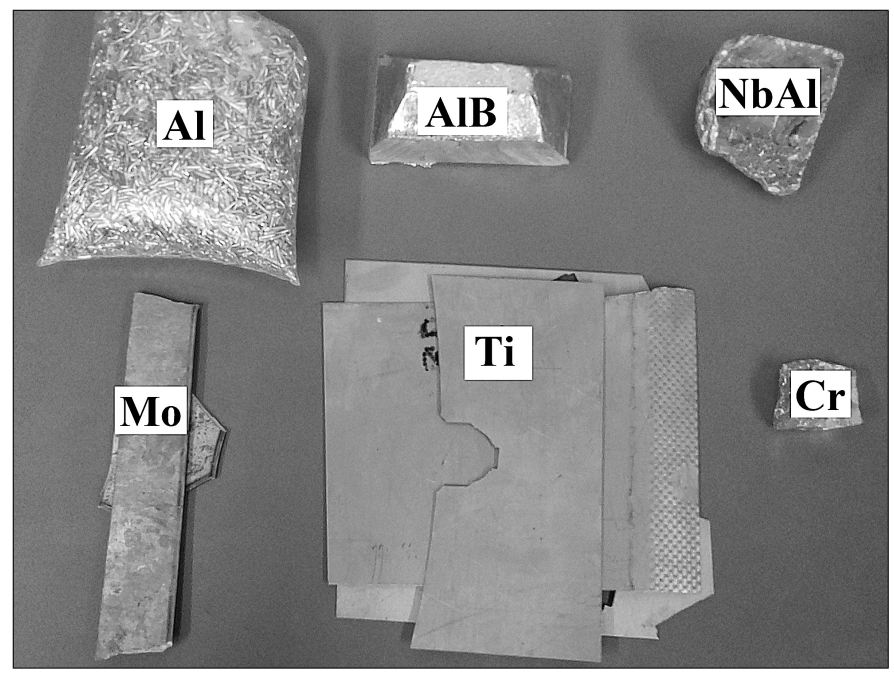

Fonte: Autor

Considerando que elementos como titânio e molibdênio apresentam um comportamento reativo e elevados pontos de fusão se faz necessário o uso de um forno a arco elétrico. Neste equipamento, o compartimento refratário para vazamento das ligas fundidas é constituído por um cadinho de cobre refrigerado a água. Este cadinho impede a contaminação do material e facilita a fundição que ocorre a partir da produção de calor gerado por uma corrente elétrica que circula entre dois eletrodos em uma atmosfera inerte.

O equipamento utilizado para este trabalho encontra-se disponível na Universidade de São Paulo (USP) câmpus Lorena, opera sob atmosfera de argônio e permite a fundição de lingotes com dimensões de $20 \mathrm{~mm}$ (largura) x $72 \mathrm{~mm}$ (comprimento) x $18 \mathrm{~mm}$ (profundidade), como mostrado na figura 9.

Figura 9: Lingote da liga Ti-48Al-2Nb-2Cr-0,5B (\% at.)

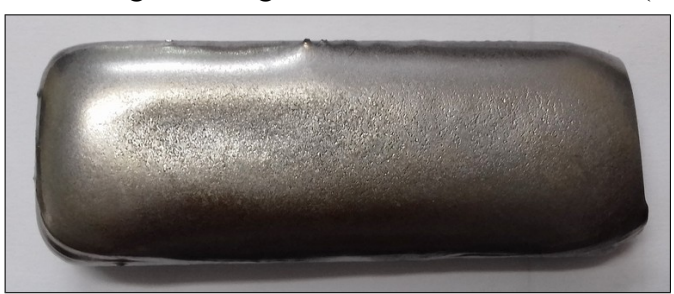

Fonte: Autor 
Após a fundição o lingote da liga Ti-48Al-2Nb-2Cr-0,5B (\% at.) apresentou uma massa de 106,85 g e o da liga Ti-44Al-4Nb-1Mo-0,5B (\% at.), 115,97 g. A partir deste material foi realizada a caracterização microestrutural por meio da utilização de técnicas de difração de raios $\mathrm{X}$, microscopia óptica $(\mathrm{MO})$ e microscopia eletrônica de varredura (MEV) como descritos a seguir.

\subsection{Caracterização microestrutural (antes do ensaio de oxidação)}

\subsubsection{Técnica de difração de raios $\mathrm{X}$}

Neste projeto a utilização desta técnica surge da necessidade de se identificar as fases presentes na liga. A análise por difratometria de raios $\mathrm{X}$ foi realizada no Laboratório de Raios X do IPEN em um equipamento Rigaku modelo Dmax, sob radiação $\mathrm{CuK}_{\alpha}$ com filtro de $\mathrm{Ni}$; e adotadas as seguintes condições: temperatura ambiente, tensão de $40 \mathrm{kV}$, corrente de $20 \mathrm{~mA}$, ângulo variando de 10 a $80^{\circ}$, passo angular de $0,02^{\circ}$ e tempo de contagem por passo de 1s. Inicialmente, as amostras seriam submetidas ao mesmo processo de preparação adotado para análise via microscopia, entretanto, visto a possibilidade de que o baquelite interferisse na leitura das fases presentes, optou-se pela utilização de uma parte do material que não havia sido embutida.

Os dados obtidos foram comparados com os registros provenientes do banco de dados do Joint Committee on Powder Diffraction Standard - JCPDS, por meio do software Crystallographica Search-Mach bem como, com difratogramas apresentados na literatura.

A fase $\gamma$-TiAl possui uma estrutura cristalina tetragonal ordenada $\left(\mathrm{L} 1_{0}\right)$, sendo a sequência de empilhamento na direção [001] constituída por planos alternados de átomos de titânio e de alumínio ${ }^{[1,45]}$, como mostrado na figura 10.

O grau de tetragonalidade corresponde à relação entre $c$ e $a$ desta célula unitária, sendo que para esta fase, o valor do parâmetro de rede $a$ está compreendido entre 0,397 e 0,401 nm; o parâmetro $c$ entre 0,406 e 0,410 nm; e o grau de tetragonalidade encontra-se entre 1,01 e 1,02 para a composição estequiométrica exata de TiAl, fase $\gamma$-TiAl $[1,45]$. 
Figura 10: Estrutura cristalina tetragonal ordenada $\left(\mathrm{L} 1_{0}\right)$ da fase $\gamma$-TiAl.

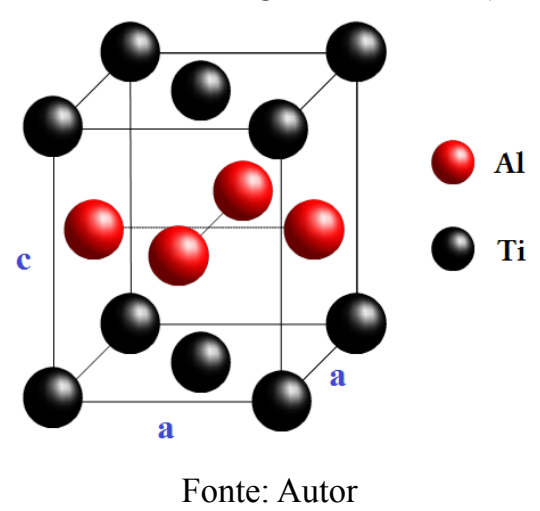

Com base nesta informação, inicialmente foi obtido por meio do software Crystallographica Search-Match a ficha de número 65-5414, que contém o difratograma referente à particular composição mencionada (irradiada por $\mathrm{CuK} \alpha_{1}$ ), figura 11; nela é possível verificar uma proximidade entre dois picos em torno de $2 \theta=45^{\circ}$.

Figura 11: Difratograma da composição estequiométrica de TiAl (ficha de número 65-5414).

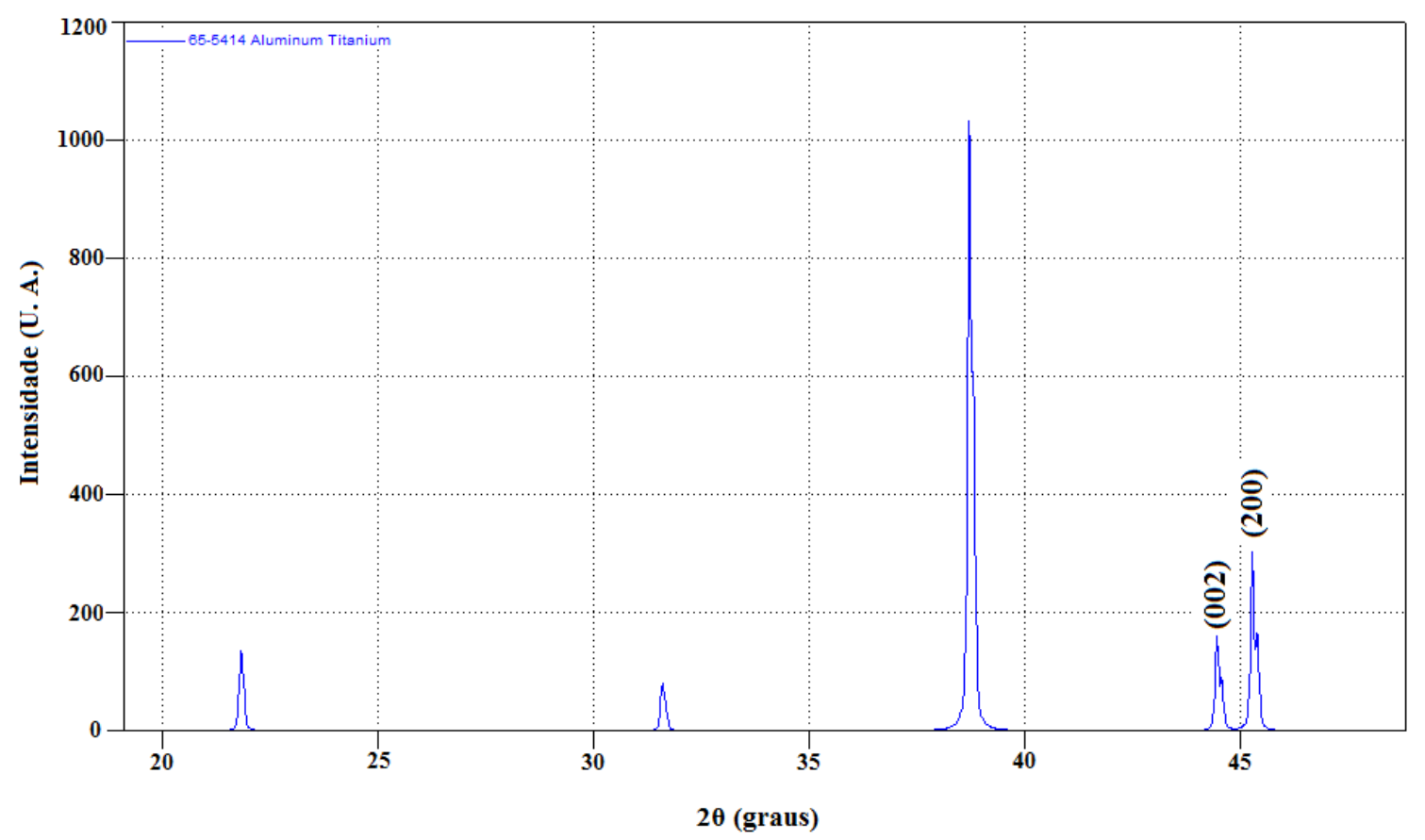

Fonte: Software Crystallographica Search-Match.

TANDA et $a l^{[46]}$ apresentou em seu estudo os difratogramas referentes a cinco ligas contendo $\mathrm{Al}$, Ti e $\mathrm{Zr}$ em composições diferentes, conforme ilustra a figura 12. Segundo o autor, a divergência observada na separação dos picos (002) e (200) indica uma mudança sistemática da tetragonalidade da fase. 
Figura 12: Espectro de difração referente a cinco ligas contendo Al, Ti e Zr em composições diferentes.

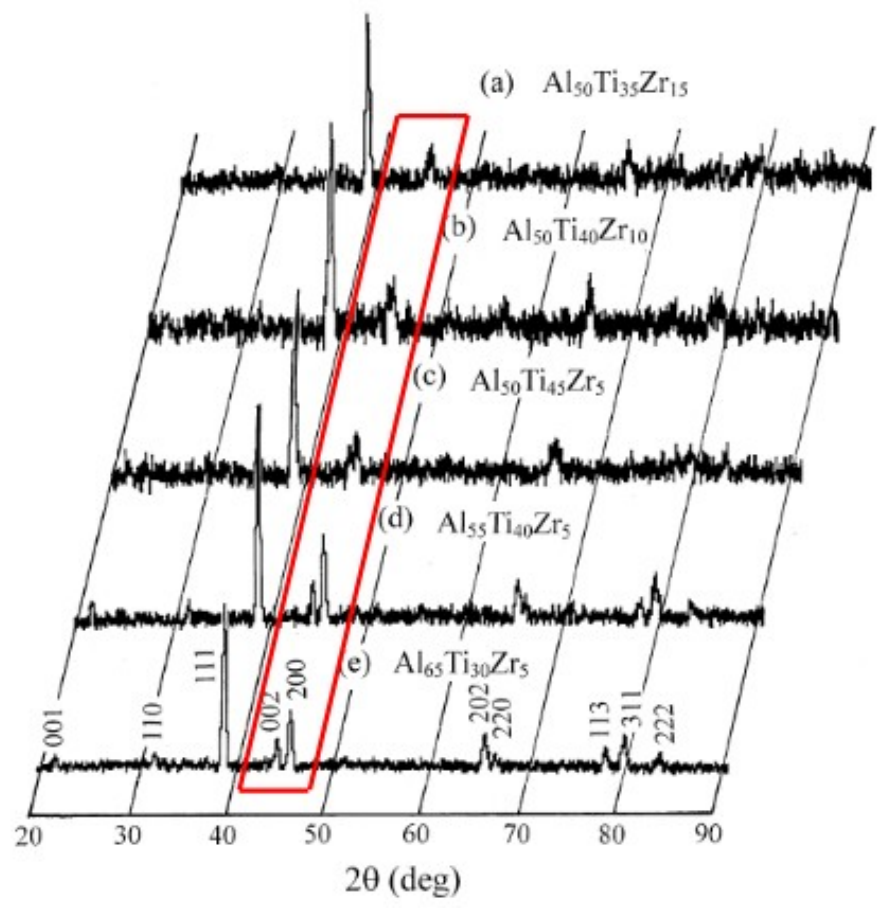

Fonte: Tanda et al ${ }^{[46]}$.

O surgimento de dois picos próximos é justificado pelo fato de que, quando desordenado, o $\gamma$-TiAl apresenta estrutura cristalina CFC que faz com que haja um único pico numa determinada região (representando um parâmetro $a$ ); entretanto, ao se tornar ordenada, sua estrutura torna-se tetragonal, o que faz com que o pico se divida em dois (ou seja, indicando dois parâmetros diferentes, $a$ e $c$ ).

Os picos (002) e (200) não foram identificados ao acaso. Quando se observa uma estrutura cristalina é possível a visualização de planos, os quais podem estar relacionados com as dimensões da célula. Aplicando este princípio na estrutura do $\gamma$-TiAl, obteve-se o que está sendo apresentado na figura 13.

Figura 13: Representação dos planos adotados para análise da estrutura cristalina do $\gamma$-TiAl. (a) Planos no eixo $\mathrm{z}$ da célula unitária e (b) planos no eixo $\mathrm{x}$.

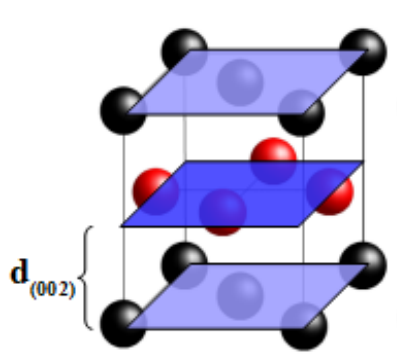

(A)

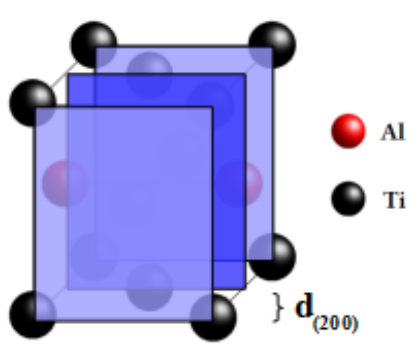

(B)

Fonte: Autor 
Analisando a figura 13(A), têm-se que a distância (d) entre os planos (002) está relacionada com o parâmetro de rede $c$, de modo que: $c=\mathbf{2} * \mathbf{d}_{\mathbf{( 0 2 2 )}}$. A mesma verificação pode ser feita para a figura 13(B), ou seja, $\boldsymbol{a}=\mathbf{2} * \mathbf{d}_{(\mathbf{2 0 0 )}}$.

Uma vez compreendida esta correlação, visando verificar se a relação $c / a$ obtida a partir dos dados da ficha encontrava-se dentro dos limites dispostos na literatura, empregou-se as seguintes:

- Equações:

$$
\begin{aligned}
& \mathrm{n} \lambda=2 \mathrm{~d} \operatorname{sen} \theta \quad \text { Equação I } \\
& \mathrm{d}_{\mathrm{hkl}}=\mathrm{a} / \sqrt{ }\left(\mathrm{h}^{2}+\mathrm{k}^{2}+\mathrm{l}^{2}\right) \quad \text { Equação II }
\end{aligned}
$$

- E métodos:

A: os valores das distâncias interplanares foram obtidos na ficha; e

B: o difratograma gerado foi analisado e da ficha foi extraído apenas o valor do comprimento de onda $\left(1,54060 * 10^{-8} \mathrm{~m}\right)$.

Com base nos resultados, foi montada a tabela a seguir, a qual mostra que os dados calculados estão em conformidade com os padrões teóricos. Além disso, comprova que a sequência utilizada para a determinação do grau de tetragonalidade é satisfatória, o que fará com que seja empregada novamente quando se dispor dos padrões de difração de raios $\mathrm{X}$ provenientes das ligas Ti-48Al-2Nb-2Cr-0,5B (\% at.) e Ti-44Al-4Nb-1Mo-0,5B (\% at.).

Tabela 2: Cálculo do grau de tetragonalidade

\begin{tabular}{c|c|c|c|c|c|c}
\hline \multirow{2}{*}{ Método } & Plano & $\boldsymbol{\theta}^{\mathbf{o}}$ & $\begin{array}{c}\mathbf{d} \\
\left(\mathbf{1 0}^{-8} \mathbf{)}\right.\end{array}$ & $\begin{array}{c}\boldsymbol{c} \\
\left(\mathbf{( 1 0}^{-8} \mathbf{)}\right.\end{array}$ & $\begin{array}{c}\boldsymbol{a} \\
\left(\mathbf{1 0}^{-8} \mathbf{)}\right.\end{array}$ & $\boldsymbol{c} / \boldsymbol{a}$ \\
\hline \multirow{2}{*}{$\mathrm{A}$} & $(002)$ & $*$ & 2,0355 & 4,071 & - & \multirow{2}{*}{1,017} \\
\cline { 2 - 6 } & $(200)$ & $*$ & 2,0005 & - & 4,001 & \\
\hline \multirow{2}{*}{$\mathrm{B}$} & $(002)$ & 22,26 & 2,0334 & 4,0668 & - & \multirow{2}{*}{1,016} \\
\cline { 2 - 6 } & $(200)$ & 22,65 & 2,0002 & - & 4,0004 & \\
\hline
\end{tabular}

$\left(^{*}\right)$ Valor não foi consultado. (-) Não se aplica. 
3.3.2 Análise via microscopias ópticas e eletrônica de varredura

Com relação à microscopia óptica foi utilizado o microscópio óptico Olympus disponível no Laboratório de Metalografia do IPEN, sendo as imagens obtidas em campos claro e escuro. A análise por microscopia eletrônica de varredura foi feita num microscópio Jeol pertencente à Universidade Presbiteriana Mackenzie. As imagens por microscopia eletrônica de varredura seriam formadas por elétrons retroespalhados para a observação de contraste entre diferentes números atômicos respectivos às fases presentes, entretanto, devido à indisponibilidade temporária do recurso no equipamento, foram utilizados os elétrons secundários, permitindo assim, a visualização de um contraste topográfico.

A preparação de amostras para a análise via microscopia seguiu os padrões usuais de metalografia, ou seja, corte transversal com o auxílio de um disco de diamante disposto em uma cortadora de precisão; seguida pelo embutimento a quente $\left(150{ }^{\circ} \mathrm{C}\right)$ sob pressão de $20 \mathrm{MPa}$; lixamento manual com lixas à base de $\mathrm{SiC}$ na sequência granulométrica de 280, 400, 600 e 1200\#; e polimento feito com uma solução de sílica coloidal (OP-S).

Posteriormente a estas etapas foram testadas nas amostras três soluções químicas responsáveis por revelar detalhes da microestrutura. A primeira delas foi a solução de $\mathrm{H}_{2} \mathrm{O}(25 \mathrm{ml})+\mathrm{HNO}_{3}(25 \mathrm{ml})+\mathrm{HF}(2 \mathrm{ml})+$ glicerina $(50 \mathrm{ml}){ }^{[15]}$, a qual se mostrou fraca para estas ligas. Já a segunda: $\mathrm{H}_{2} \mathrm{O}(150 \mathrm{ml})+\mathrm{HNO}_{3}(25 \mathrm{ml})+\mathrm{HF}(10 \mathrm{ml})$ ${ }^{[47]}$ resultou em um ataque pouco melhor que a primeira, o que levou à preparação de um ataque mais concentrado tendo como base a última solução testada. Assim surgiu a composição $\mathrm{HNO}_{3}(20 \mathrm{ml})+\mathrm{HF}(5 \mathrm{ml})$ que proporcionou imagens da microestrutura com detalhes mais intensos, ainda que aplicada por poucos segundos. É valido ressaltar que a eficácia das soluções de ataque são diretamente influenciadas por diversos fatores, tais como, a concentração dos ácidos utilizados e a temperatura ambiente de realização do preparo.

Após a análise via microscopia óptica, as amostras foram limpas com álcool isopropílico e observadas no microscópio eletrônico de varredura, sendo que não houve a necessidade de recobrimento da superfície.

No intuito de facilitar a associação entre as micrografias obtidas e a sua respectiva localização na amostra, elas foram cortadas como indica a figura 14 e posteriormente, mapeadas em regiões, como ilustra a figura 15. 
Figura 14: Área do lingote selecionada para o corte.

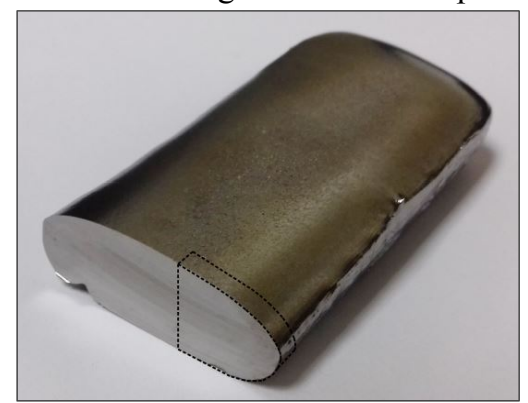

Fonte: Autor

Figura 15: Mapeamento das amostras em regiões. (a) Ti-48Al-2Nb-2Cr-0,5B (\% at.) e (b) liga Ti-44Al-4Nb-1Mo-0,5B (\% at.)

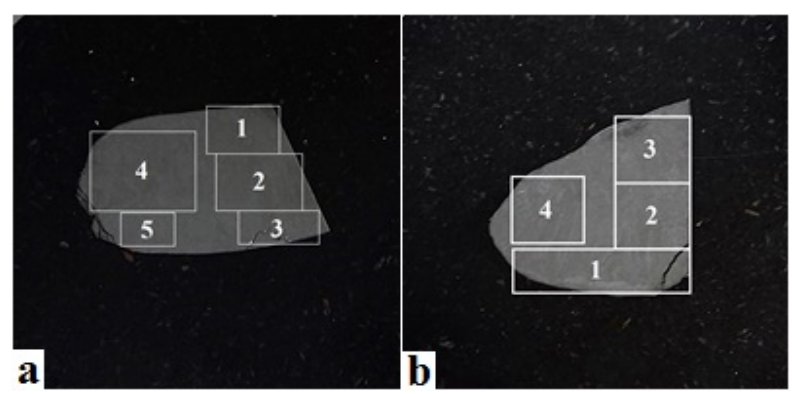

Fonte: Autor

\subsection{Ensaios de resistência a oxidação}

Este tipo de ensaio é importante para que o comportamento do material sob condições que favorecem a oxidação, como temperaturas elevadas por exemplo, seja conhecido. Visto isso, neste trabalho esta propriedade foi analisada por meio da realização de dois ensaios de resistência a oxidação em equipamentos disponíveis no Laboratório de Corrosão do IPEN.

A princípio seria realizado apenas um ensaio em forno tipo mufla sob variação de temperatura de 25 a $1000{ }^{\circ} \mathrm{C}$ e duração de 60 horas. Seriam inseridas no forno 9 amostras referentes a cada uma das ligas e retiradas 3 de cada uma delas em intervalos de 20 horas, para assim, calcular a média do ganho em massa e compôr o gráfico ganho em massa versus tempo.

Para isso, foram cortadas amostras da liga Ti-48Al-2Nb-2Cr-0,5B (\% at.) em dimensões aproximadas de 6x6x5 mm e da liga Ti-44Al-4Nb-1Mo-0,5B (\% at.), em dimensões de $6 \times 6 \times 2 \mathrm{~mm}$. Os cortes foram realizados com o auxílio de uma cortadora de precisão na sequência 1-2-3-4 a partir dos lingotes, como ilustra a figura 16. 
Figura 16: Sequência de cortes realizados a partir do lingote para a obtenção das amostras para o ensaio de resistência a oxidação (Sequência 1-2-3-4).

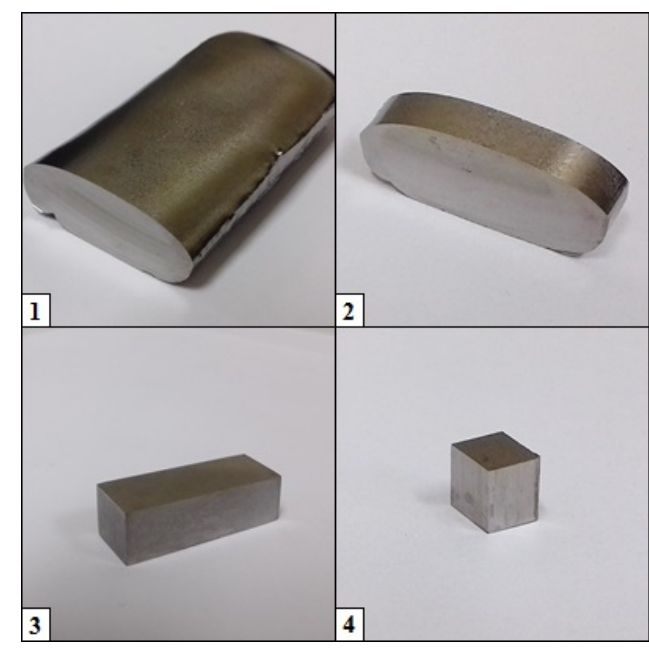

Fonte: Autor

Após esta etapa, as amostras foram lixadas manualmente com uma lixa a base de SiC com 1200\# de espessura granulométrica, pesadas em uma balança analítica com seis casas de precisão, medidas com o auxílio de um micrômetro, limpas com acetona por processo de ultrassom, lavadas com água deionizada e secas com um jato de nitrogênio.

Foi nesta fase que, mediante uma conversa com a professora Marina acerca de novos artigos publicados foi decidido realizar um ensaio termogravimétrico com 7 horas de duração no intuito de conhecer e comparar o comportamento inicial das curvas de ganho de massa destas ligas. Para isso, foi utilizada uma DTG com fluxo de ar de $100 \mathrm{~mL} / \mathrm{min}$, sob variação de temperatura de 25 a $1000{ }^{\circ} \mathrm{C}$. Por meio do software acoplado a este equipamento obtêm-se as curvas de ganho de massa versus tempo de modo mais preciso do que no ensaio isotérmico na mufla.

As amostras, uma de cada liga, foram cortadas em dimensões aproximadas de $3 \times 2 \times 2 \mathrm{~mm}$ utilizando uma cortadora de precisão. Posteriormente, foram lixadas de forma manual com lixas à base de $\mathrm{SiC}$ (600 e 1200\#), limpas com água deionizada e secas com jato de nitrogênio.

Após o término do ensaio, estas mesmas amostras seriam caracterizadas via difração de raios X e microscopia eletrônica de varredura, entretanto, devido a uma significativa escamação da camada de óxido formada não foi possível a sua utilização.

Assim, no intuito de complementar as informações obtidas no ensaio termogravimétrico e aproveitar as amostras já preparadas para o ensaio isotérmico na mufla, foram selecionadas 4 delas (duas de cada liga), as quais passaram novamente pelo 
processo de limpeza e secagem, foram inseridas individualmente em tubos de quartzo com as extremidades protegidas por lã de vidro (figura 17) e então, colocadas dentro do forno com operação ao ar e sob variação de temperatura de 25 a $1000{ }^{\circ} \mathrm{C}$ durante 7 horas.

Figura 17: Amostras das ligas Ti-48Al-2Nb-2Cr-0,5B (\% at.) e Ti-44Al-4Nb-1Mo-0,5B (\% at.) dentro de tubos de quartzo com as extremidades protegidas por lã de vidro antes de serem oxidadas em forno tipo mufla por $7 \mathrm{~h}$ sob variação de temperatura de 25 a $1000{ }^{\circ} \mathrm{C}$ e resfriadas lentamente.
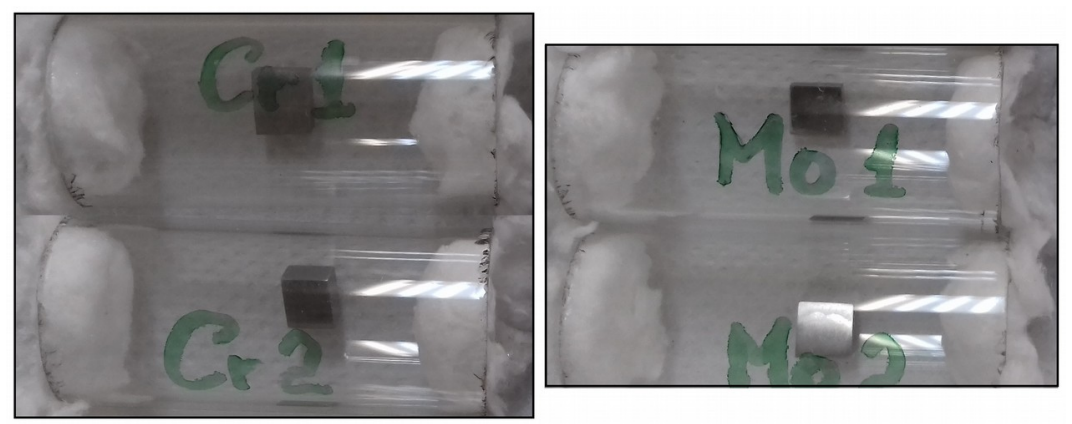

Fonte: Autor

Uma vez finalizados os ensaios, duas amostras oxidadas foram analisadas via difração de raios $\mathrm{X}$, enquanto que as outras foram embutidas em resina EPOFIX em processo a frio, lixadas com lixa a base de $\operatorname{SiC}(600$ e $1200 \#)$, polidas com pasta de diamante e recobertas com ouro. A análise via microscopia eletrônica de varredura foi feita em um equipamento disponível no Laboratório de Microscopia e Microanálise do Centro de Ciência e Tecnologia de Materiais do IPEN/CNEN, com imagens formadas por elétrons secundários. 


\section{RESULTADOS E DISCUSSÃO}

\subsection{Identificação das fases}

$\mathrm{Na}$ figura 18 encontram-se os difratogramas referentes às ligas Ti-48Al-2Nb$2 \mathrm{Cr}-0,5 \mathrm{~B}$ (\% at.) e Ti-44Al-4Nb-1Mo-0,5B (\% at.), os quais foram comparados com outros dispostos na literatura ${ }^{[14,37,48-50]}$, bem como, com as fichas 52-859, 65-5414 e 89-4913 por meio do software Crystallographica Search-Match. Com disso foi possível a identificação de três fases $\gamma$-TiAl (estrutura $\mathrm{L}_{0}$ ), $\alpha_{2}$-Tii ${ }_{3} \mathrm{Al}$ (estrutura D0 $0_{19}$ ) e $\beta_{\mathrm{o}}$-Ti (estrutura B2). Estas fases foram também identificadas por ERDELY et al ${ }^{[39]}$ em seu estudo da liga Ti-43,5Al4Nb-1Mo-0,1B (em \% at.) sob condições de temperatura ambiente.

Figura 18: Difratogramas das ligas Ti-48Al-2Nb-2Cr-0,5B (\% at.) e Ti-44Al-4Nb-1Mo-0,5B (\% at.), onde constam as fases $\gamma-\mathrm{TiAl}, \alpha_{2}-\mathrm{Ti}_{3} \mathrm{Al}, \beta(\mathrm{B} 2)$, e seus respectivos planos de difração.

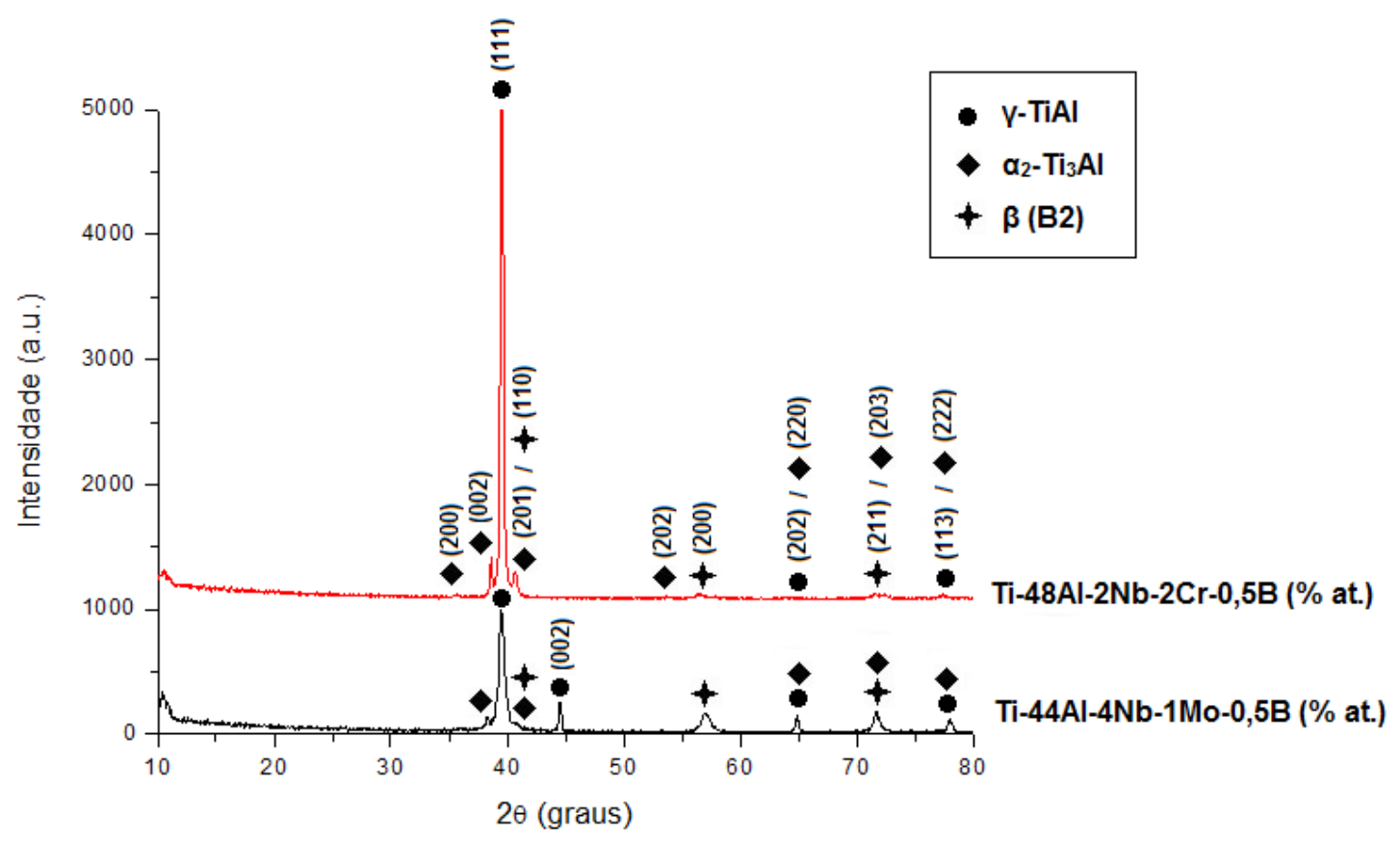

Fonte: Autor 
Ao relacionar os difratogramas referentes às ligas Ti-48Al-2Nb-2Cr-0,5B $(\%$ at.) e Ti-44Al-4Nb-1Mo-0,5B (\% at.), é possível observar que o pico de difração mais intenso refere-se ao da fase $\gamma$-TiAl, indicando ser a base dos intermetálicos. Além deste, existem outros picos de difração pertencentes a outras fases que coincidem em ambas as ligas, como o plano (002) da fase $\alpha_{2}-\mathrm{Ti}_{3} \mathrm{Al}$ e o (200) da fase $\beta(\mathrm{B} 2)$, por exemplo. Existem ainda picos peculiares à apenas uma das composições, como o da fase $\alpha_{2}-\mathrm{Ti}_{3} \mathrm{Al}$ encontrado na liga Ti-48Al-2Nb-2Cr-0,5B (\% at.) e os picos da fase $\gamma$-TiAl, visíveis no difratograma da liga Ti-44Al-4Nb-1Mo-0,5B (\% at.).

\subsection{Grau de tetragonalidade}

Considerando que as ligas Ti-48Al-2Nb-2Cr-0,5B (\% at.) e Ti-44Al-4Nb-1Mo0,5B (\% at.) estudadas neste trabalho são baseadas na fase $\gamma$-TiAl, a princípio acreditava-se que seriam obtidos picos de difração similares aos da composição estequiométrica TiAl, divergindo apenas pela presença de picos adicionais peculiares a cada uma das composições, bem como, pela diferença entre os graus de tetragonalidade já que a relação entre os picos de difração referentes aos planos (200) e (002) da fase $\gamma$-TiAl é afetada pela inserção de aditivos de liga ${ }^{[1,45]}$.

Entretanto, ao analisar os difratogramas referentes às ligas abordadas foi verificada uma situação inesperada e ainda não compreendida. Em ambas as ligas, na região próxima a $2 \theta=45^{\circ}$ não existem os planos de difração (200) e (002) da fase $\gamma$-TiAl dispostos paralelamente, o que impossibilitou o cálculo do grau de tetragonalidade destas composições mediante o método apresentado. Caso isso não tivesse ocorrido, teríamos uma informação muito importante acerca da ductilidade destas ligas, afinal, quanto maior é este parâmetro, maior é a tendência do material a se tornar frágil já que favorece o surgimento de vazios entre as camadas de titânio e alumínio.

\subsection{Análise microestrutural por microscopias óptica e eletrônica de varredura}

De um modo geral, a solidificação de uma liga não ocorre de forma homogênea: ela tem início na superfície que encontra-se em contato com o molde utilizado para a fundição e avança em direção ao centro do lingote. A medida que a espessura solidificada aumenta, o gradiente térmico diminui, resultando numa modificação da microestrutura ao decorrer do material. 
Durante o processo de solidificação é comum que a primeira região a se formar seja a zona coquilhada, que surge na região de interface metal-molde onde a elevada taxa de resfriamento favorece a nucleação de grãos, resultando em uma camada composta por grãos pequenos e heterogêneos com orientação aleatória. A figura 19 mostra este tipo de microestrutura sendo observada na parte superior da amostra referente a liga Ti-48Al-2Nb$2 \mathrm{Cr}-0,5 \mathrm{~B}$ (\% at.).

Figura 19: Zona coquilhada da liga Ti-48Al-2Nb-2Cr-0,5B (\% at.) observada na parte superior da amostra. Micrografia óptica em campo claro. Solução de ataque: $\mathrm{HNO}_{3}(20 \mathrm{ml})+\mathrm{HF}(5 \mathrm{ml})$.

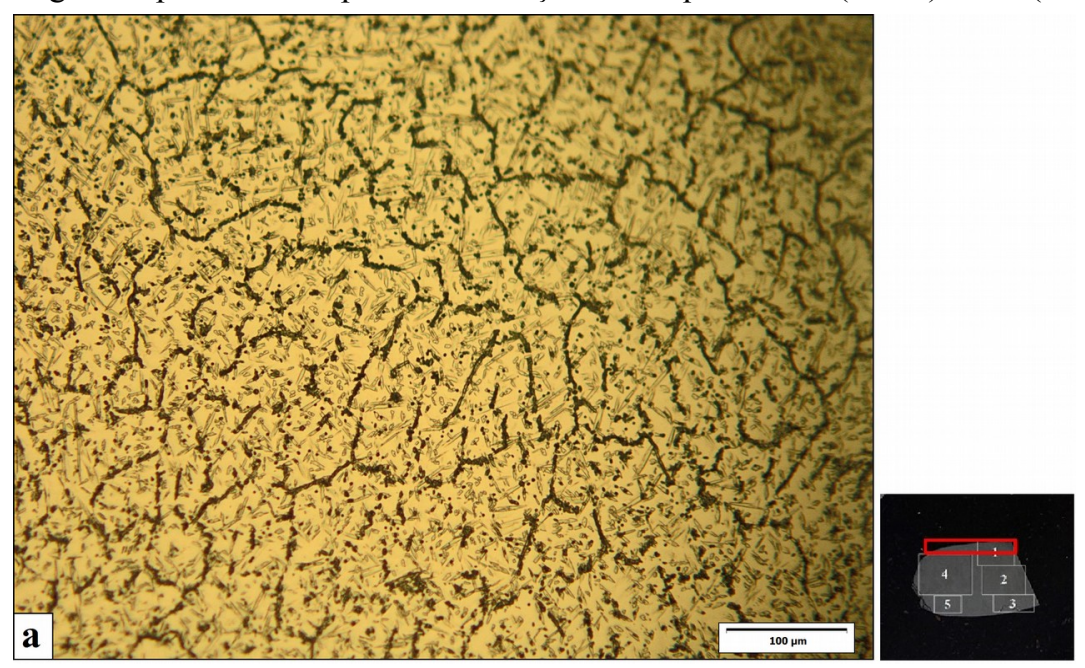

Fonte: Autor

Contudo, em alguns casos pode acontecer de a zona coquilhada ser muito pequena e até mesmo inexistente, uma vez que o seu desenvolvimento varia conforme a oscilação da temperatura durante o processo de resfriamento. Esta situação pôde ser observada na liga Ti-44Al-4Nb-1Mo-0,5B (\%at.), na qual, a espessura da zona coquilhada foi bem menor do que se comparada àquela apresentada pela liga Ti-48Al-2Nb-2Cr-0,5B (\% at.). A figura 20 apresenta uma micrografia representativa da parte inferior da amostra de Ti-44Al-4Nb-1Mo-0,5B (\% at.). 
Figura 20: Área inicial de solidificação da liga Ti-44Al-4Nb-1Mo-0,5B (\% at.). Microestrutura óptica representativa da região 1 . Solução de ataque: $\mathrm{HNO}_{3}(20 \mathrm{ml})+\mathrm{HF}(5 \mathrm{ml})$.

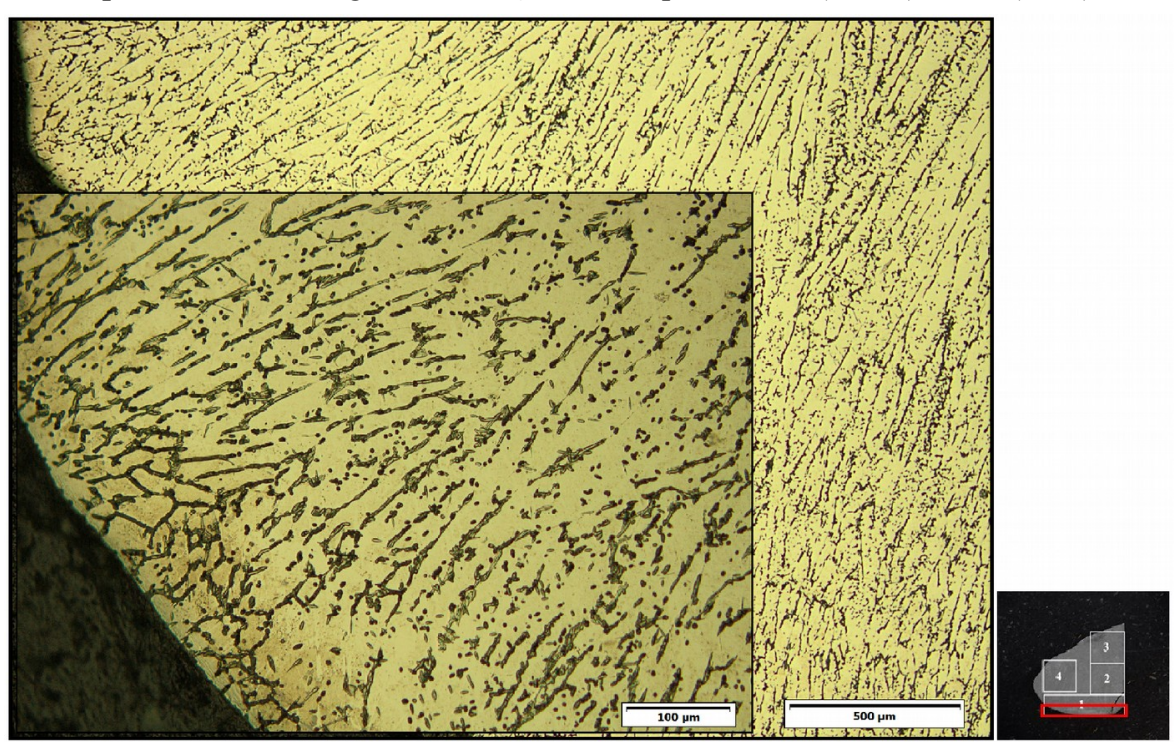

Fonte: Autor

À medida que a solidificação avança em direção ao interior do lingote, a taxa de resfriamento diminui, dificultando assim a nucleação de novos cristais, ou seja, formação da zona coquilhada. Por outro lado, favorece o crescimento daqueles grãos já existentes ${ }^{[24]}$. Mediante o fato de o crescimento lateral ser progressivamente dificultado, os cristais adotam um formato preferencial característico, que leva ao surgimento de uma região denominada zona colunar (ou também conhecida como zona lamelar) na qual podem ser observadas lamelas longas e estreitas, dispostas perpendicularmente à parede do molde que deu início à solidificação ${ }^{[24]}$.

A figura 21 mostra o contraste entre as zonas equiaxial e colunar, destacadas em (a) e (b), respectivamente, identificadas na região 1 da liga Ti-48Al-2Nb-2Cr-0,5B (\% at.). 
Figura 21: Micrografia óptica referente à região da amostra da liga Ti-48Al-2Nb-2Cr-0,5B (\% at.) ressaltada ao lado esquerdo inferior da imagem, onde observa-se em (a) a zona coquilhada e em (b) a zona colunar. Solução de ataque: $\mathrm{HNO}_{3}(20 \mathrm{ml})+\mathrm{HF}(5 \mathrm{ml})$.

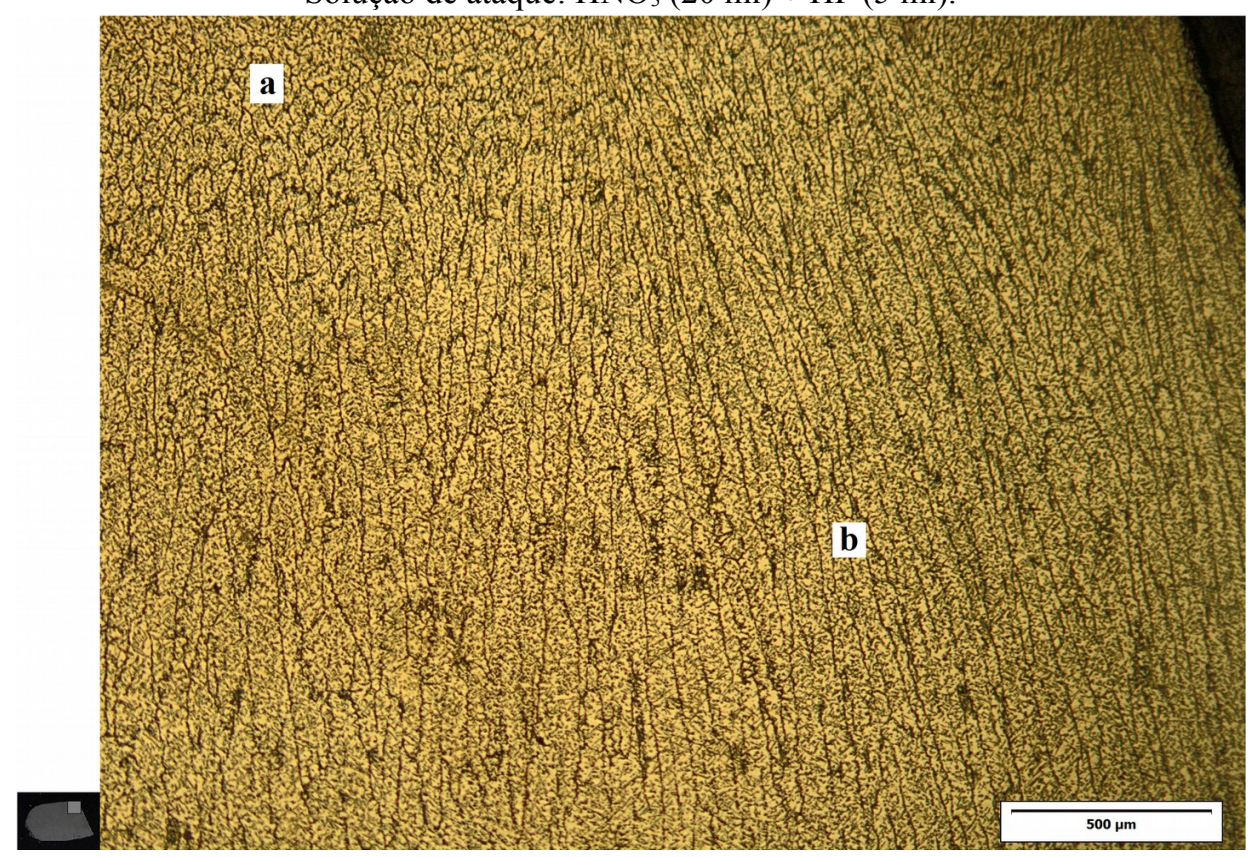

Fonte: Autor

A zona colunar, abrange a região 2 da liga Ti-48Al-2Nb-2Cr-0,5B (\% at.); e também, uma vasta área da região 1 e parte das regiões 2 e 4 da liga Ti-44Al-4Nb-1Mo$0,5 \mathrm{~B}$ (\% at.), como mostram as representações no canto inferior direito das figuras 22 e 23. A primeira corresponde a uma ampliação da zona colunar destacada na figura 21 (b). Já a figura seguinte mostra este mesmo tipo de formação sendo observado da liga Ti-44Al-4Nb$1 \mathrm{Mo}-0,5 \mathrm{~B}$ (\% at.).

Figura 22: Zona colunar da liga Ti-48Al-2Nb-2Cr-0,5B (\% at.). Micrografia óptica em campo claro referente à região (b) ressaltada na figura 21. Solução de ataque: $\mathrm{HNO}_{3}(20 \mathrm{ml})+\mathrm{HF}(5 \mathrm{ml})$.

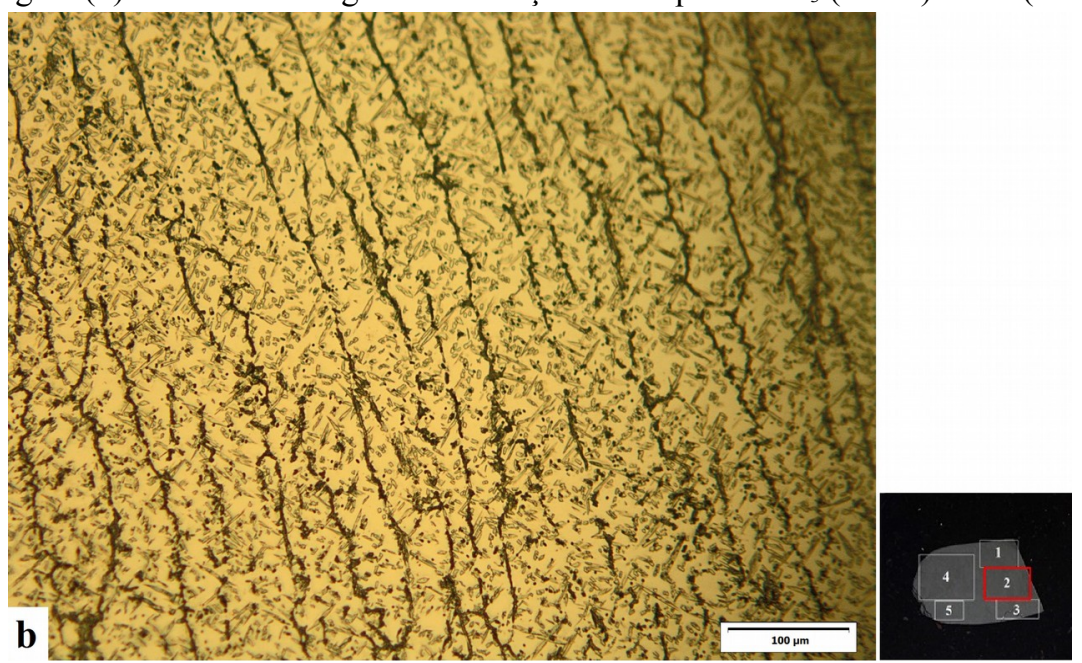

Fonte: Autor 
Figura 23: Zona colunar da liga Ti-44Al-4Nb-1Mo-0,5B (\% at.). Micrografia óptica em campo claro. Solução de ataque: $\mathrm{HNO}_{3}(20 \mathrm{ml})+\mathrm{HF}(5 \mathrm{ml})$.

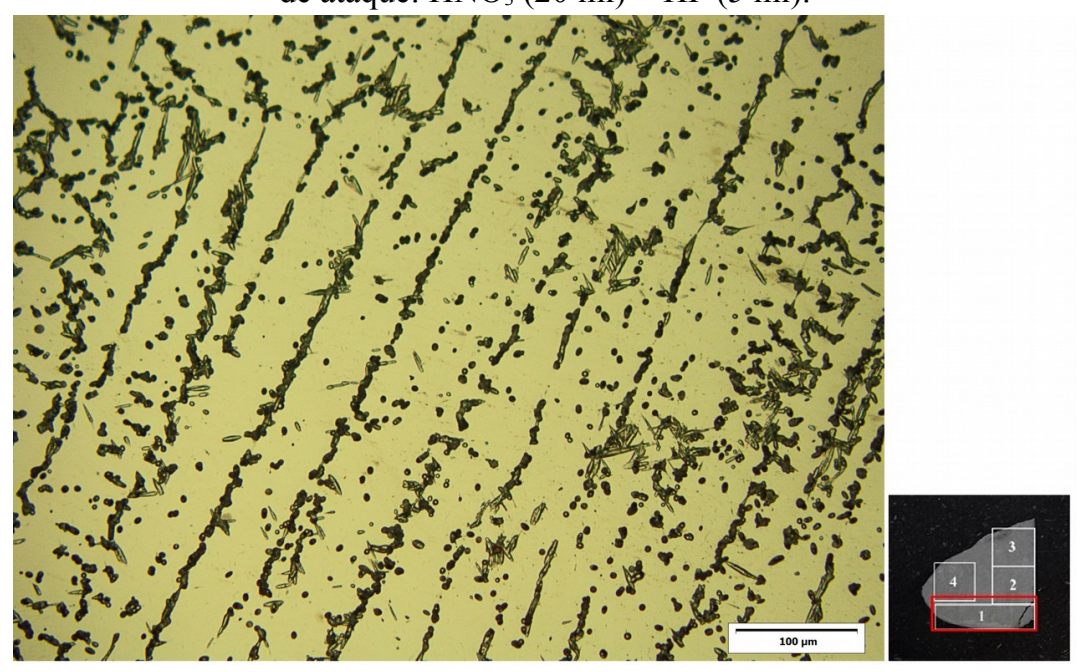

Fonte: Autor

As dendritas são um outro tipo de microestrutura bastante comum na solidificação de diversos materiais ${ }^{[51]}$ e foi encontrada em ambas as ligas estudadas neste trabalho.

Durante o processo de solidificação, quando a taxa de resfriamento encontra-se muito baixa, a interface de crescimento dos grãos torna-se instável, que favorece o surgimento de protuberâncias dendríticas ${ }^{[24]}$. Estes picos crescem rapidamente ao absorver o calor latente do líquido remanescente criando assim ramificações secundárias. A figura 24 mostra indícios do que poderia ser o início de uma ramificação secundária originada a partir de uma ramificação primária.

Figura 24: Ramificação dendrítica principal com projeções promissoras para originar a ramificação secundária na parte superior. Micrografia eletrônica de varredura formada por elétrons secundários referente a liga de Ti-48Al-2Nb-2Cr-0,5B (\% at.). Solução de ataque: $\mathrm{HNO}_{3}(20 \mathrm{ml})+\mathrm{HF}(5 \mathrm{ml})$.

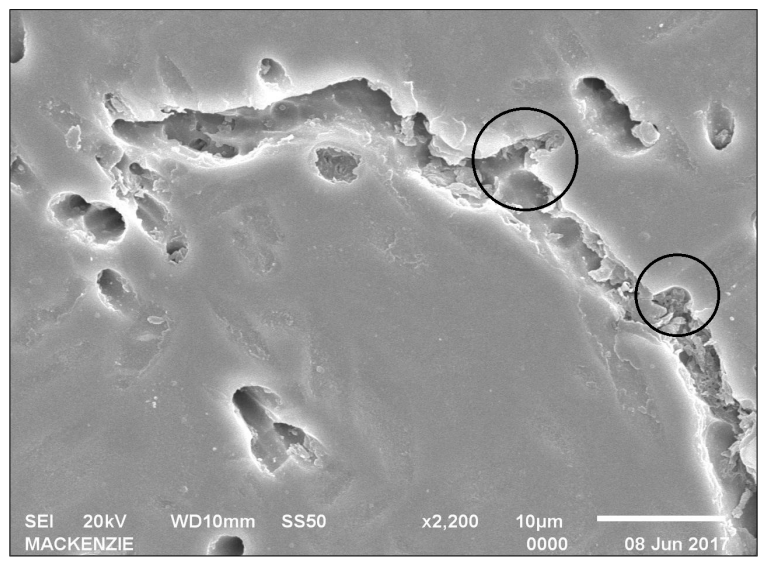

Fonte: Autor 
A formação dendrítica se caracteriza por apresentar uma microestrutura irregular composta por ramificações primárias e secundárias. Nas regiões 2 e 3 da liga Ti44Al-4Nb-1Mo-0,5B (\%at.) verifica-se uma faixa formada a partir de longas ramificações bastante espaçadas entre si e que se interligam formando estruturas similares a grãos, figura 25 (a). Um pouco mais acima, estas ramificações tendem a estar mais paralelas e próximas entre si, figura $25(\mathrm{~b})$.

As figuras 25 e 26 traçam um perfil transversal da amostra, ressaltando os pontos mencionados anteriormente e acrescentando também a zona equiaxial encontrada na extremidade superior da amostra, como mostrado na figura 26(c).

Figura 25: Região 2 da amostra de Ti-44Al-4Nb-1Mo-0,5B (\% at.) onde podem ser visualizadas duas regiões dendríticas: (a) com ramificações mais espaçadas formando estruturas similares a grãos e outra com ramificações que tendem a estar mais alinhadas (b). Micrografia óptica em campo claro. Solução de ataque: $\mathrm{HNO}_{3}(20 \mathrm{ml})+\mathrm{HF}(5 \mathrm{ml})$.

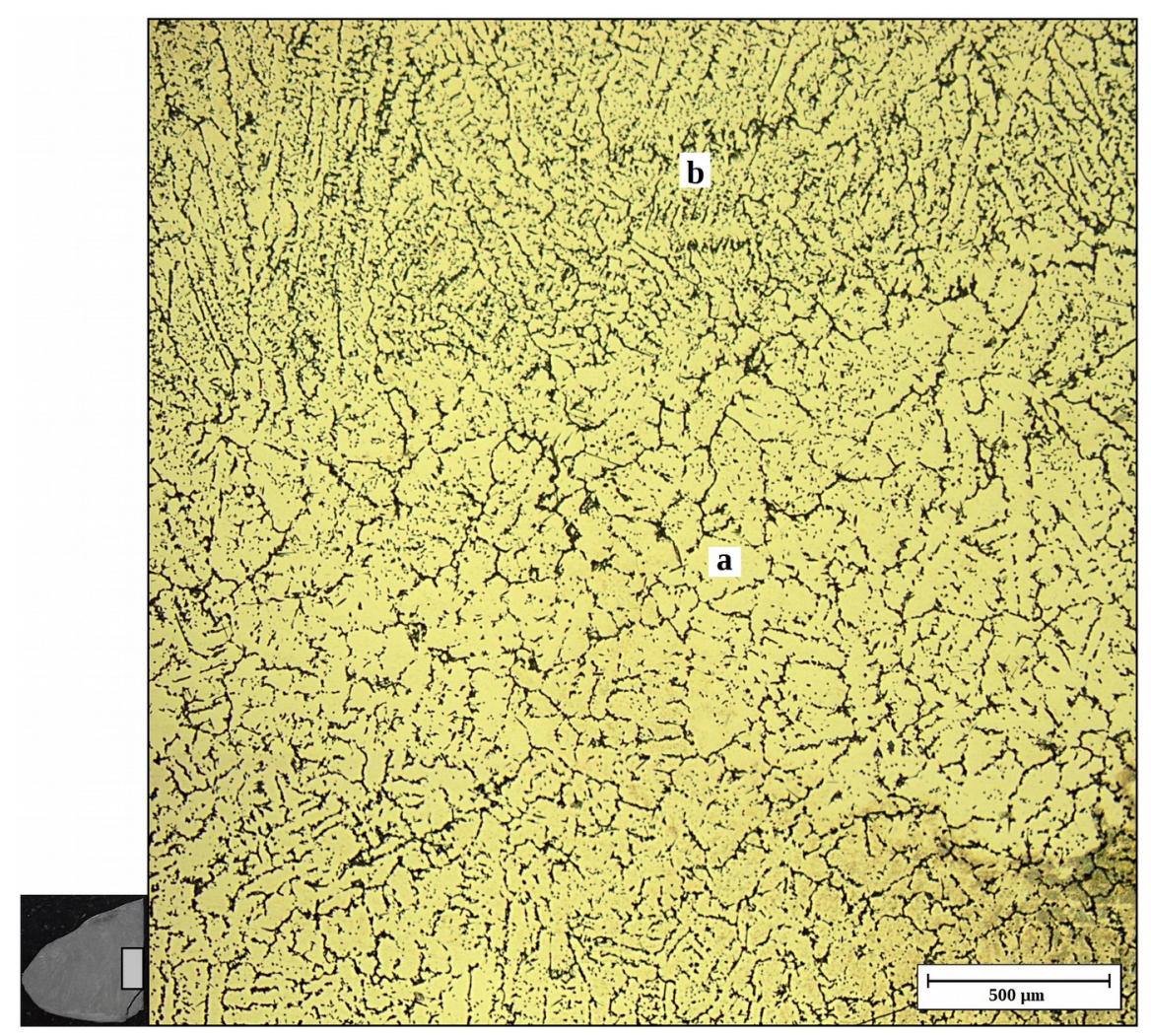

Fonte: Autor 
Figura 26: Área de transição entre região dendrítica (b) e a zona equiaxial (c) da liga Ti-44Al-4Nb-1Mo-0,5B (\% at.). Micrografia óptica em campo claro. Solução de ataque: $\mathrm{HNO}_{3}(20 \mathrm{ml})+\mathrm{HF}(5 \mathrm{ml})$.

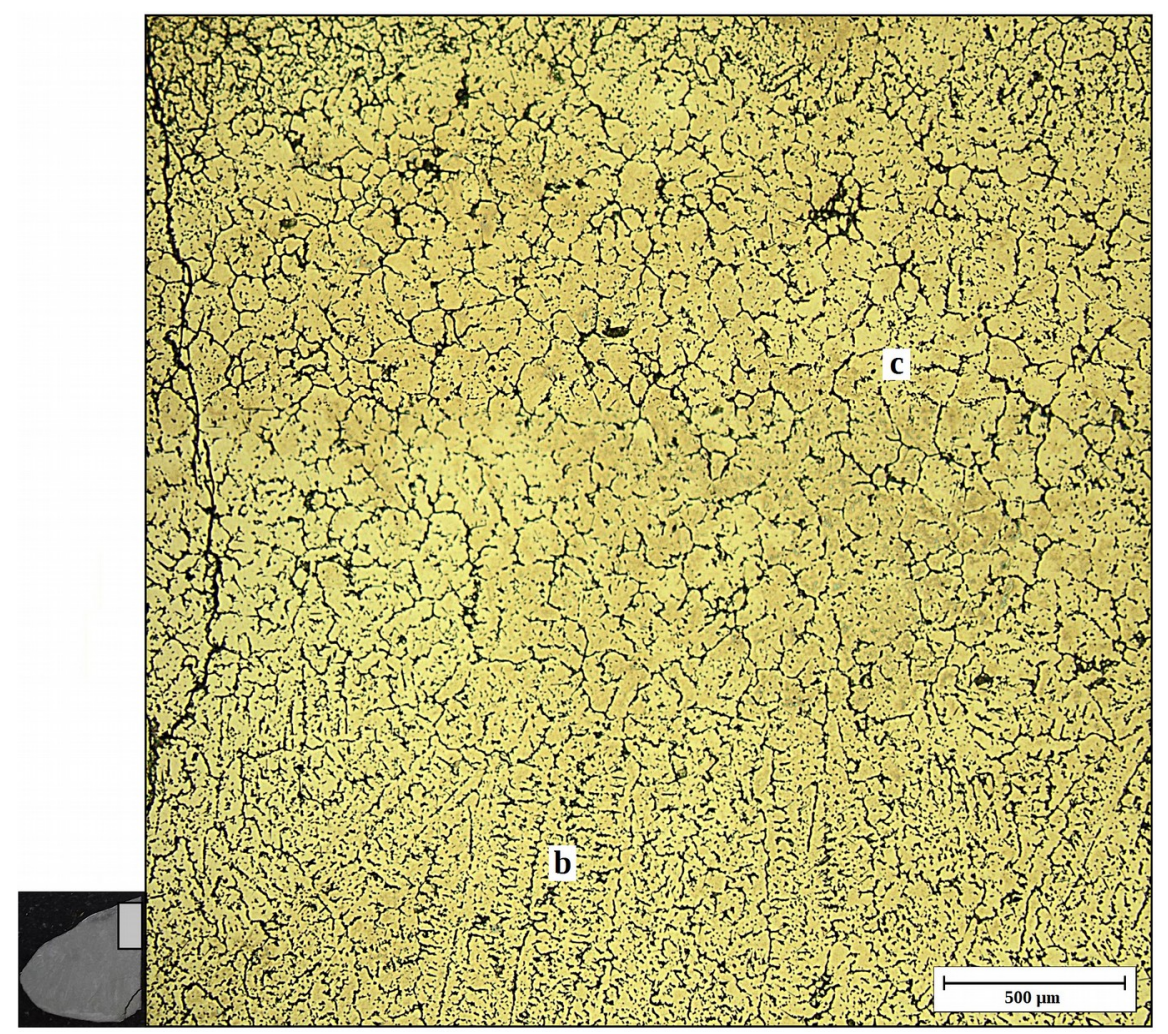

Fonte: Autor

A figura 27 apresenta uma micrografia óptica em campo escuro da liga Ti48Al-2Nb-2Cr-0,5B (\% at.). Nesta figura podem ser melhores observadas as ramificações secundárias que se interligam entre si, como ressalta a figura 25(a). Este tipo de formação microestrutural foi encontrada em toda a região 3 e na parte superior da região 5 , de acordo a representação disposta no canto inferior direito da figura.

Figura 27: Grãos formados a partir da interligação de longas ramificações dendríticas na liga Ti-48Al-2Nb2Cr-0,5B (\% at.). Microscopia óptica em campo escuro. Sem solução de ataque.

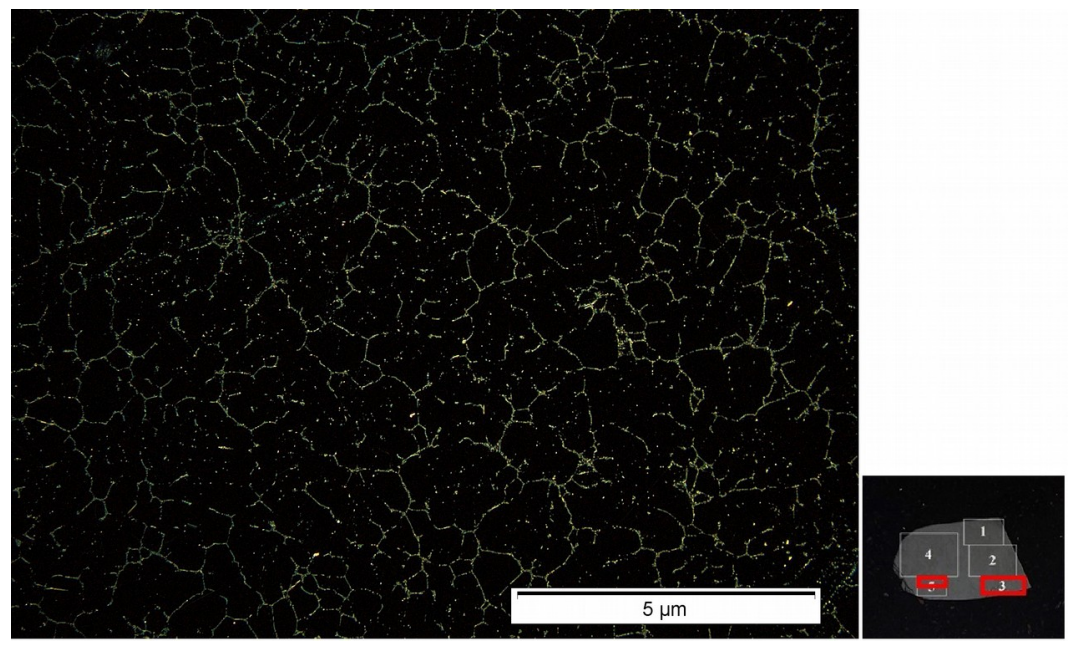

Fonte: Autor 
Na liga Ti-48Al-2Nb-2Cr-0,5B (\% at.) existe ainda uma microestrutura com um aspecto diferente com relação ao que foi apresentado sobre as dendritas até o momento. Ainda que sejam observados traços de ramificações dendríticas, estas são mais curtas e com poucas interligações, como é possível observar na figura 28.

Figura 28: Micrografia óptica referente à região 4 da amostra de Ti-48Al-2Nb-2Cr-0,5B (\% at.) em que são visualizadas longas ramificações dendríticas curtas e com poucas interligações. Solução de ataque: $\mathrm{HNO}_{3}(20$ $\mathrm{ml})+\mathrm{HF}(5 \mathrm{ml})$.

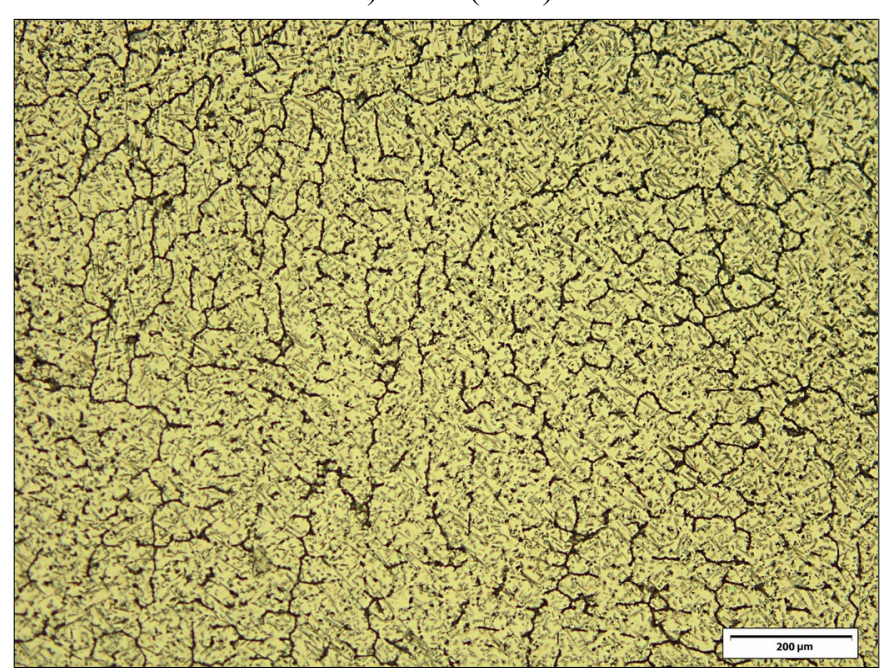

Fonte: Autor

De acordo com REILLY et al ${ }^{[52]}$, no processo de solidificação, o cromo pode contribuir para a fusão das raízes do braço dendrítico, que favorece a fragmentação dos mesmos. Isso explicaria o que está sendo observado na figura 29 (ampliação de uma das áreas da figura 28) em que são verificadas pequenas ramificações livres, ou seja, fragmentos.

Figura 29: Micrografia óptica referente à região 4 da amostra de Ti-48Al-2Nb-2Cr-0,5B (\% at.) em que são visualizadas fragmentos dendríticos. Solução de ataque: $\mathrm{HNO}_{3}(20 \mathrm{ml})+\mathrm{HF}(5 \mathrm{ml})$.

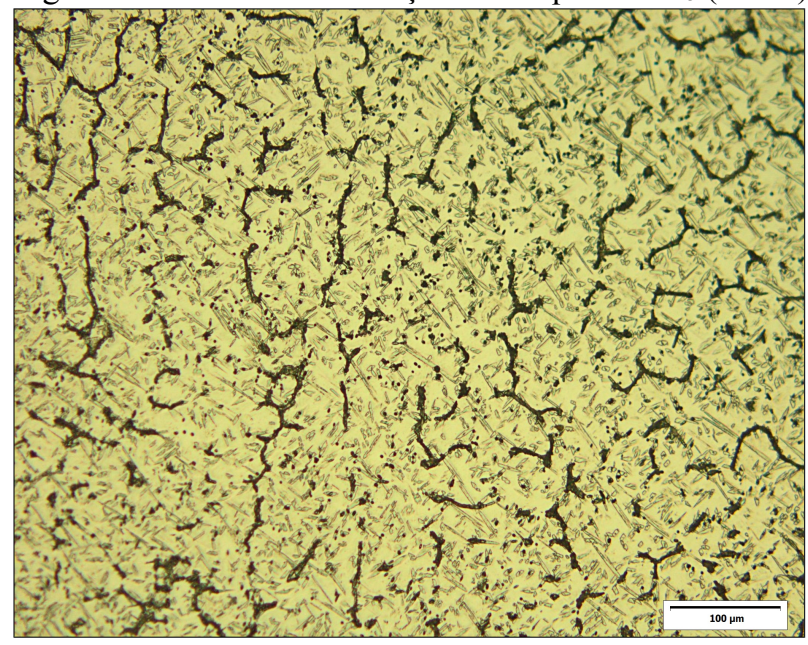

Fonte: Autor 
A figura 30 contêm uma micrografia óptica obtida em campo escuro referente a liga Ti-48Al-2Nb-2Cr-0,5B (\% at.). Nela foram destacadas algumas ramificações dendríticas, bem como, fragmentos dendríticos dispostos aleatoriamente na região 4 da amostra.

Figura 30: (a) Ramificações e (b) fragmentos dendríticos da liga Ti-48Al-2Nb-2Cr-0,5B (\% at.) visualizados na região 4 da amostra. Micrografia óptica em campo escuro. Sem solução de ataque.

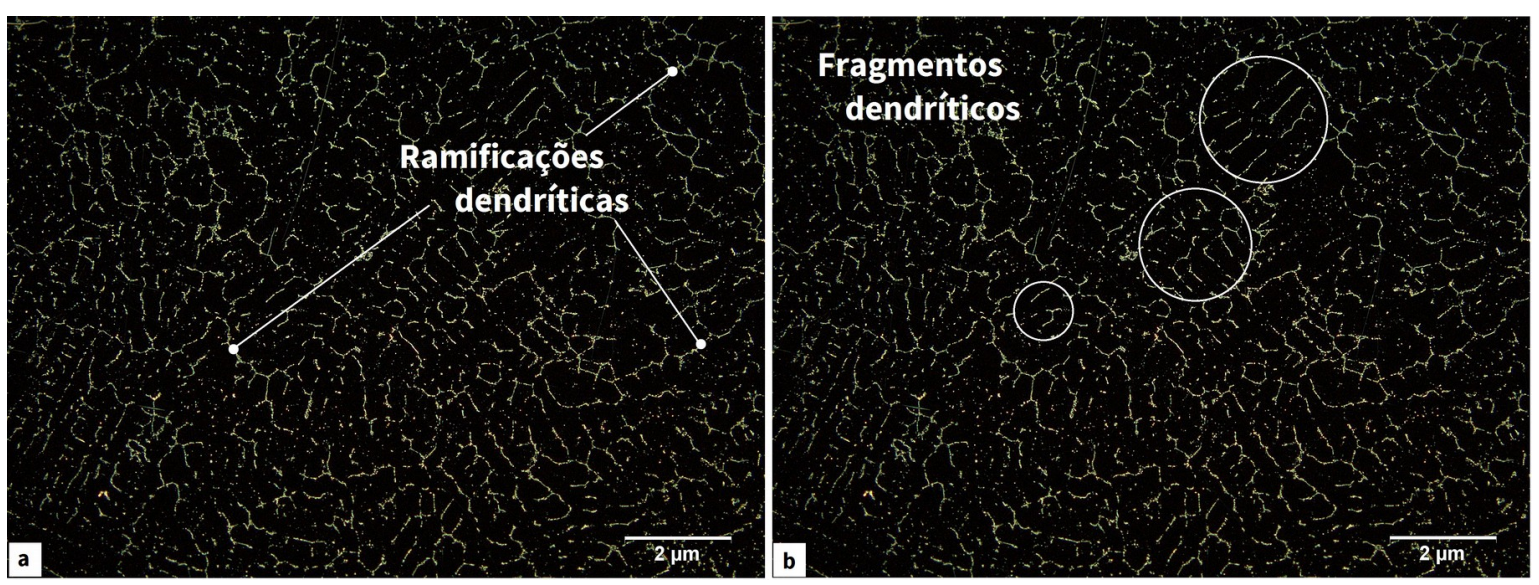

Fonte: Autor

De um modo geral o aparecimento de dendritas durante o processo de solidificação de ligas metálicas não é desejado, visto que favorece a concentração de impurezas e deformidades nas regiões entre as ramificações primárias e secundárias.

Outro tipo de formação microestrutural são os grãos equiaxiais que surgem na última região a ser solidificada. O calor latente produzido pela fusão é progressivamente retirado por meio do avanço das zonas colunares e dendríticas de modo que, em um dado momento, a última região a ser solidificada sofre um resfriamento elevado, favorecendo a nucleação de grãos, os quais surgem quase que simultaneamente e adotam dimensões semelhantes uma vez que são limitados pelas estruturas laterais ${ }^{[51]}$.

A figura 31 mostra a zona equiaxial visualizada na liga Ti-44Al-4Nb-1Mo0,5B (\% at.). Esta microestrutura foi observada ao longo da parte superior da amostra de Ti-44Al-4Nb-1Mo-0,5B (\% at.), abrangendo as regiões 3 e 4. 
Figura 31: Zona equiaxial visualizada na liga Ti-44Al-4Nb-1Mo-0,5B (\% at.). Micrografia óptica em campo claro. Solução de ataque: $\mathrm{HNO}_{3}(20 \mathrm{ml})+\mathrm{HF}(5 \mathrm{ml})$.

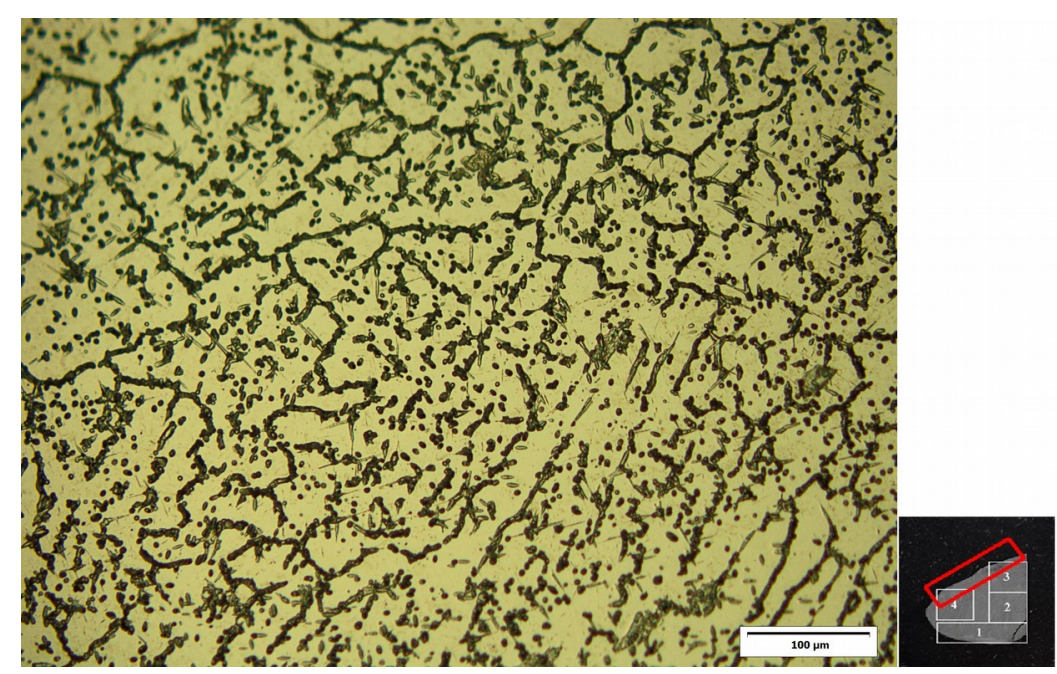

Fonte: Autor

Na região 5 da amostra de Ti-48Al-2Nb-2Cr-0,5B (\% at.), cuja microestrutura está sendo apresentada na figura 32, é possível observar uma interface entre ramificações dendríticas (c) e uma colônia de grãos equiaxiais (d). Estas duas regiões estão sendo ressaltadas na figura 33 e com base nelas é possível notar que a região (c) é composta por longas ramificações dendríticas que formam estruturas similares a grãos cujas dimensões são diferentes e em (d) os grãos são menores e com dimensões mais uniformes, ou seja, grãos equiaxiais.

Figura 32: Interface entre (c) ramificações dendríticas e (d) colônia de grãos equiaxiais, localizada na região 5 da amostra de Ti-48Al-2Nb-2Cr-0,5B (\% at.). Microscopia óptica em campo claro. Solução de ataque: HNO3 (20 ml) + HF (5 ml).
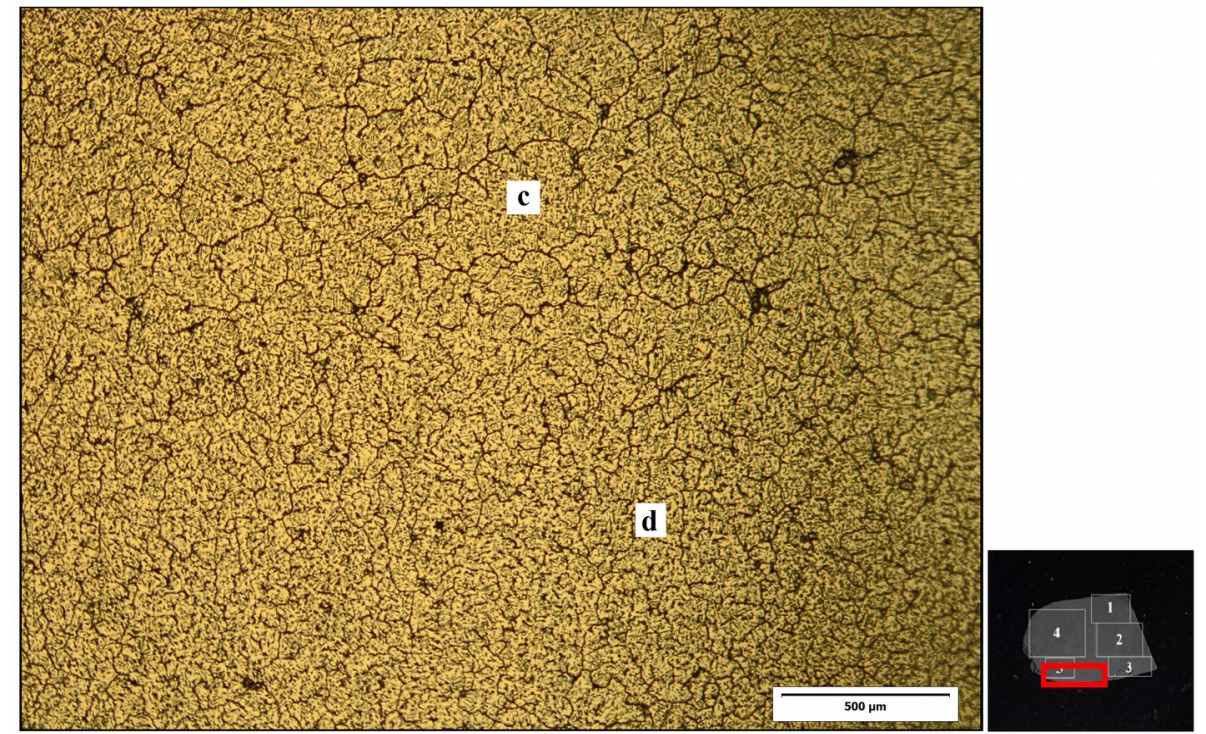

Fonte: Autor 
Figura 33: Diferença dimensional e estrutural dos grãos encontrados na região 5 da amostra de Ti-48Al-2Nb2Cr-0,5B (\% at.). Em (c) grãos formados por ramificações dendríticas e em (d) grãos com dimensões menores e mais uniformes (equiaxiais). Microscopia óptica em campo claro. Solução de ataque: $\mathrm{HNO}_{3}(20$ $\mathrm{ml})+\mathrm{HF}(5 \mathrm{ml})$.

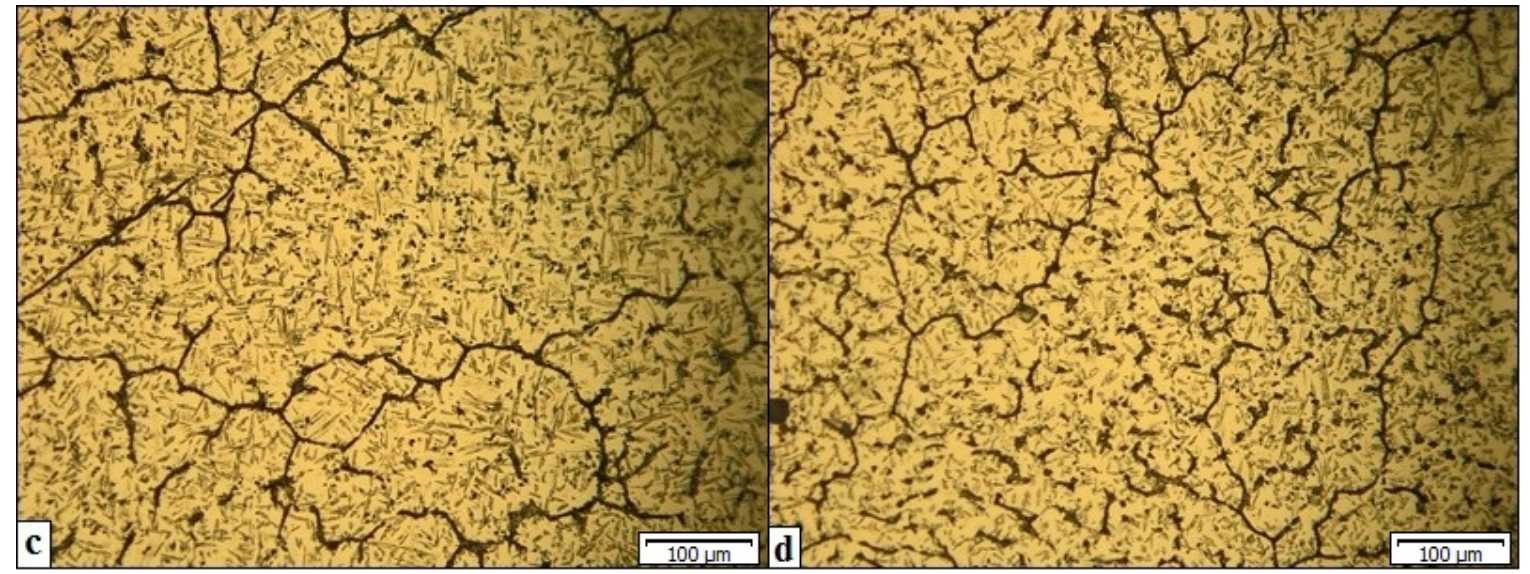

Fonte: Autor

Ao analisar a micrografia referente a região 4 da liga Ti-44Al-4Nb-1Mo-0,5B (\% at.), disposta na figura 34 , uma diversidade de microestruturas dentro de uma mesma área pôde ser identificada.

Dentre elas, podem ser observadas duas zonas colunares com espaçamento visualmente diferenciado (d) e (f), evidenciadas na figura 35. A primeira delas se estende por toda a superfície inferior da amostra, a qual esteve em contato com o molde. A segunda, por sua vez, compreende apenas uma área restrita da parte interna da amostra.

Além destas, verificam-se ainda outras microestruturas ressaltadas na figura 36: (e) região de intersecção de ramificações dendríticas provenientes de diferentes direções; (g) zona de grãos equiaxiais que se iniciam em uma faixa estreita ao lado da zona lamelar mais fina (f) e percorre o limite superior da amostra. É provável que (h) seja uma microestrutura de transição entre os grãos equiaxiais (g) e a zona colunar (d), enquanto que (i), seja uma interface de transição entre a zona colunar e outra similar a uma região dendrítica. 
Figura 34: Micrografia óptica refente a região 4 da amostra de Ti-44Al-4Nb-1Mo-0,5B (\% at.). Interface entre diferentes micrestruturas. (d) e (f) zonas colunares com espaçamento visualmente diferenciado; (e) região de intersecção de ramificações dendríticas provenientes de diferentes direções; (g) zona de grãos equiaxiais que se iniciam em uma faixa estreita ao lado da zona lamelar mais fina (f) e percorre o limite superior da amostra; (h) provável microestrutura de transição entre os grãos equiaxiais ( $\mathrm{g}$ ) e a zona colunar (d); e (i), interface de transição entre a zona colunar e outra, similar a uma região dendrítica. Solução de ataque: $\mathrm{HNO}_{3}(20 \mathrm{ml})+\mathrm{HF}(5 \mathrm{ml})$.

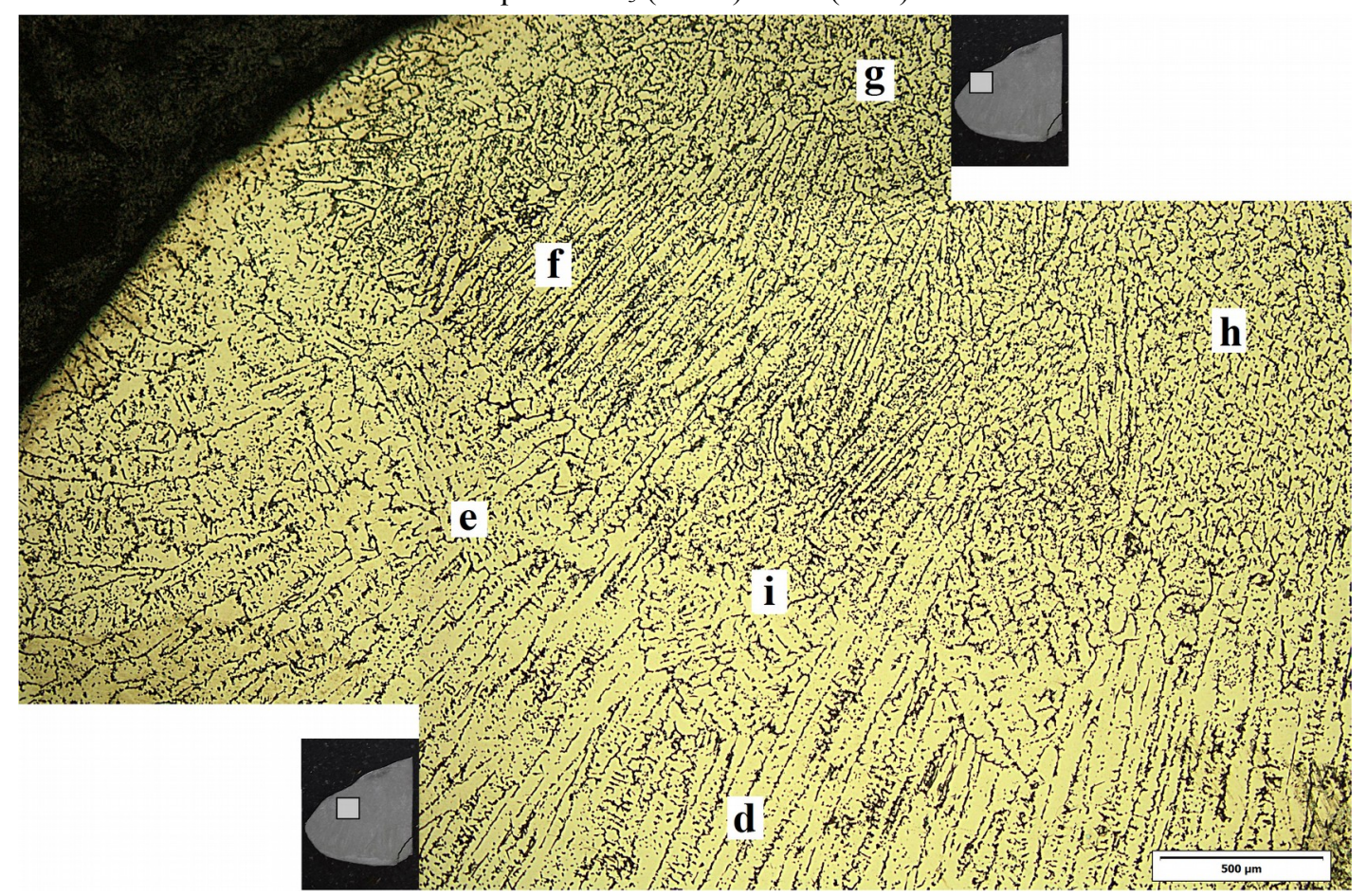

Fonte: Autor

Figura 35: Zonas colunares referentes a liga Ti-44Al-4Nb-1Mo-0,5B (\% at.). Em (d) notam-se lamelas mais espaçadas do que em (f). Micrografias ópticas em campo claro. Solução de ataque: $\mathrm{HNO}_{3}(20 \mathrm{ml})+\mathrm{HF}(5$ $\mathrm{ml})$.

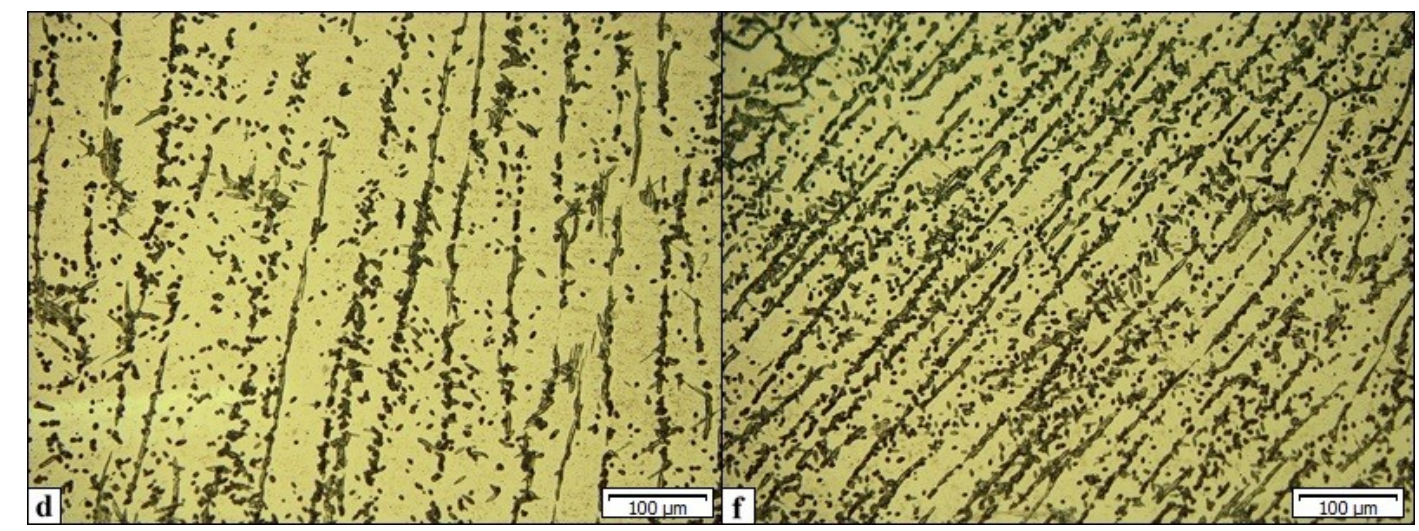

Fonte: Autor 
Figura 36: Microestruturas presentes na região. (e) intersecção de ramificações dendríticas provenientes de diferentes direções; (g) zona de grãos equiaxiais, a região dendrítica; (h) provável microestrutura de transição entre os grãos equiaxiais (g) e a zona colunar; e (i) interface de transição entre a zona colunar e outra, similar a uma região dendrítica.

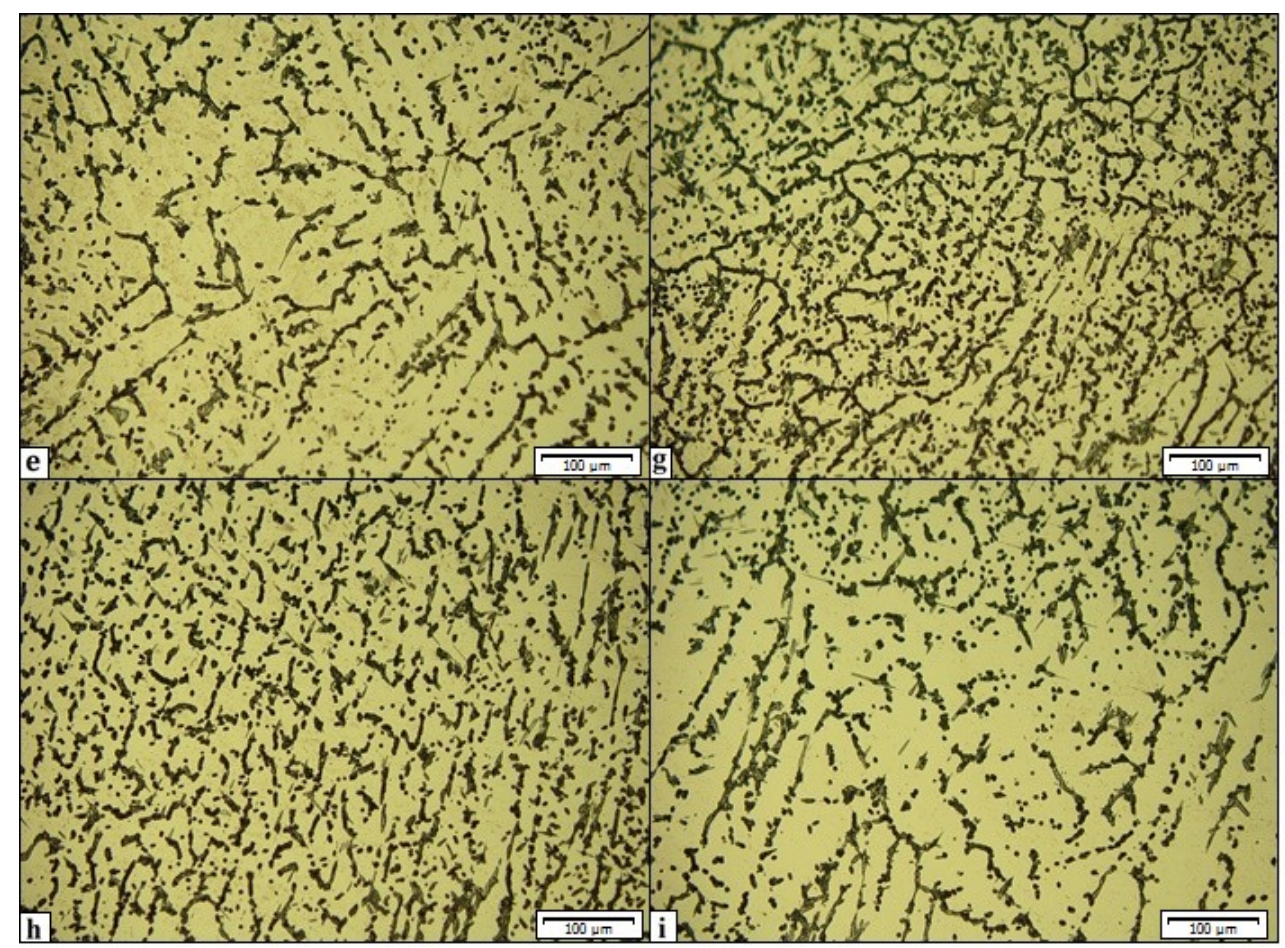

Fonte: Autor

A solução química utilizada para o ataque da microestrutura reagiu com a fase encontrada no contorno de grão, resultando na sua extração. Contudo é possível identificar a sua existência nos contornos de grão mediante a observação da micrografia eletrônica de varredura mostrada na figura 37.

Figura 37: Presença de fase no contorno dos grãos. Ainda que a fase tenha reagido com a solução utilizada para o ataque químico, é possível observar resquícios de sua existência nos contornos de grãos. Ligas (a) Ti48Al-2Nb-2Cr-0,5B (\%at.) e (b) Ti-44Al-4Nb-1Mo-0,5B (\%at.). Microscopia eletrônica de varredura formada por elétrons secundários. Solução de ataque: $\mathrm{HNO}_{3}(20 \mathrm{ml})+\mathrm{HF}(5 \mathrm{ml})$.

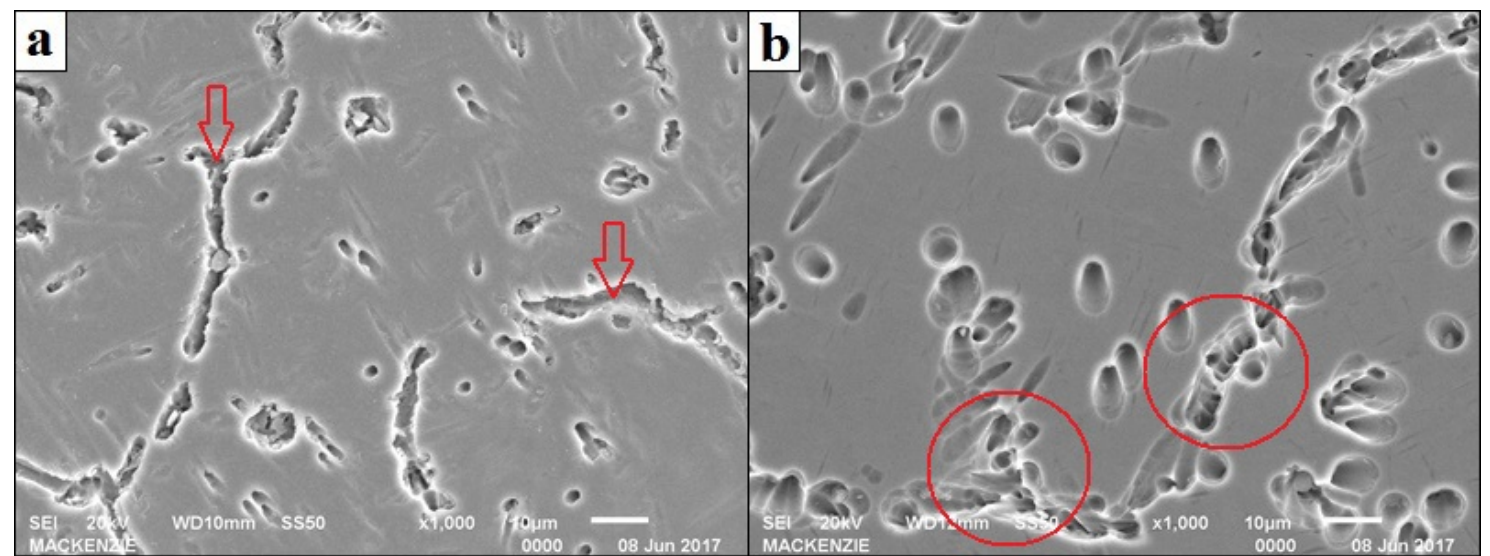

Fonte: Autor 
Dependendo da concentração de alumínio e aliada a adição de nióbio e elementos estabilizadores $\beta$, os aluminetos de titânio tendem a concentrar esta fase nos contornos de grão e originar a morfologia dendrítica ${ }^{[52,53]}$, o que leva a acreditar que foi a fase $\beta$ quem reagiu com a solução química.

Outra estrutura observada nas amostras referentes a ambas as ligas corresponde à fase $\alpha_{2}-\mathrm{Ti}_{3} \mathrm{Al}^{[54]}$, a qual se apresenta no formato de bastonetes, como está sendo mostrada na figura 38. Na liga Ti-44Al-4Nb-1Mo-0,5B (\% at.), entretanto, foi visualizada em dimensões visualmente menores do que na liga Ti-48Al-2Nb-2Cr-0,5B (\%at.).

Figura 38: Identificação da fase $\alpha_{2}-\mathrm{Ti}_{3} \mathrm{Al}$ nas ligas. (a) Ti-48Al-2Nb-2Cr-0,5B (\%at.) e (b) Ti-44Al-4Nb1Mo-0,5B (\%at.). Microscopia eletrônica de varredura formada por elétrons secundários. Solução de ataque: $\mathrm{HNO}_{3}(20 \mathrm{ml})+\mathrm{HF}(5 \mathrm{ml})$.

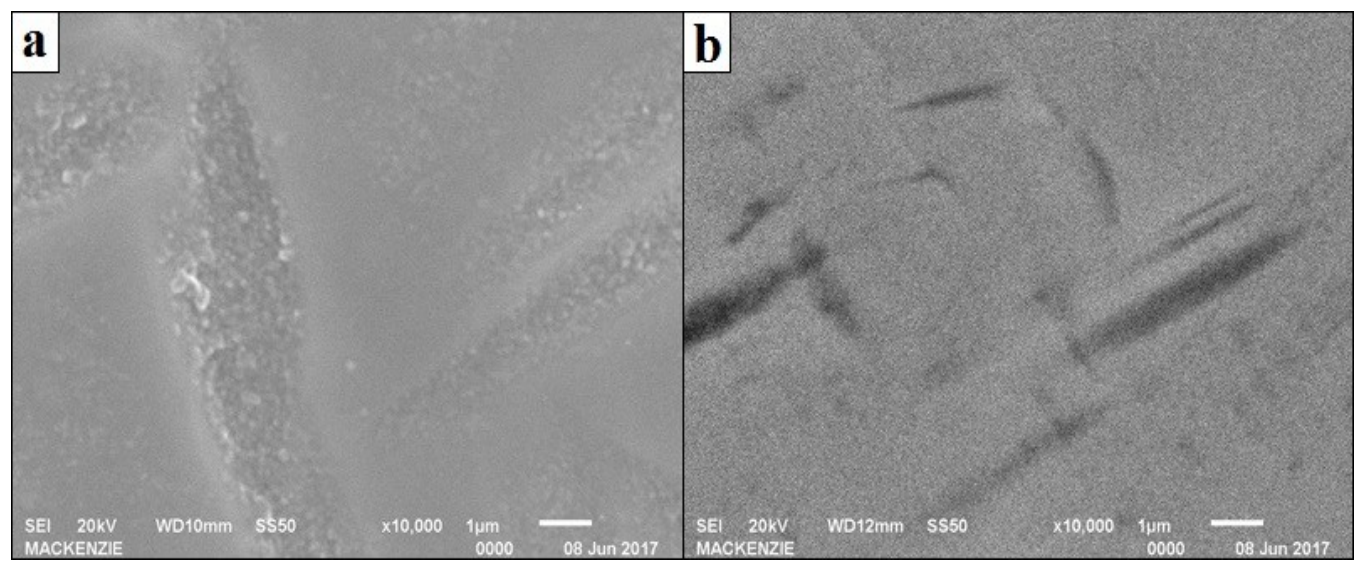

Fonte: Autor

Ao contrário do que ocorre na liga Ti-44Al-4Nb-1Mo-0,5B (\% at.), na liga Ti$48 \mathrm{Al}-2 \mathrm{Nb}-2 \mathrm{Cr}-0,5 \mathrm{~B}$ (\% at.) a fase $\alpha_{2}-\mathrm{Ti}_{3} \mathrm{Al}$ é encontrada de forma intensa na liga Ti-48Al$2 \mathrm{Nb}-2 \mathrm{Cr}-0,5 \mathrm{~B}$ (\% at.), enquanto que na liga Ti-44Al-4Nb-1Mo-0,5B (\% at.) a fase $\alpha_{2}-\mathrm{Ti}_{3} \mathrm{Al}$ aparece de modo mais discreto e com menor intensidade, o que deixa a microestrutura com um aspecto mais homogêneo, como é possível observar na figura 39. A provável justificativa para esta evidência com relação a liga Ti-44Al-4Nb-1Mo-0,5B (\% at.), corresponde à maior concentração de alumínio, elemento estabilizador desta fase. 
Figura 39: Contraste entre a evidência da fase $\alpha_{2}-\mathrm{Ti}_{3} \mathrm{Al}$. Em (a) Ti-48Al-2Nb-2Cr-0,5B (\%at.) é encontrada de forma intensa do que em (b) Ti-44Al-4Nb-1Mo-0,5B (\%at.), provavelmente devido a maior concentração de alumínio. Microscopia óptica em campo claro. Solução de ataque: $\mathrm{HNO}_{3}(20 \mathrm{ml})+\mathrm{HF}(5 \mathrm{ml})$.

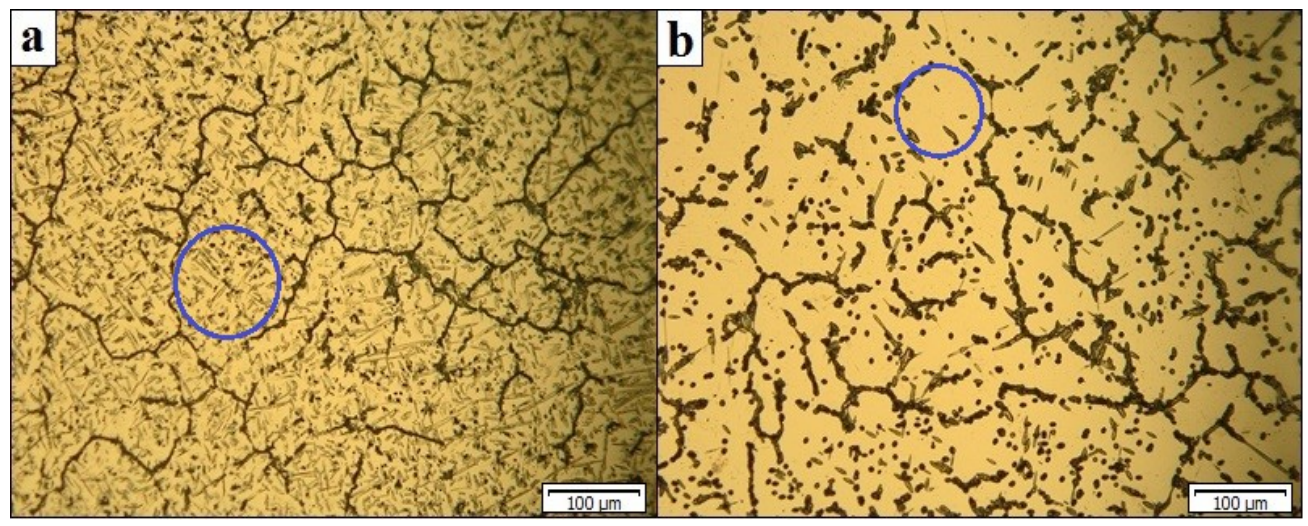

Fonte: Autor

$\mathrm{Na}$ figura 40 estão sendo apresentadas micrografias obtidas por microscopia eletrônica de varredura referentes às duas ligas, onde estão sendo observadas a fase $\alpha_{2}$ $\mathrm{Ti}_{3} \mathrm{Al}$ na região mais interna dos grãos e a provável localização da fase $\beta$ nos contornos de grão.

Figura 40: Observação da fase $\alpha_{2}-\mathrm{Ti}_{3} \mathrm{Al}$ na região mais interna dos grãos e provável localização da fase $\beta$ nos contornos de grão. Ligas (a) Ti-48Al-2Nb-2Cr-0,5B (\%at.) e (b) Ti-44Al-4Nb-1Mo-0,5B (\%at.). Microscopia eletrônica de varredura formada por elétrons secundários. Solução de ataque: $\mathrm{HNO}_{3}(20 \mathrm{ml})+\mathrm{HF}(5 \mathrm{ml})$.

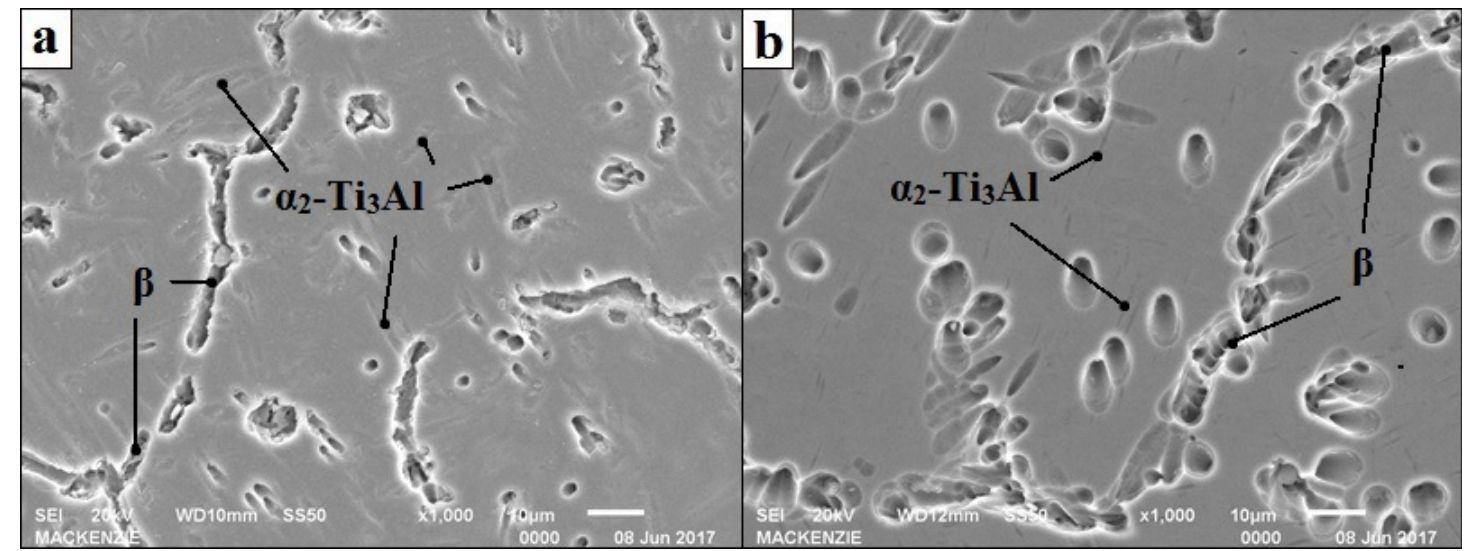

Fonte: Autor

\subsection{Análise do comportamento da resistência a oxidação sob temperaturas elevadas}

Neste trabalho, o comportamento da propriedade de resistência a oxidação das ligas Ti-48Al-2Nb-2Cr-0,5B (\% at.) e Ti-44Al-4Nb-1Mo-0,5B (\% at.) foi analisado mediante a realização de um ensaio termogravimétrico e outro isotérmico em forno tipo mufla, sendo que ambos tiveram a mesma duração e foram submetidos a mesma variação de temperatura de 25 a $1000{ }^{\circ} \mathrm{C}$. 
4.4.1 Curvas de ganho em massa versus tempo

Na figura 41 está sendo mostrada em (a) a variação da temperatura ao decorrer do ensaio termogravimétrico e em (b) as curvas de ganho em massa versus tempo referentes a cada uma das ligas. Com base nestas curvas é possível verificar que ambas as ligas apresentam um baixo ganho de massa no período inicial do ensaio, até 1 hora e meia aproximadamente, período que corresponde à etapa de aquecimento do equipamento onde o comportamento da curva tende a ser linear. É nesta primeira fase que se inicia a formação da camada de óxido na superfície da amostra, a qual cresce conforme o aumento da temperatura.

Figura 41: (a) Variação da temperatura ao decorrer do tempo de ensaio e (b) curvas de ganho em massa versus tempo das ligas Ti-48Al-2Nb-2Cr-0,5B (\%at.) e Ti-44Al-4Nb-1Mo-0,5B (\%at.) registradas em ensaio termogravimétrico em uma DTG com fluxo de ar de $100 \mathrm{~mL} / \mathrm{min}$ e variação de temperatura de 25 a $1000{ }^{\circ} \mathrm{C}$.
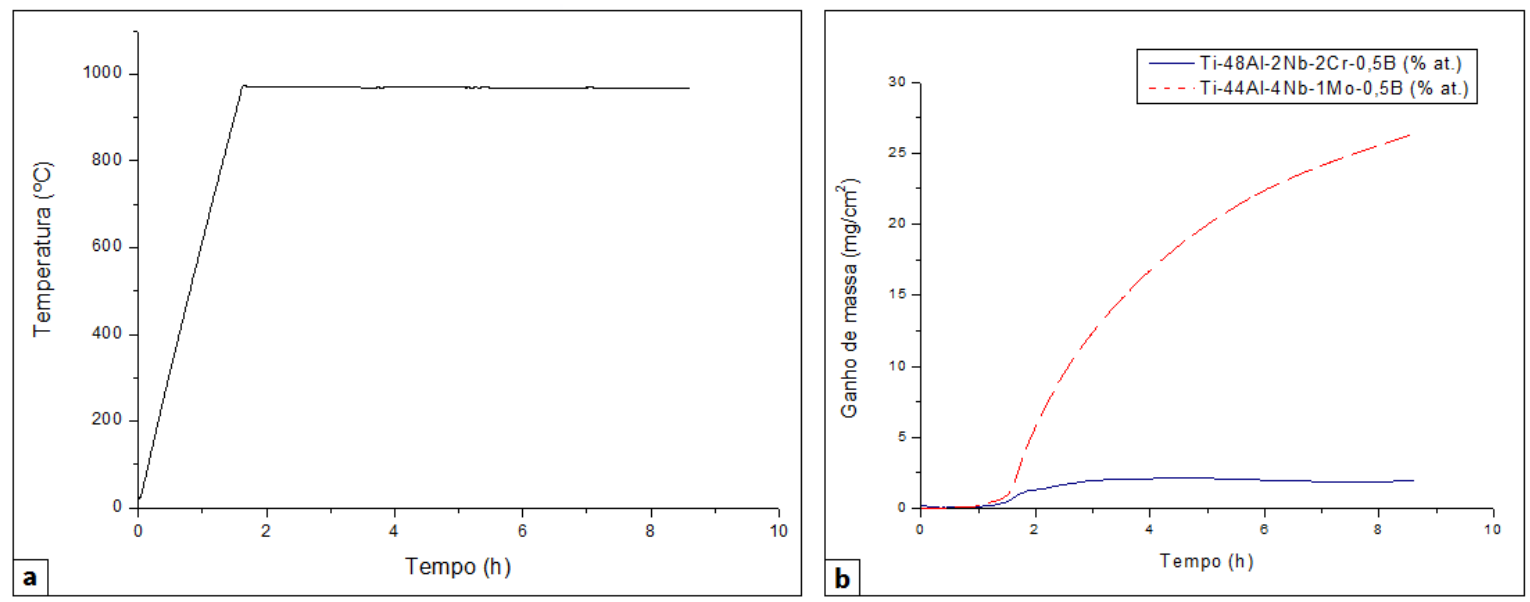

Fonte: Autor

A oxidação mais significativa foi observada a partir de $900{ }^{\circ} \mathrm{C}$ para a liga Ti48Al-2Nb-2Cr-0,5B (\%at.) e $850{ }^{\circ} \mathrm{C}$ para a liga Ti-44Al-4Nb-1Mo-0,5B (\%at.). Após esta temperatura, o ganho em massa dessas ligas adquire um comportamento parabólico como destaca a figura 42 . 
Figura 42: Curvas de ganho em massa versus tempo das ligas Ti-48Al-2Nb-2Cr-0,5B (\%at.) e Ti-44Al-4Nb$1 \mathrm{Mo}-0,5 \mathrm{~B}$ (\%at.) registradas em ensaio termogravimétrico em uma DTG com fluxo de ar de $100 \mathrm{~mL} / \mathrm{min} \mathrm{e}$ variação de temperatura de 25 a $1000{ }^{\circ} \mathrm{C}$, com destaque para o comportamento parabólico adotado pelas duas ligas.

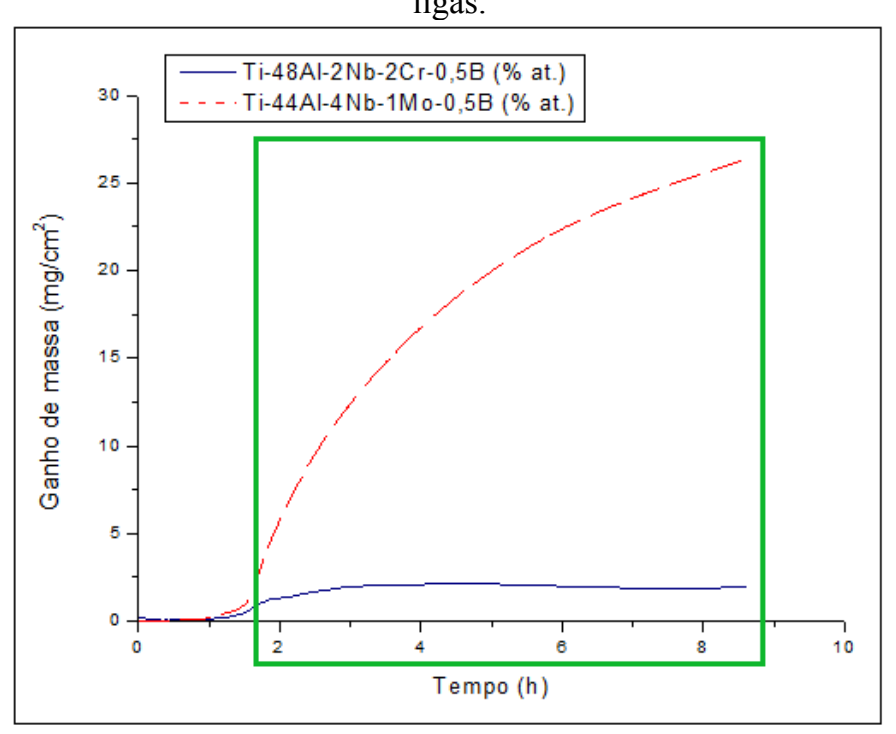

Fonte: Autor

Ainda que ambas as ligas apresentem um comportamento parabólico, a liga Ti48Al-2Nb-2Cr-0,5B (\%at.) revela uma maior resistência a oxidação ao controlar o formato da curva e estabilizar o ganho de massa em torno de $2 \mathrm{mg} / \mathrm{cm}^{2}$, valor significativamente menor do que o que foi apresentado pela liga Ti-44Al-4Nb-1Mo-0,5B (\%at.).

OSTROVSKAYA et al ${ }^{[7]}$ por sua vez, aponta um resultado diferente em seu estudo. Segundo ele, ao ser adicionado em concentração inferior a 4 (\%at) o cromo resulta num efeito prejudicial na resistência a oxidação, assim, concluiu que as ligas com maior teor de $\mathrm{Nb}$ e Mo apresentaram melhor comportamento de resistência à oxidação do que a liga de $\mathrm{Ti}-48 \mathrm{Al}-2 \mathrm{Cr}-2 \mathrm{Nb}$.

É fato que a adição de elementos como $\mathrm{Nb}$ e Mo às ligas $\gamma$-TiAl resulta em um aprimoramento da resistência à oxidação, e visto isso, era esperado que a liga Ti-44Al$4 \mathrm{Nb}-1 \mathrm{Mo}-0,5 \mathrm{~B}$ (\%at.) se destacasse como afirma OSTROVSKAYA et al ${ }^{[7]}$. Entretanto, a liga Ti-48Al-2Nb-2Cr-0,5B (\%at.) estudada neste trabalho superou as expectativas.

Este resultado pode estar relacionado a diversos fatores como: tipo de fundição adotado, ausência do tratamento térmico, adição de boro como um elemento específico para refinamento de grão associado a elementos como alumínio, nióbio e cromo que proporcionam um efeito de passivação à liga, ou ainda, à combinação de todas estas possibilidades. 
4.4.2 Análise das amostras oxidadas via difração de raios X

A figura 43 apresenta os difratogramas obtidos a partir das amostras oxidadas no ensaio em mufla. Eles foram comparados com as fichas 65-5414, 52-859, 44-1288, 21 1276, 81-2266 e 74-1378 por meio do software Crystallographica Search-Match, e como já era esperado foram identificados em ambos os intermetálicos as fases $\alpha_{2}-\mathrm{Ti}_{3} \mathrm{Al}, \beta$-Ti e $\gamma$ TiAl; e ainda, os óxidos: $\mathrm{Al}_{2} \mathrm{O}_{3}$ (alumina $\alpha$ ), $\mathrm{TiO}_{2}$ (rutilo) e $\mathrm{NbO}_{2}$.

Figura 43: Difratogramas de raios x das ligas Ti-48Al-2Nb-2Cr-0,5B (\%at.) e Ti-44Al-4Nb-1Mo-0,5B(\%at.) após o ensaio de oxidação em mufla sob temperatura de $1000{ }^{\circ} \mathrm{C}$ durante 7 horas.

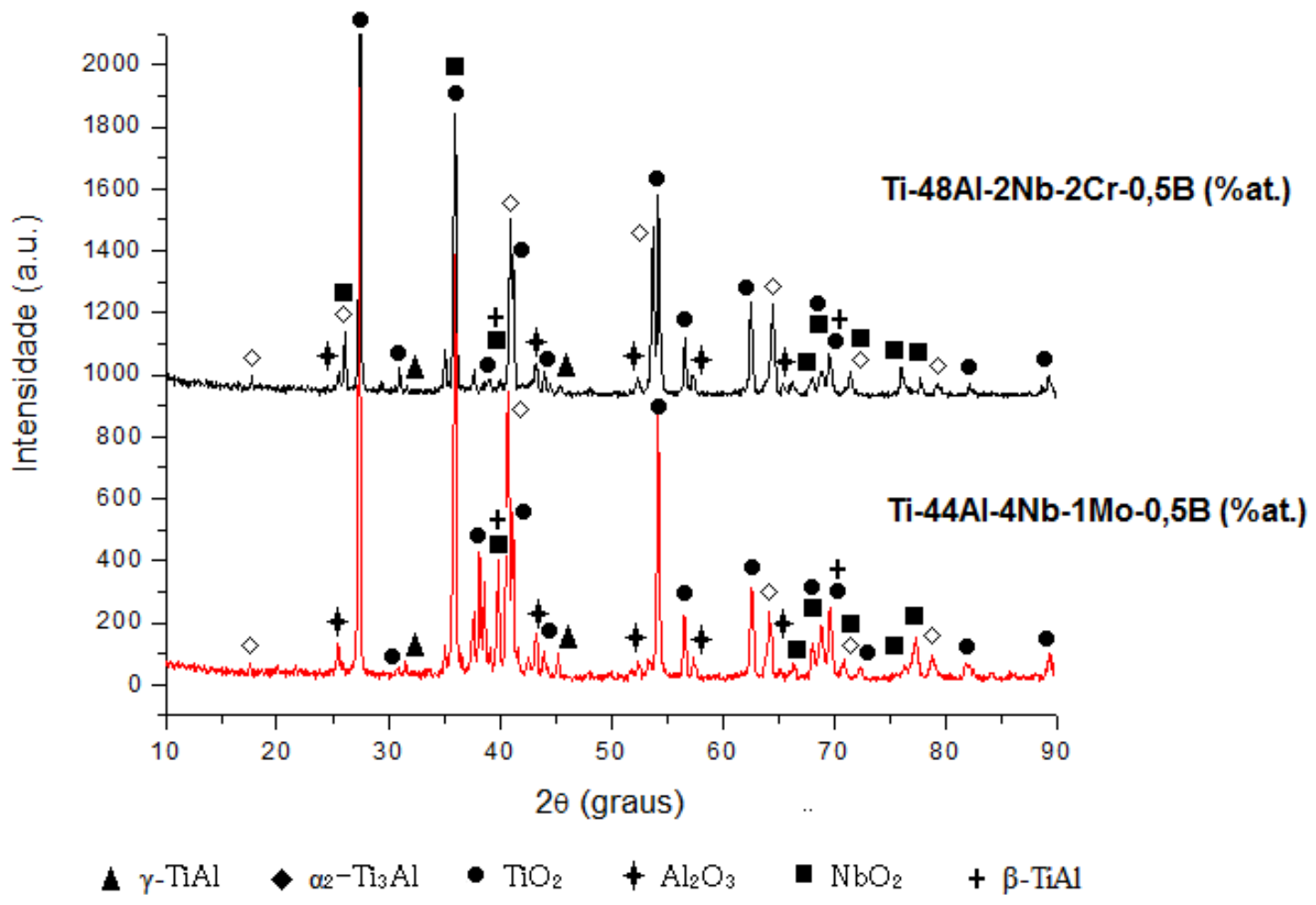

Fonte: Autor

O alumina $\alpha$ é um óxido com poucos defeitos e, por isso, resulta numa camada mais compacta e com melhor propriedade de resistência a oxidação. Já o rutilo, embora também seja um óxido protetor, é bastante suscetível a apresentar defeitos, por isso não é tão eficiente quanto a alumina $\alpha$.

Visto a intensidade com a qual aparece nos difratogramas verifica-se que o rutilo $\left(\mathrm{TiO}_{2}\right)$ é o principal óxido formado, que indica que a camada oxidada apresenta uma dificuldade em garantir o efeito de passivação, uma vez que a concentração de $\mathrm{Al}_{2} \mathrm{O}_{3}$ (alumina $\alpha$ ) não é predominante em nenhuma das ligas. 
OSTROVSKAYA et al ${ }^{[7]}$ também constatou a presença de $\mathrm{TiO}_{2}$ (rutilo) e $\mathrm{Al}_{2} \mathrm{O}_{3}$ (alumina $\alpha$ ) nas amostras de Ti-48Al-2Cr-2Nb (\% at.) e Ti-43,5Al-4Nb-1Mo (\% at.). Entretanto, na liga Ti-43,5Al-4Nb-1Mo (\% at.) foi identificada também a fase $\mathrm{NbO}$ e não $\mathrm{NbO}_{2}$ como apresentado neste trabalho. Esta diferença pode ter ocorrido devido a uma maior oferta de oxigênio no sistema.

4.4.3 Caracterização da camada de óxidos via microscopia eletrônica de varredura

Por meio da análise das imagens obtidas por microscopia eletrônica de varredura foi possível a visualização da camada de óxidos formada nas amostras submetidas ao ensaio em mufla. A figura 44(b) apresenta a camada de óxido que se desenvolveu na liga Ti-44Al-4Nb-1Mo-0,5B ( $\%$ at.), na qual podem ser identificadas várias imperfeições (vazios). Esses defeitos não estão tão evidentes na camada formada na liga Ti-48Al-2Nb-2Cr-0,5B (\% at.), figura 44(a), a qual se mostra mais uniforme, compacta e com uma interface substrato-óxido bastante discreta.

Figura 44: Camada de óxido formada nas amostras de (a) Ti-48Al-2Nb-2Cr-0,5B (\% at.) e (b) Ti-44Al-4Nb1Mo-0,5B (\%at.) após ensaio de oxidação em mufla sob temperatura de $1000{ }^{\circ} \mathrm{C}$ durante 7 horas. Micrografia eletrônica de varredura obtida por elétrons secundários.

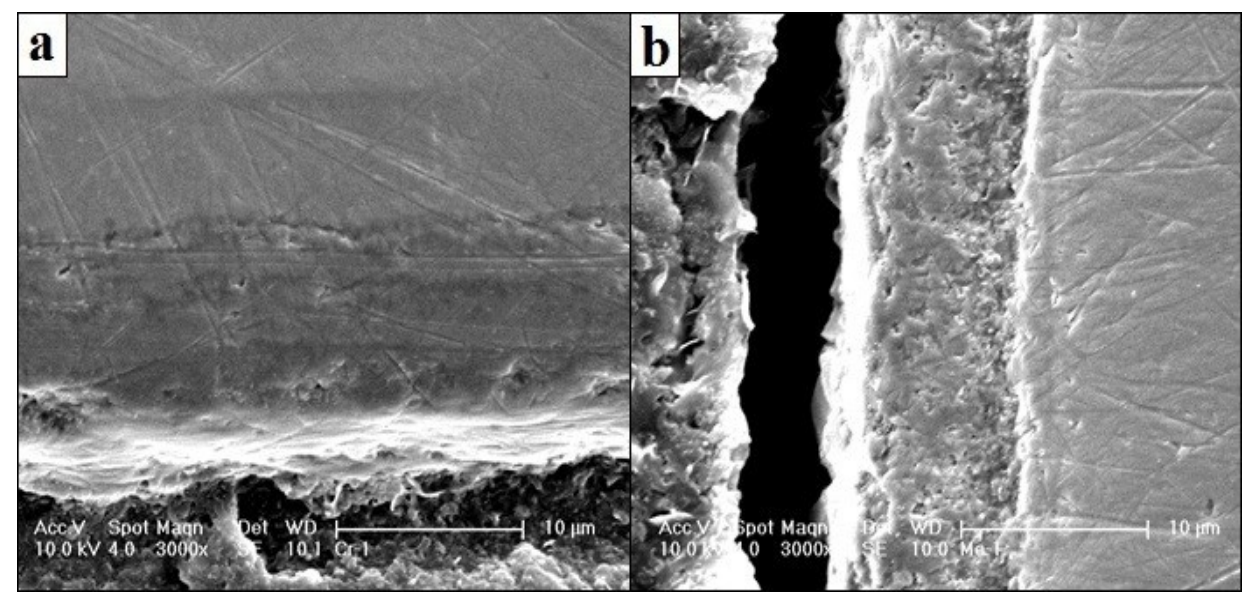

Fonte: Autor

A figura 45 contêm uma imagem referente a liga Ti-48Al-2Nb-2Cr-0,5B (\%at.), representativa do fenômeno de escamação da camada de óxido observado em ambas as ligas ao término dos ensaios. Nela é possível observar que a camada de óxido na borda inferior está se soltando em relação a amostra, enquanto que na lateral direita não existe mais. 
Figura 45: Escamação da amostra. Devido à escamação da camada de óxido que ocorreu na lateral direita da amostra, a camada pode ser visualizada apenas na borda inferior, a qual também está se soltando.

Microscopia eletrônica de varredura da liga Ti-48Al-2Nb-2Cr-0,5B (\% at.) após ensaio de oxidação em mufla sob temperatura de $1000{ }^{\circ} \mathrm{C}$ durante 7 horas.

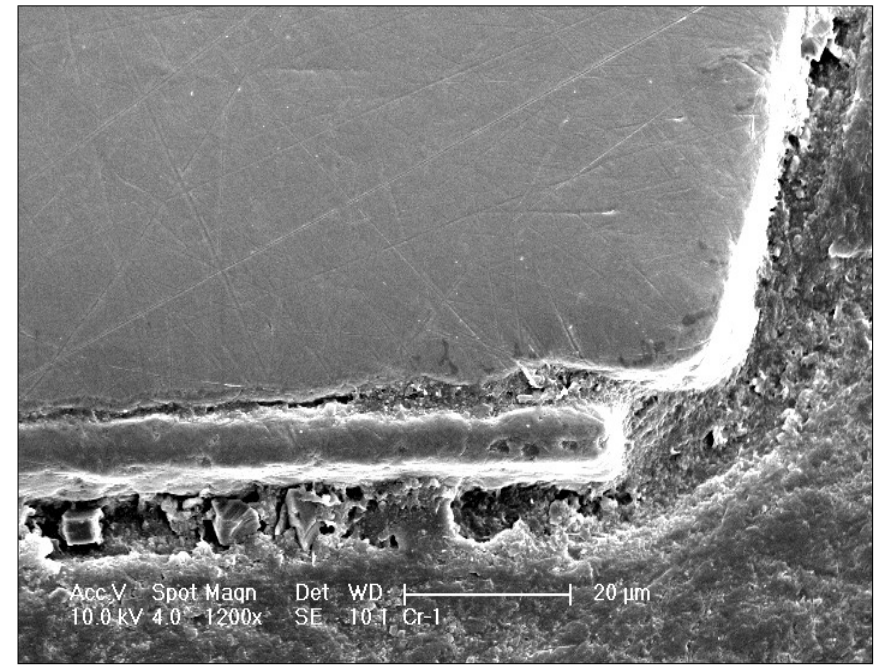

Fonte: Autor

O ideal seria que nenhuma, ou ao menos uma das amostras escamasse visto que o tempo de exposição à $1000{ }^{\circ} \mathrm{C}$ foi muito baixo considerando uma aplicação prática, entretanto não foi o que aconteceu, ocorrendo de forma mais significativa nas amostras de Ti-48Al-2Nb-2Cr-0,5B (\%at.), como mostra a figura 46, onde podem ser observadas as amostras oxidadas dentro de tubos de quartzo com as extremidades protegidas por lã de vidro (oxidação em forno tipo mufla por $7 \mathrm{~h}$ sob variação de temperatura de 25 a $1000{ }^{\circ} \mathrm{C}$ ).

Figura 46: Amostras das ligas (a) Ti-48Al-2Nb-2Cr-0,5B (\% at.) e (b) liga Ti-44Al-4Nb-1Mo-0,5B (\% at.) dentro de tubos de quartzo com as extremidades protegidas por lã de vidro após oxidação em forno tipo mufla por $7 \mathrm{~h}$ sob variação de temperatura de 25 a $1000^{\circ} \mathrm{C}$ e resfriadas lentamente.

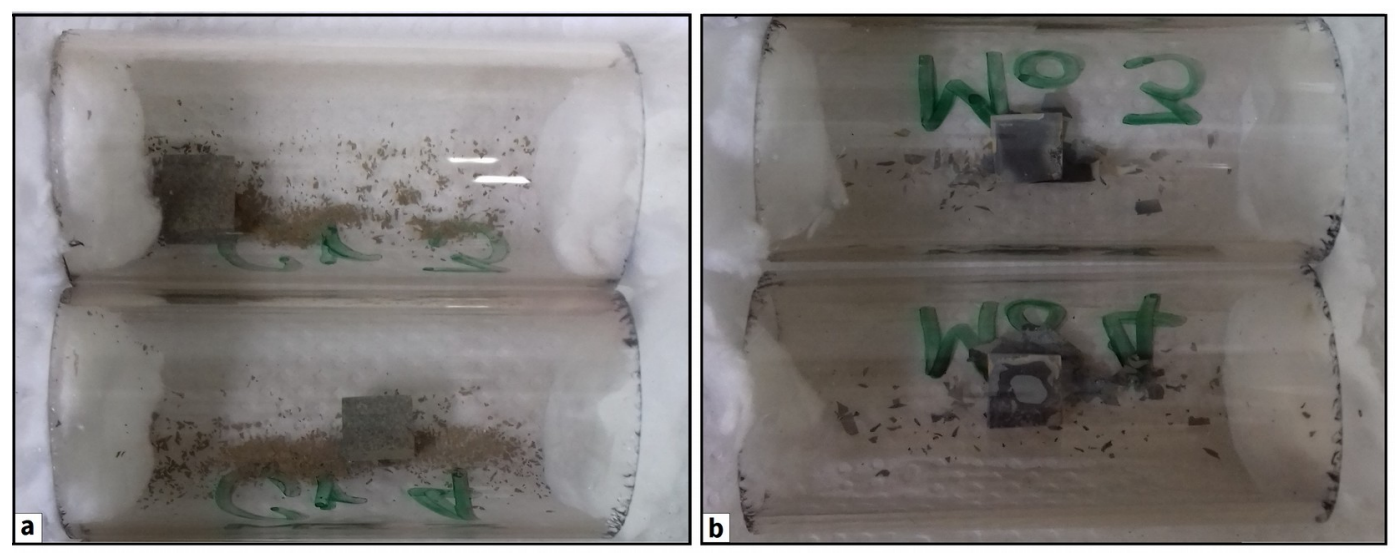

Fonte: Autor 
Com relação ao tipo de escamação apresentado pelas ligas verifica-se que na amostra de Ti-48Al-2Nb-2Cr-0,5B (\%at.) o óxido se desprendeu em fragmentos pequenos com dimensões mais uniformes, como observado na figura 46(a); enquanto que na liga Ti44Al-4Nb-1Mo-0,5B (\%at.) a escamação ocorreu em placas com dimensões e formatos diferentes, como mostrado na figura 46(b). Em ambas as ligas foram verificados fragmentos com coloração amarelada, devido provavelmente à presença de rutilo $\left(\mathrm{TiO}_{2}\right)$.

Dentre estes, o melhor tipo de escamação está sendo representado pela figura 47(a), visto que, por se desprender em pequenos fragmentos a camada de óxido remanescente não é tão afetada quanto o desprendimento de placas maiores, figura 47(b), que deixam uma grande área desprotegida.

Figura 47: Tipos de escamação da camada de óxido observados nas ligas após ensaio isotérmico em forno tipo mufla sob temperatura de $1000^{\circ} \mathrm{C}$. (a) Amostra da liga Ti-48Al-2Nb-2Cr-0,5B (\%at.) com a camada fragmentada em pequenas e uniformes dimensões; e (b) amostra da liga Ti-44Al-4Nb-1Mo-0,5B (\%at.) com escamação em placas cujas dimensões e formatos são diferentes.

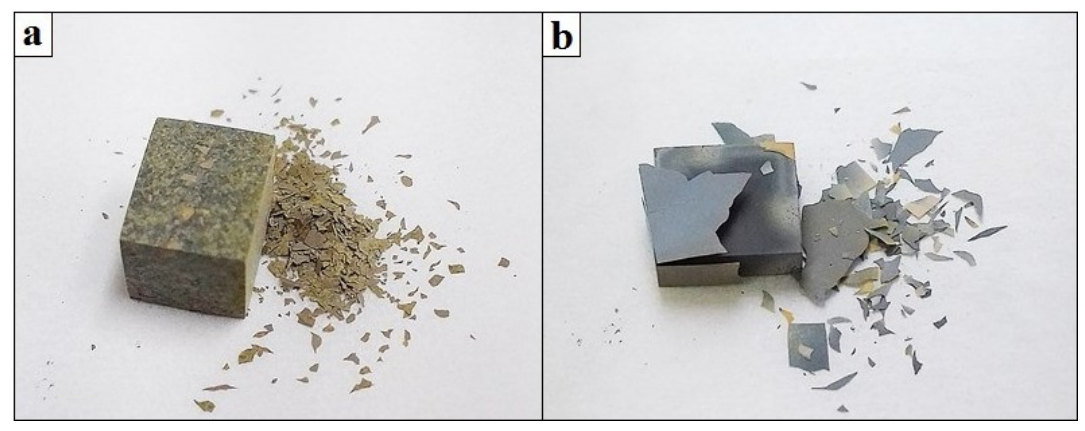

Fonte: Autor

A escamação da camada de óxidos pode estar relacionada a diversos fatores, tais como, a espessura desta camada ou o processo de resfriamento da amostra ao término do ensaio, já que os coeficientes de contração térmica do metal e do óxido são diferentes, o que dificulta a justificativa da ocorrência deste fenômeno nas ligas. 


\section{CONCLUSÃO}

O estudo da caracterização microestrutural e do comportamento à oxidação em temperaturas elevadas das ligas Ti-44Al-4Nb-1Mo-0,5B (\%at.) e Ti-48Al-2Nb-2Cr-0,5B (\%at.) fundidas em um forno a arco elétrico sob atmosfera de argônio e sem tratamento térmico permitiu concluir que:

- Ambas as ligas são compostas pelas fases $\gamma$-TiAl, $\alpha_{2}-\mathrm{Ti}_{3} \mathrm{Al}$ e $\beta$-Ti(B2), sendo que a fase $\gamma$-TiAl corresponde à matriz. A fase $\alpha_{2}-\mathrm{Ti}_{3} \mathrm{Al}$ foi observada de forma mais intensa na liga Ti-48Al-2Nb-2Cr-0,5B (\%at.).

- As microestruturas inerentes ao processo de solidificação: zonas coquilhada, equiaxial, colunar e dendrítica foram verificadas nas amostras. Na liga de Ti48Al-2Nb-2Cr-0,5B (\% at.) também são encontradas colônias de fragmentos dendríticos.

- A camada de óxidos formada em ambas as ligas é composta por $\mathrm{Al}_{2} \mathrm{O}_{3}$ (alumina $\alpha$ ), $\mathrm{NbO}_{2}$ e $\mathrm{TiO}_{2}$ (rutilo), sendo que este último aparece com maior intensidade.

- Após o ensaio a $1000^{\circ} \mathrm{C}$ a camada de óxido formada na liga Ti-48Al-2Nb$2 \mathrm{Cr}-0,5 \mathrm{~B}$ (\%at.) escamou no formato de pequenos fragmentos granulados, enquanto que a liga Ti-44Al-4Nb-1Mo-0,5B (\%at.) apresentou uma escamação em placas.

- Ambas as composições apresentam um ótimo comportamento de resistência a oxidação quando submetidos a temperaturas abaixo de $850^{\circ} \mathrm{C}$. Entretanto, a $1000^{\circ} \mathrm{C}$, a liga Ti-48Al-2Nb-2Cr-0,5B (\% at.) apresenta uma melhor propriedade de resistência a oxidação quando comparada com a liga Ti-44Al-4Nb-1Mo-0,5B (\%at.). 


\section{REFERÊNCIAS BIBLIOGRÁFICAS}

[1] DUARTE, L. I. S. Ligações no estado sólido de $\boldsymbol{\gamma}$-TiAl. 2005. 114 p. Dissertação de mestrado em Engenharia de Materiais. Faculdade de Engenharia da Universidade do Porto. Disponível em: <https://repositorio-aberto.up.pt/bitstream/10216/11989/2/Texto \%20integral.pdf $>$

[2] GUEDES, A. J. R. Ligação de uma liga $\boldsymbol{\gamma}$-TiAl por brasagem por difusão. 2004. 192 p. Tese de doutorado em Engenharia Mecânica. Universidade do Minho.

Disponível em: <http://hdl.handle.net/1822/2592>

[3] LAPIN, J. TiAl-based alloys: Present status and future perspectives. Metal 2009. 19. - 21. 5. 2009, Hradec nad Moravici. Disponivel em:

$<$ http://metal2013.tanger.cz/files/proceedings/metal_09/Lists/Papers/077.pdf >

[4] BELOV, N. A.; AKOPYAN, T. K.; BELOV, V. D.; GERSHMAN, J. S.; GORSHENKOV, M. V. The effect of $C r$ and $Z r$ on the structure and phase composition of TNM gamma titanium aluminide alloy. 2017. Intermetallics, V. 84, May 2017, P. 121 129. Disponível em < https://doi.org/10.1016/j.intermet.2017.01.006>

[5] DAHAR, M. S.; TAMIRISAKANDALA, S. A.; LEWANDOWSKI, J. J. Fatigue crack growth and fracture behavior of as-cast Ti-43.5Al-4Nb-1Mo-0.1B (TNM) compared to Ti-48Al-2Nb-2Cr (4822). 2017. Intermetallics, v. 91, December 2017, P. 158-168. Disponível em: <https://doi.org/10.1016/j.intermet.2017.08.015>

[6] BANUMATHY, S; NEELAM, N. S.; CHANDRAVANSHI, V.; BHATTACHARJEE, A.; RAVI, K. R. The Effect of Nb addition on microstructure, oxidation behavior and strength of some $\gamma$-TiAl alloys. 2018. Materials Today: Proceedings. V. 5, Issue 2, Part 1, 2018, P. 5514-5520. Disponível em: <https://doi.org/10.1016/j.matpr.2017.12.141>

[7] OSTROVSKAYA, O.; BADINI, C.; BAUDANA, G.; PADOVANO, E.; BIAMINO, S. Thermogravimetric investigation on oxidation kinetics of complex Ti-Al alloys. 2018. Intermetallics, V. 93, February 2018, P. 244-250.

Disponível em: $<$ https://doi.org/10.1016/j.intermet.2017.09.020 >

[8] MITORAJ, M.; GODLEWSKA, E.; HEINTZ, O.; GEOFFROY, N.; FONTANA, S.; CHEVALIER. S. Scale composition and oxidation mechanism of the Ti-46Al-8Nb alloy in air at 700 and $800^{\circ} \mathrm{C}$. 2011. Intermetallics, V. 19, Issue 1, January 2011, P. 39-47. Disponível em: <https://doi.org/10.1016/j.intermet.2010.09.006>

[9] BEAN, G. E.; EBRAHIMI, F.; MANUEL, M. V. High temperature deformation of TiAl-Nb-Cr-Mo alloy with ultrafine microstructure. 2014. Intermetallics, V. 49, June 2014, P. 132-137. Disponível em: <https://doi.org/10.1016/j.intermet.2014.01.013> 
[10] XU, W.; JIN, X.; HUANG, K.; ZONG, Y.; WU, S.; ZHONG, X.; KONG, F.; SHAN, D.; NUTT, S. Improvement of microstructure, mechanical properties and hot workability of a TiAl-Nb-Mo alloy through hot extrusion. 2017. Materials Science \& Engineering A, V. 705, 29 September 2017, P. 200-209.

Disponível em: <https://doi.org/10.1016/j.msea.2017.08.082 >

[11] QU, S. J.; TANGA, S. Q.; FENG, A. H.; FENG, C.; SHEN, J.; CHEN, D. L. Microstructural evolution and high-temperature oxidation mechanisms of a titanium aluminide based alloy. 2018. Acta Materialia, V. 148, 15 April 2018, P. 300-310. Disponível em: <https://doi.org/10.1016/j.actamat.2018.02.013>

[12] DAHAR, M. S.; SEIFI, S. M.; BEWLAY, B. P.; LEWANDOWSKI, J. J. Effects of test orientation on fracture and fatigue crack growth behavior of third generation ascast Ti-48Al-2Nb-2Cr. 2015. Intermetallics, V. 57, February 2015, P. 73-82.

Disponível em: <https://doi.org/10.1016/j.intermet.2014.10.005>

[13] SUNG, Si-Young; KIM, Young-Jig. Economic net-shape forming of TiAl alloys for automotive parts. 2006. Intermetallics, V. 14, Issues 10-11, October-November 2006, P. 1163-1167. Disponível em: <https://doi.org/10.1016/j.intermet.2005.11.025>

[14] GERLING, R.; SCHIMANSKY, F. P.; STARK, A.; BARTELS, A.; KESTLER, H.; CHA, L.; SCHEU, C.; CLEMENS, H. 2008. Microstructure and mechanical properties of Ti 45Al 5Nb+(0-0.5C) sheets. Intermetallics, V. 16, Issue 5, May 2008, P. 689-697. Disponível em: <https://doi.org/10.1016/j.intermet.2008.02.004 >

[15] ABDALLAH, Z.; WHITTAKER, M. T.; BACHE, M. R. High temperature creep behaviour in the y titanium aluminide Ti-45Al-2Mn-2Nb. 2013. Intermetallics, $V$. 38, July 2013, P. 55-62. Disponível em: <https://doi.org/10.1016/j.intermet.2013.02.003>

[16] BROTZU, A.; FELLI, F.; PILONE, D. Effect of alloying elements on the behaviour of TiAl-based alloys. 2014. Intermetallics, V. 54, November 2014, P. 176-180.

Disponível em: $<$ https://doi.org/10.1016/j.intermet.2014.06.007.

[17] SCHWARTZ, M. 1996. Lancaster, Pa.: Technomic Pub. Co. Emerging Engineering Materials: Design, Processes and Applications. Disponível em: $<$ https://books.google.com.br/books?id=ppP9zFUXaUgC\&pg=PR3\&lpg=PR3\& $\mathrm{dq}=$ Emerging + Engineering + Materials: + Design, + Processes + and + Applications $\&$ source $=$ bl\&ots=yU4JhtO8Xp\&sig=T6ukiRMyg8k2DTTjDH8wX6iCB7o\&hl=pt-BR\&sa=X\&ved $=2$ ahUKEwjQtvii59zdAhWFHJAKHavTBTsQ6AEwBHoECAYQAQ\#v=onepage \&q=Em erging\%20Engineering\%20Materials\%3A\%20Design $\% 2 \mathrm{C} \% 20$ Processes $\% 20$ and $\% 20$ Applications.\&f=false $>$

[18] ZHANG, S. Z.;ZHAO, Y. B.; ZHANG, C. J.; HAN, J.C.; SUN, M. J.; XU, M. The microstructure, mechanical properties, and oxidation behavior of beta-gamma TiAl alloy with excellent hot workability. 2017. Materials Science \& Engineering A, V. 700, 17 July 2017, P. 366-373. Disponível em: <https://doi.org/10.1016/j.msea.2017.06.025>

[19] SEIFI, M.; SALEM, A. A.; SATKO, D. P.; ACKELID, U.; SEMIATIN, S. L.; LEWANDOWSKI, J. J. Effects of HIP on microstructural heterogeneity, defect distribution and mechanical properties of additively manufactured EBM Ti-48Al-2Cr- 
2Nb. Journal of Alloys and Compounds. Journal of Alloys and Compounds, V. 729, 30 December 2017, P. 1118-1135.

Disponível em: $<$ https://doi.org/10.1016/j.jallcom.2017.09.163 >

[20] THOMAS, M.; BACOS, M. -P. Processing and characterization of TiAl-based Alloys: Towards an Industrial Scale. 2011. Journal AerospaceLab. Issue 3, p. 1-11. November 2011.

Disponível em: $<$ https://hal.archives-ouvertes.fr/hal-01183638/document $>$

[21] PILONE, D.; FELLI, F. Isothermal oxidation behaviour of TiAl-Cr-Nb-B alloys produced by induction melting. Intermetallics, V. 26, July 2012, P. 36-39.

Disponível em: <https://doi.org/10.1016/j.intermet.2012.03.008 >

[22] OEHRING, M.; STARK, A.; PAUL, J. H.; LIPPMANN, T.; PYCZAK; F. 2013. Microstructural refinement of boron-containing $\beta$-solidifying $\gamma$-titanium aluminide alloys through heat treatments in the $\beta$ phase field. Intermetallics, V. 32, January 2013, P. 12-20. Disponível em: <https://doi.org/10.1016/j.intermet.2012.08.010>

[23] BRAUN, R.; LASKA, N.; KNITTEL, S.; SCHULZ, U. Effect of intermetallic coatings on the tensile properties of a $\boldsymbol{\gamma}$-TiAl based TNM alloy. 2017. Materials Science and Engineering: A, V. 699, 24 June 2017, P. 118-127.

Disponível em: <https://doi.org/10.1016/j.msea.2017.05.077>

[24] SMALLMAN, R. E., BISHOP, R. J. 1995. Modern Physical Metallurgy and Materials Engineering: Science, process, applications. Sixth Edition. Disponível em: $<$ http://fmipa.umri.ac.id/wp-content/uploads/2016/03/Smallman_R.E._Modern_Physical_ Metallurgy_And_MatBookZZ.org_.pdf $>$

[25] YAN, S.; SONG, G.; LI, Z.; WANG, H.; ZHENG, D.; CAO, F.; HORYNOVA, M.; DARGUSCHC, M. S.; ZHOU, L. A state-of-the-art review on passivation and biofouling of Ti and itsalloys in marine environments. 2018. Journal of Materials Science \& Technology, V. 34, Issue 3, March 2018, P. 421-435.

Disponível em: <https://doi.org/10.1016/j.jmst.2017.11.021 >

[26] MA, C. P.; GUAN, Y. C.; ZHOU, W. Laser polishing of additive manufactured Ti alloys. 2017. Optics and Lasers in Engineering, V. 93, June 2017, P. 171-177.

Disponível em: <https://doi.org/10.1016/j.optlaseng.2017.02.005 >

[27] OLIVEIRA, H. P. Análise da estrutura das ligas de Ti-Nb-3\%Al temperadas e sua alteração à temperatura. 2007. 157 p. Dissertação de Mestrado. Universidade Estadual do Norte Fluminense Darcy Ribeiro - UENF. Campos dos Goytacazes-RJ, Disponível em: <http:/uenf.br/posgraduacao/engenharia-de-materiais/wpcontent/uploads/sites/2/2013/07/Dissertação-final-Hellen-Prata.pdf>

[28] BADINI, C.; DEAMBROSIS, S. M.; OSTROVSKAYA, O.; ZIN, V.; PADOVANO, E.; MIORIN, E.; CASTELLINO, M.; BIAMINO, S. Cyclic oxidation in burner rig of TiAlN coating deposited on Ti-48 Al-2Cr-2Nb by reactive HiPIMS. Ceramics International. V. 43, Issue 7, May 2017, P. 5417-5426.

Disponível em: $<$ https://doi.org/10.1016/j.ceramint.2017.01.031 > 
[29] JUŘICA, J.; SKOTNICOVÁ, K.; PETLÁK, D. 2015. Refinement of microstructure of several $\gamma$-TiAl alloys by massive transformation and effect of refinement on compression properties. Metal 2015. Jun 3rd-5th 2015, Brno, Czech Republic, EU. Disponível em: <http://konsys2.tanger.cz/files/proceedings/21/papers/3876.pdf>

[30] PFLUMM, R.; FRIEDLE, S.; SCHÜTZE, M. Oxidation protection of $\boldsymbol{\gamma}$-TiAl-based alloys - A review. 2015. Intermetallics, V. 56, January 2015, P. 1-14.

Disponível em: $<$ https://doi.org/10.1016/j.intermet.2014.08.002 >

[31] VALKOV, S.; PETROV, P.; LAZAROVA, R.; BEZDUSHNYI, R.; DECHEV, D. Formation and characterization of $\mathrm{Al}-\mathrm{Ti}-\mathrm{Nb}$ alloys by electron-beamsurface alloying. 2016. Applied Surface Science, V. 389, 15 December 2016, P. 768-774.

Disponível em: <https://doi.org/10.1016/j.apsusc.2016.07.170>

[32] SOARES, A. I. P. Brasagem de ligas de TiAl com uma liga de Ti revestida com Ag e Cu. 2016. 70 p. Dissertação de mestrado. Faculdade de Engenharia da Universidade do Porto - Engenharia Metalúrgica e materiais.

Disponível em: $<$ https://repositorio-aberto.up.pt/bitstream/10216/85625/2/147981.pdf $>$

[33] RASHKOVA, B.; SPIRADEK-HAHN, K.; BRABETZ, M.; ZHANG, Z.;

SCHÖBERL, T.; CLEMENS, H.; MAYER. S. Microstructural evolution and grain refinement in an intermetallic titanium aluminide alloy with a high molybdenum content. 2014. "XV International Conference on Electron Microscopy".

[34] APPEL, F.; DAVID, J.; PAUL, H.; OEHRING, M. Gamma Titanium Aluminide Alloys: Science and Technology, First Edition. 2011. Wiley-VCH Verlag GmbH \& Co. KGaA. Published 2011 by Wiley-VCH Verlag GmbH \& Co. KgaA. Disponível em: $<$ https://books.google.com.br/books?id=86-4BwAAQBAJ\&pg=PA5\&lpg=PA5\&dq= Gamma+Titanium ++ Published $+2011+$ by + Wiley-VCH + Verlag + GmbH\&source $=$ bl\&ots $=$ 1JzfB154bs\&sig=ES_1w0FJ4CH6_z4g5e6umk36yzk\&hl=pt-BR\&sa=X\&ved=2ahUKE wjBn9q1s-DdAhVJEJAKHUHfDT'gQ6AEwBHoECAUQAQ\#v=onepage\&q=Gamma $\%$ 20Titanium\%20\%20Published\%202011\%20by\%20Wiley-VCH\%20Verlag $\% 20 \mathrm{GmbH} \& \mathrm{f}=$ false $>$

[35] LI, X. Y.; TANIGUCHI, S. Correlation of high temperature oxidation with tensile properties for $\mathrm{Ti}-48 \mathrm{Al}-\mathbf{2 C r}-\mathbf{2 N b}$ and $\mathrm{Ti}-48 \mathrm{Al}-\mathbf{2 C r}-2 \mathrm{Fe}$ alloys. Intermetallics. $\mathrm{V} . \mathrm{13}$, Issue 7, July 2005, P. 683-693.

Disponível em: <https://doi.org/10.1016/j.intermet.2004.09.016>

[36] BANUMATHY, S.; NEELAM, N. S.; CHANDRAVANSHI, V.; BHATTACHARJEE, A.; RAV, K. R. The Effect of Nb addition on microstructure, oxidation behavior and strength of some $\boldsymbol{\gamma}$-TiAl alloys. ScienceDirect. Materials Today: Proceedings, V. 5, Issue 2, Part 1, 2018, P. 5514-5520. Disponível em: <https://doi.org/10.1016/j.matpr.2017.12.141>

[37] CHEN, G. L.; XU, X. J.; TENG, Z. K.; WANG, Y. L.; LIN, J. P. Microsegregation in high $\mathrm{Nb}$ containing TiAl alloy ingots beyond laboratory scale. 2007. Intermetallics, V. 15, Issues 5-6, May-June 2007, P. 625-631.

Disponível em: <https://doi.org/10.1016/j.intermet.2006.10.003> 
[38] XIA, Y.; LUO, S. D.; WU, X.; SCHAFFER, G. B.; QIAN, M. The sintering densification, microstructure and mechanical properties of gamma Ti-48Al-2Cr-2Nb alloy with a small addition of copper. Materials Science and Engineering: A, V. 559, 1 January 2013, P. 293-300. Disponível em: <https://doi.org/10.1016/j.msea.2012.08.100 >

[39] ERDELY, P.; STARONB, P.; MAAWAD, E.; SCHELL, N.; KLOSE J.; CLEMENS, H.; MAYER, S. Design and control of microstructure and texture by thermomechanical processing of a multi-phase TiAl alloy. 2017. Materials and Design, V. 131, 5 October 2017, P. 286-296. Disponível em: <http://dx.doi.org/10.1016/j.matdes.2017.06.030>

[40] VOJT ECH, D.; POPELA, T.; KUBÁSEK, J.; MAIXNER, J.; NOVÁK, P. Comparison of $\mathrm{Nb}$ - and Ta-effectiveness for improvement of the cyclic oxidation resistance of TiAl-based intermetallics. Intermetallics, V. 19, Issue 4, April 2011, P. 493501. Disponível em: <https://doi.org/10.1016/j.intermet.2010.11.025>

[41] SILVA, P. R. S. A. Estudo da difusão entre a fase intermetálica $\boldsymbol{\gamma}$-TiAl e Fe/Aço. 2015. 125 p. Escola de Engenharia de Lorena da Universidade de São Paulo. Dissertação de Mestrado em Engenharia dos Materiais. Disponível em:

$<$ www.teses.usp.br/teses/disponiveis/97/97134/tde-08102015.../EMD15008_C.pdf $>$

[42] ASNIS, E. A.; PISKUN, N. V.; STATKEVICH, I. I.; EPASHKIN, A. A.; GORSHENKOV, M.V.; AKOPYAN, T. K. Complementary thermodynamic and dilatometric assessment of phase transformation pathway in new $\beta$-stabilized TiAl intermetallics. 2017. Materials Letters, V. 189, 15 February 2017, P. 217-220. Disponível em: <https://doi.org/10.1016/j.matlet.2016.12.019>

[43] JIANG, H.; RONG, T. S.; HU, D.; JONES, I. P.; VOICE, W. Thermal cycling of Ti46Al-8Nb-1B. 2006. Intermetallics, V. 14, Issue 12, December 2006, P. 1433-1447. Disponível em: <https://doi.org/10.1016/j.intermet.2006.01.062>

[44] ZHOU, Y.; WANG, J. Q.; ZHANG, B.; KE, W.; HAN, E. H. High-temperature fatigue property of Ti46Al8Nb alloy with the fully lamellar microstructure. 2012. Intermetallics, V. 24, May 2012, P. 7-14. Disponível em:

$<$ https://doi.org/10.1016/j.intermet.2011.10.005>

[45] DENQUIN, A. Étude des Transformations de Phase Et Approche du Comportement Mécanique des Alliages Biphasés à base de TiAl: Une Contrffiution au développement de Nouveaux Alliages Intermétalliques. Université des Sciences et Technologies de Lille.

[46] TANDA, D.; TANABE, T.; TAMURA, R.; TAKEUCHI, S. Synthesis of ternary L10 compounds of $\mathbf{T i}-\mathbf{A l}-\mathrm{Zr}$ system and their mechanical properties. 2004. Materials Science and Engineering A, V. 387-389,15 December 2004, P. 991-995.

Disponível em: <https://doi.org/10.1016/j.msea.2004.01.113>

[47] LAPIN, J.; PELACHOVÁ, T.; DOMÁNKOVÁ, M. Creep behaviour of a new airhardenable intermetallic Ti-46Al-8Ta alloy. 2011. Intermetallics, V. 19, Issue 6, June 2011, P. 814-819. Disponível em: <https://doi.org/10.1016/j.intermet.2010.11.023> 
[48] RIOS, O.; GOYEL, S.; KESLER, M. S.; CUPID, D. M.; SEIFERT, H. J.; EBRAHIMI, F. An evaluation of high-temperature phase stability in the Ti-Al-Nb system. 2009. Scripta Materialia, V. 60, Issue 3, February 2009, P. 156-159.

Disponível em: $<$ https://doi.org/10.1016/j.scriptamat.2008.09.023>

[49] LIU, B.; LIU, Y.; LI, Y. P.; ZHANG, W.; CHIBA, A. Thermomechanical characterization of b-stabilized Ti-45Al-7Nb-0.4W-0.15B alloy. 2011. Intermetallics, $V$. 19, Issue 8, August 2011, P. 1184-1190. Disponível em: $<$ https://doi.org/10.1016/j.intermet.2011.03.021>

[50] YANG, F.; KONG, F.; CHEN, Y.; XIAO, S. Hot workability of as-cast Ti-45Al5.4V-3.6Nb-0.3Y alloy. 2013. Journal of Alloys and Compounds, V. 589, 15 March 2014, P. 609-614. Disponível em: <https://doi.org/10.1016/j.jallcom.2013.12.010>

[51] Ciência dos materiais. Disponível em: http://www.cienciadosmateriais.org

[52] REILLY, N. T.; ROUAT, B.; MARTIN, G.; DALOZ, D.; ZOLLINGER, J. 2017. Enhanced dendrite fragmentation through the peritectic reaction in TiAl-based alloys. Intermetallics, V. 86, July 2017, P. 126-133. Disponível em:

$<$ https://doi.org/10.1016/j.intermet.2017.03.022>

[53] SCHWAIGHOFER, E.; CLEMENS, H.; MAYER, S.; LINDEMANN, J.; KLOSE, J.; SMARSLY, W.; GÜTHER, V. Microstructural design and mechanical properties of a cast and heattreated intermetallic multi-phase $\boldsymbol{\gamma}$-TiAl based alloy. 2014. Intermetallic, $V$. 44, January 2014, P. 128-140. Disponível em:

$<$ https://doi.org/10.1016/j.intermet.2013.09.010>

[54] GE, W.; GUO, C.; LIN. F. Effect of process parameters on microstructure of TiAl alloy produced by electron beam selective melting. 2014. Procedia Engineering, $V .81$, 2014, P. 1192-1197. Disponível em: <https://doi.org/10.1016/j.proeng.2014.10.096> 